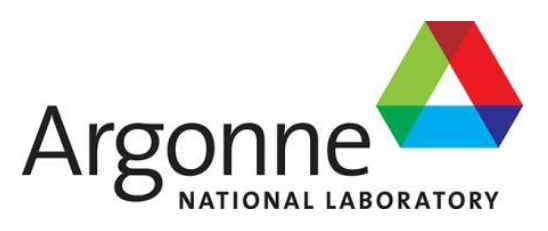

ANL-ART-50

\title{
Dry Air Cooler Modeling for Supercritical Carbon Dioxide Brayton Cycle Analysis
}

Nuclear Engineering Division 


\begin{abstract}
About Argonne National Laboratory
Argonne is a U.S. Department of Energy laboratory managed by UChicago Argonne, LLC under contract DE-AC02-06CH11357. The Laboratory's main facility is outside Chicago, at 9700 South Cass Avenue, Argonne, Illinois 60439. For information about Argonne and its pioneering science and technology programs, see www.anl.gov.
\end{abstract}

\title{
DOCUMENT AVAILABILITY
}

Online Access: U.S. Department of Energy (DOE) reports produced after 1991 and a growing number of pre-1991 documents are available free via DOE's SciTech Connect (http://www.osti.gov/scitech/)

Reports not in digital format may be purchased by the public from the National Technical Information Service (NTIS):

U.S. Department of Commerce

National Technical Information Service

5301 Shawnee Rd

Alexandria, VA 22312

www.ntis.gov

Phone: (800) 553-NTIS (6847) or (703) 605-6000

Fax: (703) 605-6900

Email:orders@ntis.gov

Reports not in digital format are available to DOE and DOE contractors from the Office of Scientific and Technical Information (OSTI):

U.S. Department of Energy

Office of Scientific and Technical Information

P.O. Box 62

Oak Ridge, TN 37831-0062

www.osti.gov

Phone: (865) 576-8401

Fax: (865) 576-5728

Email: reports@osti.gov

\footnotetext{
Disclaimer

This report was prepared as an account of work sponsored by an agency of the United States Government. Neither the United States Government nor any agency thereof, nor UChicago Argonne, LLC, nor any of their employees or officers, makes any warranty, express or implied, or assumes any legal liability or responsibility for the accuracy, completeness, or usefulness of any information, apparatus, product, or process disclosed, or represents that its use would not infringe privately owned rights. Reference herein to any specific commercial product, process, or service by trade name, trademark, manufacturer, or otherwise, does not necessarily constitute or imply its endorsement, recommendation, or favoring by the United States Government or any agency thereof. The views and opinions of document authors expressed herein do not necessarily state or reflect those of the United States Government or any agency thereof, Argonne National Laboratory, or UChicago Argonne, LLC.
} 


\section{Dry Air Cooler Modeling for Supercritical Carbon Dioxide Brayton Cycle Analysis}

prepared by

A. Moisseytsev, Q. Lv, and J. J. Sienicki

Nuclear Engineering Division, Argonne National Laboratory

July 28, 2016 



\section{ABSTRACT}

Modeling for commercially available and cost effective dry air coolers such as those manufactured by Harsco Industries has been implemented in the Argonne National Laboratory Plant Dynamics Code for system level dynamic analysis of supercritical carbon dioxide (sCO2) Brayton cycles. The modeling can now be utilized to optimize and simulate sCO2 Brayton cycles with dry air cooling whereby heat is rejected directly to the atmospheric heat sink without the need for cooling towers that require makeup water for evaporative losses. It has sometimes been stated that a benefit of the sCO2 Brayton cycle is that it enables dry air cooling implying that the Rankine steam cycle does not. A preliminary and simple examination of a Rankine superheated steam cycle and an air-cooled condenser indicates that dry air cooling can be utilized with both cycles provided that the cycle conditions are selected appropriately 


\section{EXECUTIVE SUMMARY}

The ANL Plant Dynamics Code (PDC) has been extended in capability to calculate dry air cooling for supercritical carbon dioxide $\left(\mathrm{sCO}_{2}\right)$ Brayton cycle power converters whereby heat is rejected directly from $\mathrm{CO}_{2}$ to the atmospheric heat sink. That capability includes modeling of commercially available modular air coolers such as those manufactured by Harsco which are a practical and cost effective approach for dry air cooling for $\mathrm{sCO}_{2}$ cycles. An air cooler module incorporates fans that blow air vertically across horizontal finned tubes containing flowing $\mathrm{CO}_{2}$. Air coolers are existing commercially available technology and there is no need to develop a new heat exchanger technology for dry air cooling for $\mathrm{sCO}_{2}$ cycles.

The supercritical carbon dioxide $\left(\mathrm{sCO}_{2}\right)$ Brayton cycle's capability to reject heat with dry air cooling is emerging as one of the most significant benefits of the cycle. The benefits of dry air cooling for any power plant are obvious, since not relying on water for heat rejection significantly extends the siting options for a power plant. The most recent work at ANL and elsewhere shows that due to the specifics of heat rejection from the $\mathrm{sCO}_{2}$ cycle, there are some benefits in adopting dry air cooling for this cycle compared to the Rankine steam cycle.

The ANL Plant Dynamic Code (PDC) was extended to include design and performance calculations for $\mathrm{CO}_{2}$-to-air crossflow heat exchangers which require treatment of twodimensional temperature fields. Two heat exchanger design options were investigated. The first is a commercially-available modular air cooler design in which air is blown upward by fans across horizontal finned tubes through which the $\mathrm{CO}_{2}$ flows. This is a standard commercially-available air cooler technology (e.g., Harsco), although the application to $\mathrm{sCO}_{2}$ is new. For the finned tube design, the code was verified against the manufacturer's quote for the $\mathrm{sCO}_{2}$ cooler application and satisfactory agreement was obtained. The analysis confirmed the capability of finned tube crossflow heat exchangers to achieve sufficiently small temperature approaches such that the $\mathrm{CO}_{2}$ flow can be cooled to temperatures very close to the critical point of $30.98^{\circ} \mathrm{C}$ even with an assumed air ambient temperature of $30^{\circ} \mathrm{C}$.

The other heat exchanger design option considered in this work was compact diffusionbounded heat exchangers, similar to those investigated in the previous air cooling analysis, but with a crossflow arrangement. The crossflow configuration was indeed found to be beneficial for this application, since it is better suited to achieve a low pressure drop on the air side - an important consideration in order to maintain a reasonable power requirement for air blowers $(5 \%$ or less of the plant output). The crossflow compact diffusion-bonded heat exchanger was also found to be more compact than the finned tube design reducing the heat exchanger core volume by about $50 \%$, but is still estimated to be up to six times as expensive.

As a result of the heat exchanger design analyses, the finned tube design is selected as a better option and as a reference option for the $\mathrm{sCO}_{2}$ air cooler application. Using PDC cycle analysis with an integrated crossflow air cooler, a cost-based optimization was first carried out for the reference AFR-100 Sodium-Cooled Fast Reactor (SFR) $\mathrm{sCO}_{2}$ cycle conditions, where the $\mathrm{CO}_{2}$ is cooled to conditions just above the critical point $-31.25^{\circ} \mathrm{C}$ and $7.4 \mathrm{MPa}$ at the compressor inlet. It was found that with the optimal cooler design, the plant $\$ / \mathrm{kWe}$ cost is about $7 \%$ higher than with direct water cooling and 5\% higher than water cooling with ultimate heat rejection to air through the use of cooling towers.

To further reduce the plant capital cost, the cost-based optimization was repeated for $\mathrm{sCO}_{2}$ cycle conditions with $35^{\circ} \mathrm{C}$ and $8.2 \mathrm{MPa}$ at compressor inlet and $25 \mathrm{MPa}$ at the compressor outlet. The integrated cycle and cooler calculations showed that the plant $\$ / \mathrm{kWe}$ cost is further 
reduced compared to dry air cooling with the reference AFR-100 conditions to a value which is only $2 \%$ higher than with direct water cooling and basically the same as the water cooling with cooling towers.

Based on the analysis presented in this report, it is concluded that crossflow heat exchanger designs are better suited for $\mathrm{sCO}_{2}$ dry air coolers than counter flow designs. The commercially available modular finned tube air coolers are the best currently available option for this application, and there is a minimal economic impact of dry air cooling compared to direct water cooling or the use of water cooling towers to reject heat to air. At the same time, dry air cooling requires no water usage which greatly extends siting options for a power plant.

To compare the size of the $\mathrm{CO}_{2}$ air cooler and the cycle performance with dry air cooling with those for a Rankine superheated steam cycle plant with dry air cooling, a preliminary analysis of a steam cycle and air-cooled condenser has been carried out. Since implementation of a condenser calculation into the PDC would require significant code revisions to treat phase change, a simplified spreadsheet-type analysis of an air-cooled condenser was carried out. In this analysis, constant properties and heat transfer coefficients were assumed and the heat transfer rate is calculated based on a LMTD approach. The same Harsco air cooler design is assumed for the steam condenser calculations with steam flow replacing the $\mathrm{CO}_{2}$ flow inside the tubes. Calculations of heat transfer on the steam side are done in a simplified form based on condensation correlations from the open literature; calculations of heat transfer on the air side are performed similarly to those implemented in the PDC for finned tubes. To obtain conditions for an air-cooled steam condenser, a preliminary model of a steam plant power converter for the AFR-100 SFR was developed using the GateCycle software. The condenser sizing calculations were done for two conditions on steam side: a reference state at $5 \mathrm{kPa}$ condenser back pressure and $32.9{ }^{\circ} \mathrm{C}$ and a higher temperature corresponding to $10 \mathrm{kPa}$ back pressure and $45.8{ }^{\circ} \mathrm{C}$. Both calculations show that a steam condenser with the Harsco design would be feasible, but, obviously, low-temperature conditions would require a very large heat exchanger and air flow rate for the assumed air inlet temperature of $30{ }^{\circ} \mathrm{C}$. Based on the condenser sizing results, a preliminary cost-based optimization was carried out for the same two sets of steam conditions. For these calculations, the steam cycle efficiencies were calculated by the GateCycle software. The results show that the efficiency decreases from $43.5 \%$ at $5 \mathrm{kPa}$ to $41.8 \%$ at $10 \mathrm{kPa}$. Still, due to much smaller condenser and smaller air circulation power requirement, the $10 \mathrm{kPa}, 45.8^{\circ} \mathrm{C}$ case is calculated to be more economical resulting in a lower $\$ / \mathrm{kWe}$ plant cost. When compared to the optimal conditions for the $\mathrm{sCO}_{2}$ cycle, the main cycle and heat exchanger results, including cycle and plant efficiencies, plant power output, cooler/condenser size, air flow rate, and air fan power for the steam cycle are remarkably close. 


\section{Table of Contents}

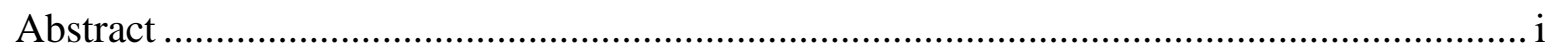

Executive Summary ………………………………................................................. ii

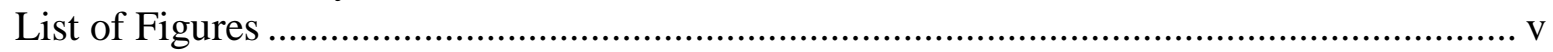

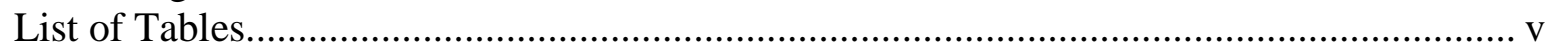

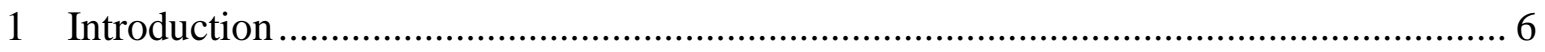

2 Development of Cross-Flow Heat Exchanger Subroutine ………………………….... 10

3 Finned Tube Cross-Flow Heat Exchanger Analysis ………………….......................... 15

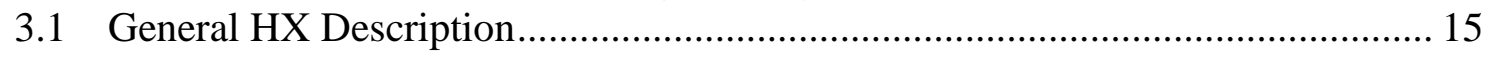

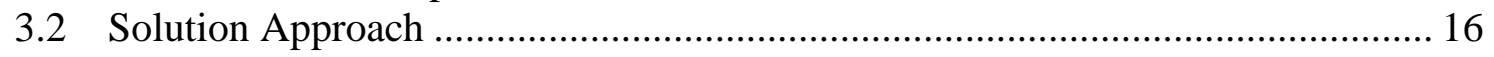

3.3 Geometric Parameters ................................................................................... 18

3.4 Heat Transfer and Pressure Drop Correlations ………….................................... 20

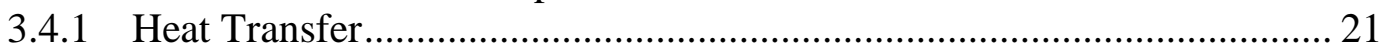

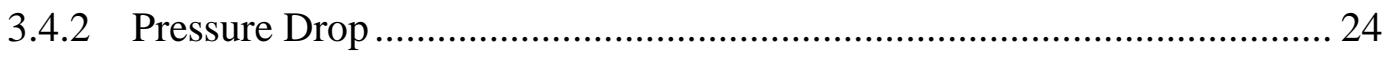

3.4.3 Fin Efficiency ………………........................................................... 27

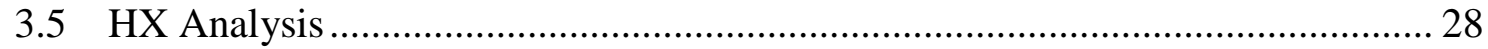

3.5.1 Comparison with Harsco Quote ................................................................ 28

3.5.2 Design Options............................................................................... 30

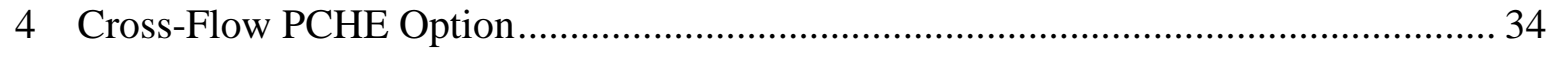

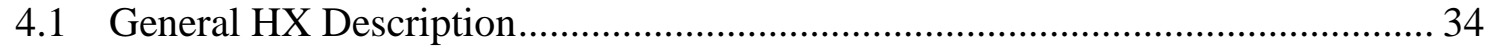

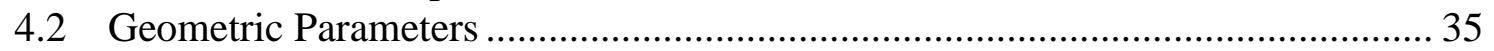

4.3 Heat Transfer and Pressure Drop Correlations ................................................... 36

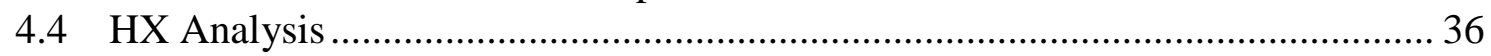

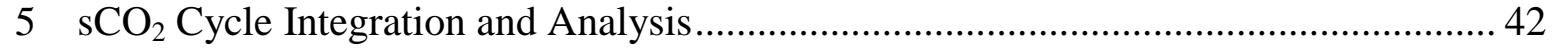

5.1 ANL Plant Dynamics Code Modifications …………………………………..... 42

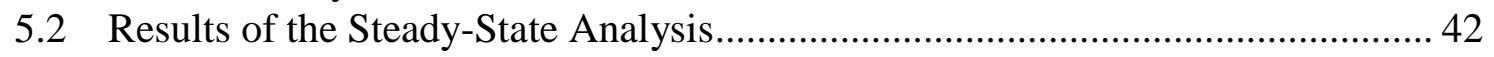

5.2.1 Air Cooler Design at Reference AFR-100 Conditions .............................. 42

5.2.2 Air Cooler Design Optimization at Reference AFR-100

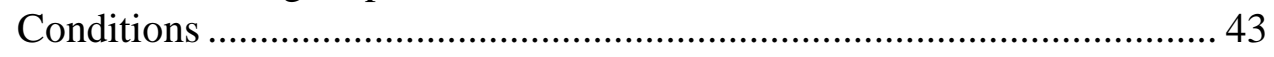

5.2.3 Air Cooler Design Optimization at Optimal AFR-100

Conditions for Dry Air Cooling ............................................................. 46

6 Comparison with an Air-Cooled Steam Condenser ...................................................... 52

6.1 Air-Cooled Steam Condenser Sizing Analysis ................................................... 55

6.2 Air-Cooled Steam Condenser Optimization ………........................................... 58

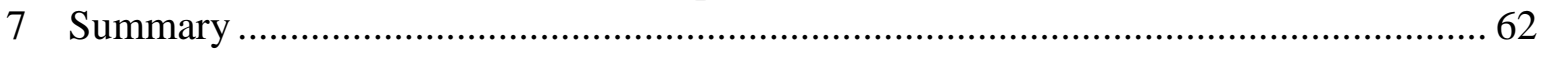

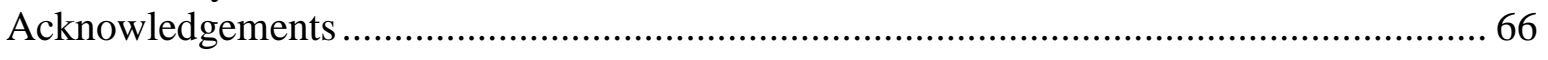

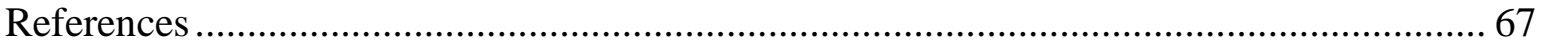




\section{LIST OF FIGURES}

Figure 1. Typical Finned Tube Heat Exchanger Design and Components................................... 7

Figure 2. Optimal Cycle Conditions for Dry Air Cooling [1] .................................................. 8

Figure 3. Reference AFR-100 $\mathrm{sCO}_{2}$ Cycle Conditions with Water Cooling.................................. 9

Figure 4. Temperature Field in a Cross-Flow Heat Exchanger. ................................................ 10

Figure 5. Finned Tube Cross Flow Heat Exchanger [1] ........................................................... 15

Figure 6. Tube Lattices: Triangular (Left) and Square (Right) ……………………………...... 16

Figure 7. Treatment of Multi-Pass HX with Separate HXs. ....................................................... 17

Figure 8. $j$ Factor for the Kays and London geometry............................................................ 22

Figure 9. Comparison between the Kays and London, and Briggs and Young Correlations........ 23

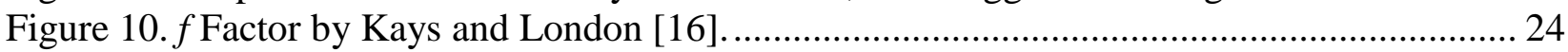

Figure 11. Comparison between the Kays and London, and Robinson and Briggs Correlations. . 25

Figure 12. Comparison of the Three Pressure Drop Correlations................................................. 27

Figure 13. Fin Efficiency Comparison Results....................................................................... 28

Figure 14. Concept of Cross-Flow PCHE .......................................................................... 34

Figure 15. Temperature Profiles in a Three-Pass Cross-Flow PCHE: $\mathrm{CO}_{2}$ (Top) and Air (Bottom).

Figure 16. Parametric Study of Cross-Flow PCHE Cooler Width. ............................................ 40

Figure 17. $\mathrm{sCO}_{2}$ Cycle Conditions with Cross-Flow Finned Tube Cooler..................................... 43

Figure 18. Cost-Based Cooler Optimization at Reference AFR-100 Conditions. .......................... 45

Figure 19. Cycle Conditions with Optimal Cooler Design for Reference AFR-100 Conditions. . 46

Figure 20. Cost-Based Cooler Optimization at Optimal Air Cooling Design at $25 \mathrm{MPa}$.............. 49

Figure 21. $\mathrm{sCO}_{2}$ Cycle Conditions at $25 \mathrm{MPa}$ and Optimal Cooler Design. ................................. 50

Figure 22. $\mathrm{sCO}_{2}$ Cycle Conditions with Air Cooler Design from Open Literature.......................5 51

Figure 23. GateCycle Model of AFR-100 Steam Cycle with $5 \mathrm{kPa}$ Condenser Back Pressure. ... 53

Figure 24. AFR-100 Steam Cycle with $10 \mathrm{kPa}$ Condenser Back Pressure................................... 54

Figure 25. Condenser Temperature and Cycle Efficiency as Functions of Condenser Back

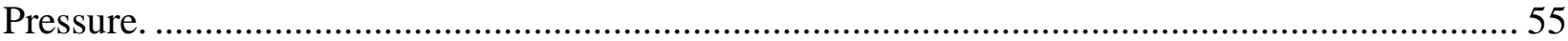

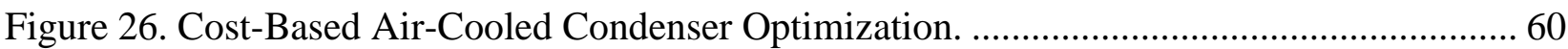

\section{LIST OF TABLES}

Table 1. Comparison between the Harsco Design and the Kays and London Design [1] ............. 21

Table 2. Rating Results of the Harsco Design ........................................................................... 29

Table 3. Rating Results with a $\mathrm{sCO}_{2}$-side Inlet Pressure of $7.736 \mathrm{MPa}$....................................... 29

Table 4. Mesh Convergence Study Results .................................................................................. 30

Table 5. Results of Finned Tube Cross-flow Heat Exchanger Calculations .................................... 31

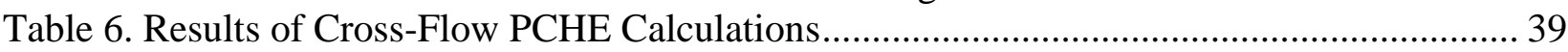

Table 7. Cycle and Component Design Changes between Optimal Water and Air Cooling Designs

Table 8. Sizing Results of the Air Cooled Steam Condenser .......................................................5 58

Table 9. Comparison of Optimal $\mathrm{sCO}_{2}$ Air Cooler with Optimal Steam Condenser...................... 61 


\section{Introduction}

As interest in, development, and demonstration of the supercritical carbon dioxide $\left(\mathrm{sCO}_{2}\right)$ Brayton cycle grows worldwide, one particular aspect of the cycle - the capability to reject heat with dry air cooling - is emerging as one of the most significant benefits of the cycle. The most recent work at ANL [1] and elsewhere [2,3] shows that due to the specifics of heat rejection from the $\mathrm{sCO}_{2}$ cycle, there are some benefits in adopting dry air cooling for this cycle compared to the Rankine steam cycle. The benefits of dry air cooling for any power plant are obvious, since not relying on water for heat rejection significantly extends the siting options for a power plant [3].

The work on dry air cooling analysis for $\mathrm{sCO}_{2}$ cycles at ANL began a few years ago [4]. In that early work, it was concluded that although dry air cooling is possible, it would most likely be cost-prohibitive, since it would require either a very large heat exchanger, a large air circulation power requirement, or both. However, later discussion with experts who had some experience in dry cooling options [5], revealed that the assumptions in that early work were probably not realistic and led to very expensive heat exchanger options. Those assumptions were:

- Counter-flow heat exchanger arrangement, which required a long flow path on the air side increasing the pressure drop and, therefore, air circulation power. That heat exchanger type was previously found to be required for other $\mathrm{sCO}_{2}$ cycle heat exchangers, such as recuperators, since high effectiveness of those heat exchangers for both sides is critical to achieving high cycle efficiency, and

- Using compact heat exchangers, such as Printed Circuit Heat Exchangers (PCHEs) manufactured by Heatric Division of Meggitt, UK [6]. Again those heat exchangers were previously found to be beneficial for other $\mathrm{SCO}_{2}$ cycle heat exchangers, since they allow achieving the large heat transfer area needed for these applications in a relatively small volume. However, the main design feature of these heat exchangers - small channel size - may not be a good choice for air cooling applications where large flow areas are needed in order to keep the air side pressure drop to a very low value.

In order to investigate the effect of these assumptions on the heat exchanger cost and air side pumping power, the work on dry air cooling was continued last year under US Department of Energy Nuclear Energy University Programs (NEUP) Project NUEP 12-3318, "Advanced Supercritical Carbon Dioxide Brayton Cycle Development." conducted jointly with the University of Wisconsin-Madison (UW-Madison). The focus was on investigating a standard commercially-available cross-flow finned-tube heat exchanger design for which a quote from a heat exchanger manufacturer, Harsco Industrial [7], was obtained earlier that year. A simplified analysis of this heat exchanger using the Engineering Equation Solver (EES) software was carried out under the NEUP project to independently confirm its performance for $\mathrm{sCO}_{2}$ cycle cooler applications and the results [1] were promising in significantly reducing both the heat exchanger cost and air circulation power, compared to the previous results in Reference [4]. Significantly, the required air cooler technology is already commercially available, as demonstrated in Figure 1, and does not require a development program. 


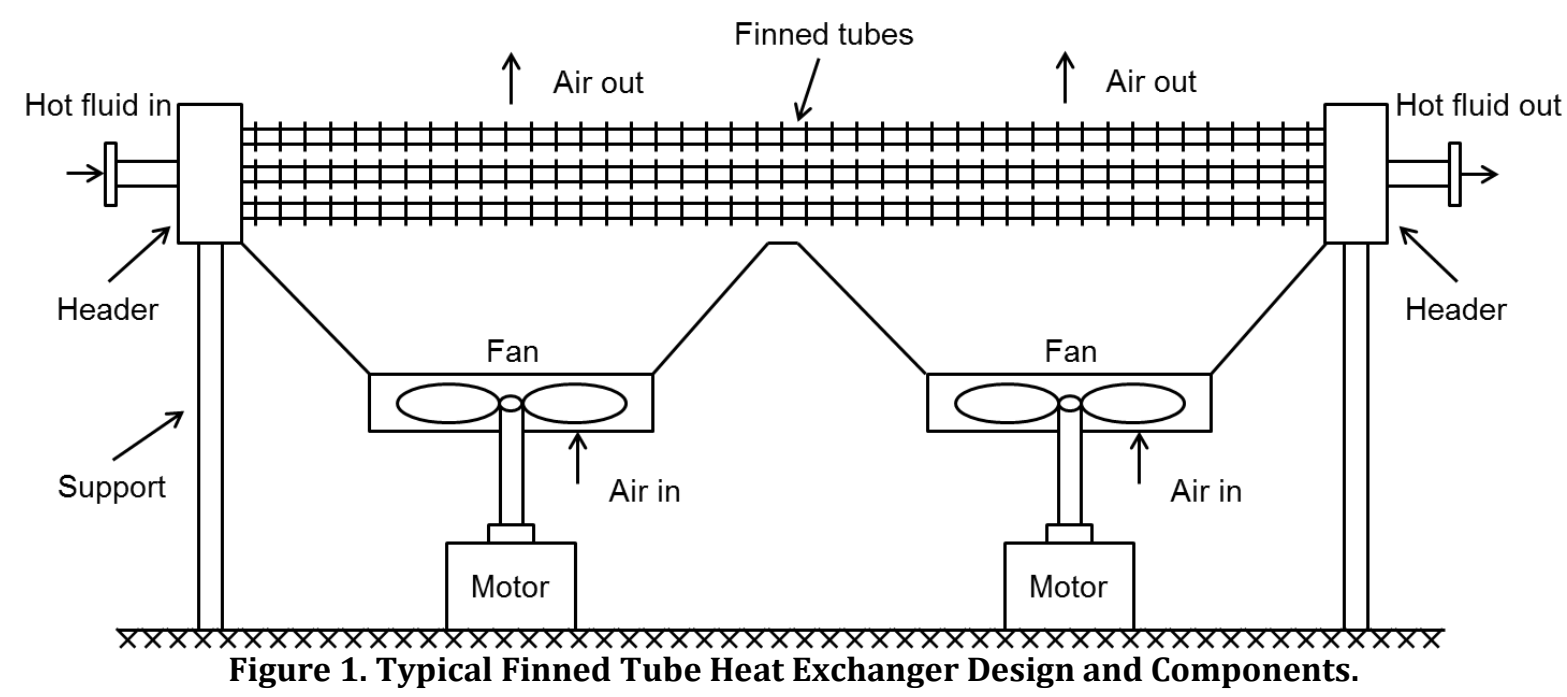

The other significant result from the NEUP work was the realization that the $\mathrm{sCO}_{2}$ cycle optimal conditions may be different for the dry air cooling option than previously adopted for water cooling. In previous work for water cooling $[8,9,10]$, it was found beneficial to keep the compressor inlet (or cooler outlet) conditions as close to the $\mathrm{CO}_{2}$ critical point of $30.98{ }^{\circ} \mathrm{C}$ as possible in order to maximize cycle efficiency. Achieving a cooler-outlet temperature of $32{ }^{\circ} \mathrm{C}$ was found possible and practical, in terms of the cooler size, due to the good heat transfer properties of water, even when a conservatively high water inlet temperature of $30{ }^{\circ} \mathrm{C}$ was assumed. However, the same temperature goals were found to be challenging with air cooling even with the same air inlet temperature of $30{ }^{\circ} \mathrm{C}$ which is not necessarily a conservative assumption for some locations, even in the U.S. In order to reduce the size and cost of the air cooler as well as air flow rate and circulating power requirement, it was found [1] beneficial to increase the compressor inlet temperature to $35{ }^{\circ} \mathrm{C}$ along the $\mathrm{sCO}_{2}$ pseudo-critical line, while, at the same time, increasing the compressor outlet pressure from $20 \mathrm{MPa}$ to $25 \mathrm{MPa}$ to recover some of the lost cycle efficiency. The optimal cycle conditions for air cooling for the AFR-100 100 MWe SFR application are presented in Figure 2. These results were obtained using the cost-based optimization technique [11] developed previously at ANL and also accounting for the greater structure thicknesses required for higher $\mathrm{CO}_{2}$ pressure. It was calculated that with the conditions in Figure 2, the overall plant capital cost per unit electrical output $(\$ / \mathrm{kWe})$ was only higher by 1$2 \%$ compared to the direct water cooling option, which is a significant improvement over the 40 $60 \%$ increase calculated in the earlier dry cooling work [4]. 


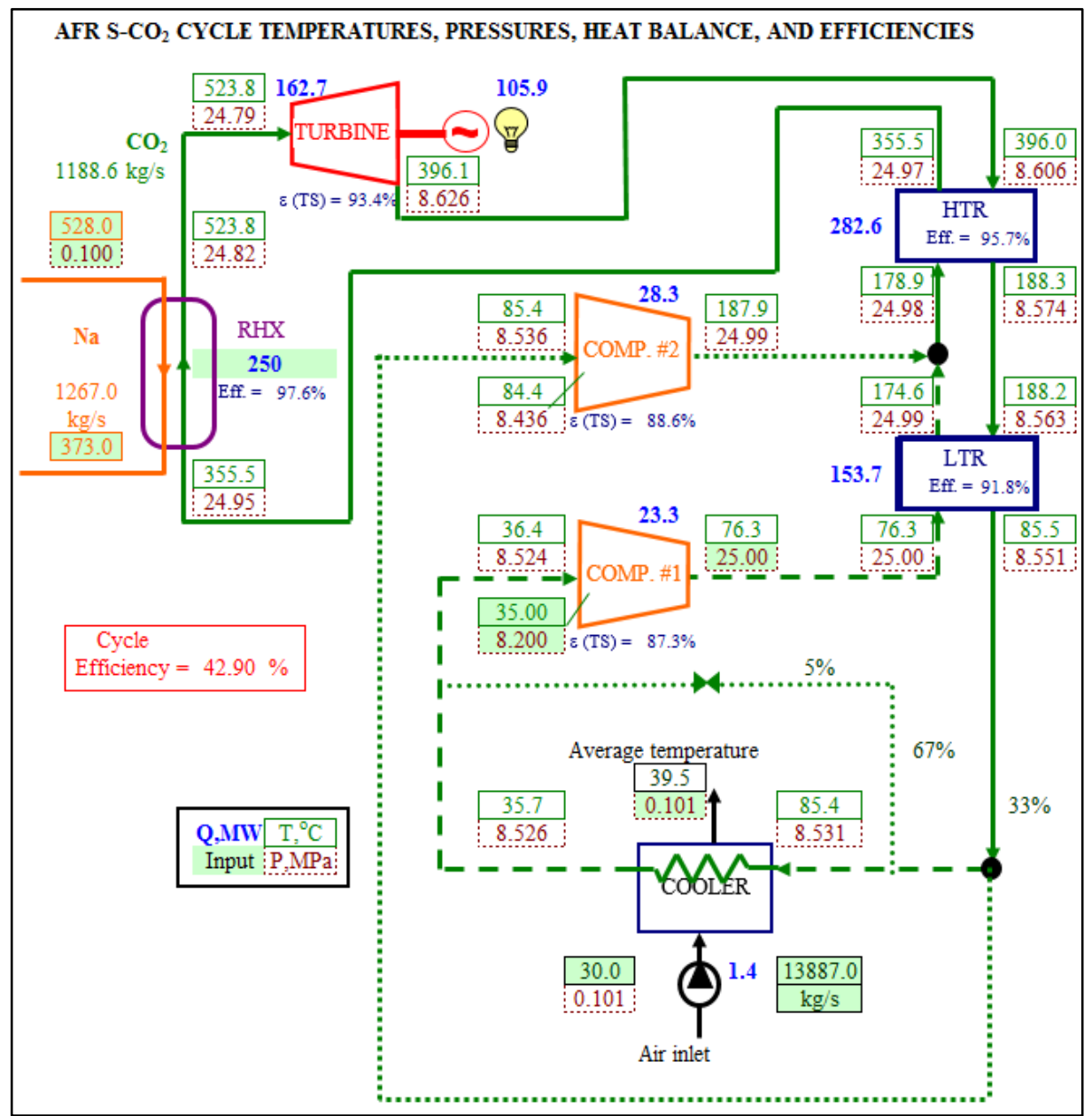

Figure 2. Optimal Cycle Conditions for Dry Air Cooling [1].

Because of such promising results, it was decided to continue the investigation of cross-flow heat exchanger options for dry air cooling of $\mathrm{sCO}_{2}$ cycles. Since the NEUP project ended in FY15, the work was continued this year under the U. S. Department of Energy Advanced Reactor Technologies (ATR) Program. The following goals were set for the present work:

- Develop a cross-flow heat exchanger subroutine modeling the Harsco Industrial modular finned-tube air cooler in Fortran,

- Incorporate the subroutine into the ANL Plant Dynamics Code (PDC) $[12,13]$ for integral calculations of a $\mathrm{SCO}_{2}$ cycle and air cooler heat exchangers ${ }^{1}$ initially at steady state with the ultimate goal of transient analysis,

- Validate the subroutine against the Harsco quote,

1 The FY15 NEUP work used the cooler analysis in the EES software with cycle analysis in the PDC, which required a manual interface between the codes. 
- Confirm the FY15 NEUP results, both for the heat exchanger performance and cycle optimization,

- Identify and investigate other potential heat exchanger options, such as a cross-flow PCHE,

- Make the code flexible enough to investigate heat exchanger design options, such as the number of tube passes and fin design, for example.

The ultimate goal, though, was the development a computational tool that can be used for future analyses of various options and conditions for $\mathrm{sCO}_{2}$ cycles with dry air cooling.

The cooler calculation described below in this report started from the reference AFR-100 conditions presented in Figure 3. Although those conditions were obtained with water cooling, as a first step in air cooler analysis, the cooler was designed to match the same cooler conditions.

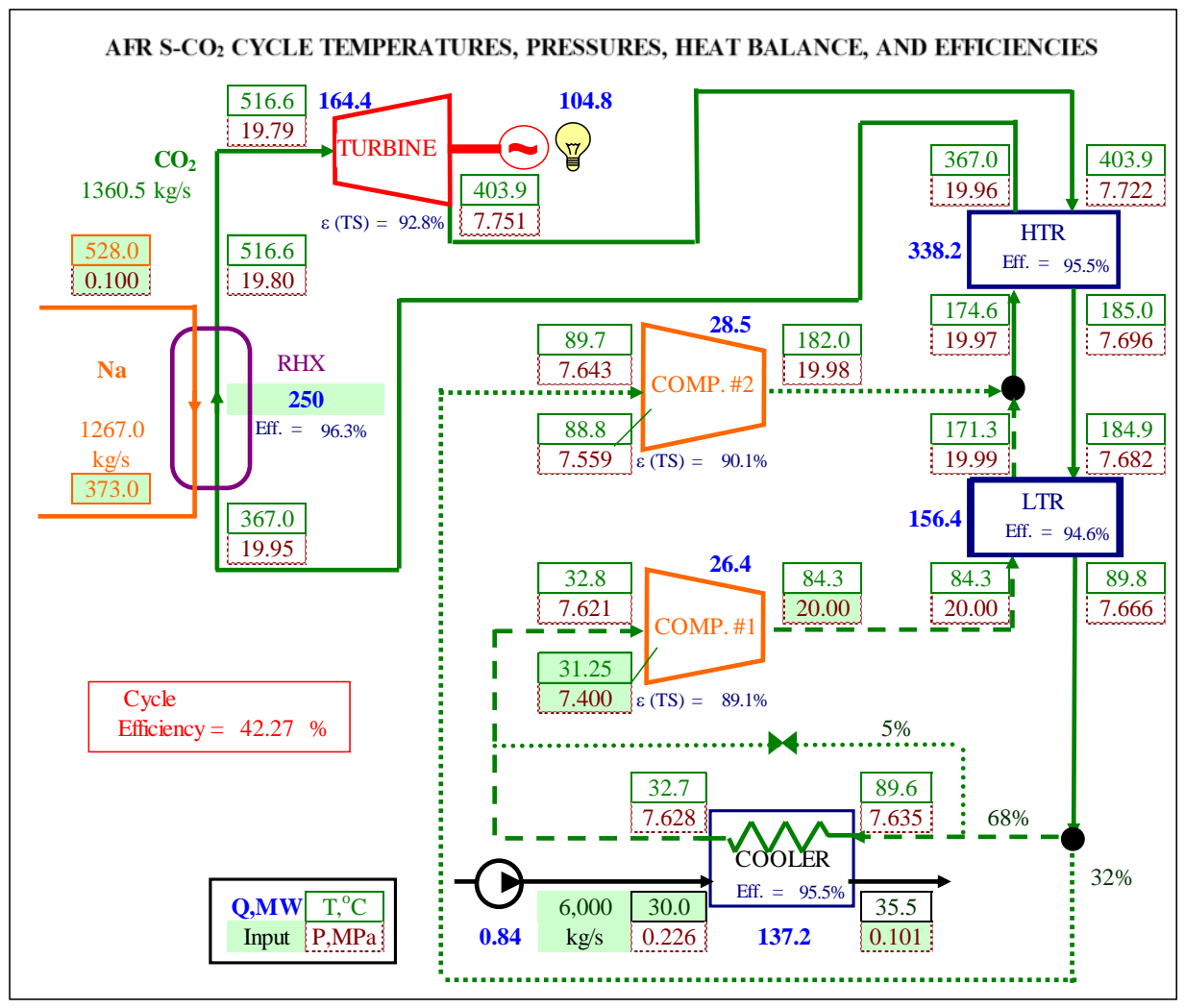

Figure 3. Reference AFR-100 $\mathrm{sCO}_{2}$ Cycle Conditions with Water Cooling. 


\section{Development of Cross-Flow Heat Exchanger Subroutine}

The main difference between the cross-flow and counter flow heat exchangers is that the former has necessarily a two-dimensional temperature field, as demonstrated in Figure 4. As two fluids flow in perpendicular directions, fluids in parallel channels will "see" opposite side fluids of different temperature. For example, in Figure 4, the hot fluid in the top channel is in contact with the warmer cold side fluid near the exit of the heat exchanger, while the hot side fluid in the bottom channel will "see" much colder cold side fluid at the entrance of the heat exchanger. Therefore, the amount of heat transfer, which is proportional to the temperature difference between the two fluids, will not be the same for the parallel hot side channels. Therefore, the temperature change in the hot side fluid will be less in the top channel, compared to the bottom channel, which is schematically illustrated by arbitrary temperature changes in hot side channels in Figure 4.

In a similar fashion, the left-most cold side flow in Figure 4 will "see" colder hot side flow than the right-most channel, leading to smaller temperature rises and lower temperatures in that flow, compared to all other channels. Therefore, in a cross-flow heat exchanger, a two-dimensional temperature field will always exist where the fluid temperatures are different both along the channel (or tube) length as well as between the channels (tubes).

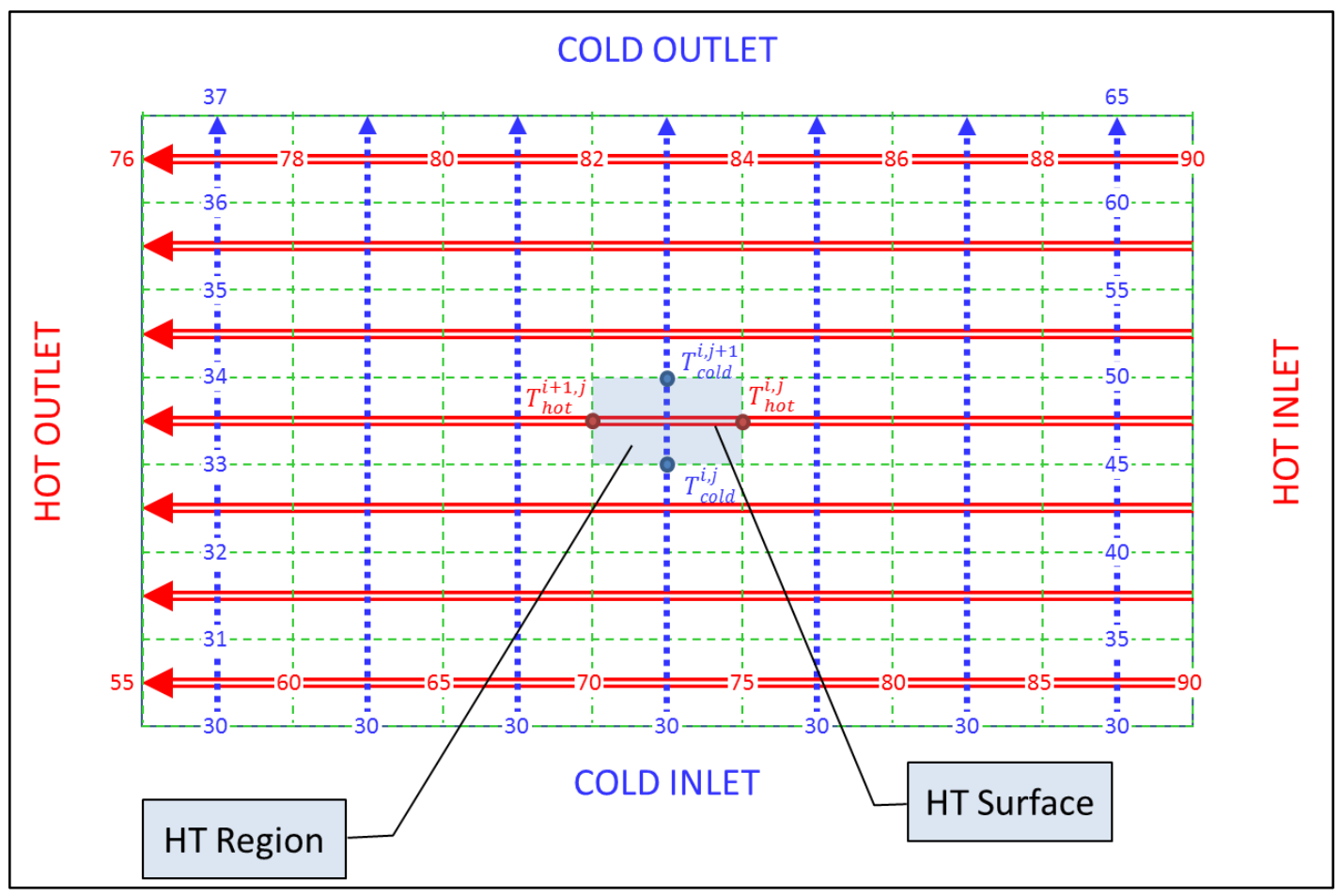

Figure 4. Temperature Field in a Cross-Flow Heat Exchanger.

The unavoidable air temperature variation along the $\mathrm{CO}_{2}$ outlet node (left-most air channel in Figure 4) was the main reason why the cross-flow heat exchangers were not considered for the $\mathrm{CO}_{2}$ cooler applications in the early ANL work. The reasons were that as the air temperature 
increase from one $\mathrm{CO}_{2}$ tube to another, it will not be able to cool $\mathrm{CO}_{2}$ close to its critical point, which is already close to the air ambient temperature. However, as the actual calculation below will show, the air temperature rise at this part of the heat exchanger is not that great. First, the overall air temperature increase in the entire heat exchanger is only of the order of $5-10{ }^{\circ} \mathrm{C}$, on average. However, more importantly, in this cold end of the heat exchanger, the heat transfer rate between colder $\mathrm{CO}_{2}$ and air is small, such that the air temperature rise in this section is also small, on the order of about $1{ }^{\circ} \mathrm{C}$ or less, which makes it practical to achieve the required $\mathrm{CO}_{2}$ temperatures even with the cross-flow configuration.

Because of the two-dimensional temperature field, the solution approach to a cross-flow heat exchanger must be different from that adopted previously for counter-flow heat exchanger. The first obvious difference is that two-dimensional temperature arrays need to be stored for heat transfer and properties calculations inside the heat exchanger. For the $\mathrm{CO}_{2}$ cooler application, this consideration is important since in order to track $\mathrm{CO}_{2}$ property changes, many axial nodes are required. If the same accuracy is retained for the cross-flow heat exchanger, the total number of nodes would increase by a factor equal to the number of vertical nodes, leading to a proportional increase in properties calculations. In addition, in previous calculations, a fast-running solution algorithm was developed [8] where once the fluid properties in each axial region are calculated, the heat transfer equations were solved simultaneously for the entire length of the heat exchangers using an analytical solution in each region. That approach could not be retained for the cross-flow heat exchangers because it will require finding an analytical solution for the two-dimensional temperature field, which is much more complicated. Instead, the solution of temperature field needs to be found in each heat transfer region, shown in Figure 4, and then the iterations need to be done in calculating how heat transfer in each region affects the conditions and heat transfer in other locations downstream that particular region in both flow directions. All these aspects would lead to a significant slowing down of the heat exchanger calculations.

Other than those differences, the solution to the heat transfer equations is similar to those implemented previously for a counterflow heat exchanger. The amount of heat transfer between the two fluids is defined by the temperature difference between the fluids and overall heat transfer coefficient for that region, while the same amount of heat transfer affects the temperature (or enthalpy) change in each region for both fluids. For example, considering the heat transfer region in Figure 4, the heat transfer equations are formulated as:

$$
\begin{aligned}
& Q_{i, j}=H S_{i, j}\left(\bar{T}_{h o t}-\bar{T}_{\text {cold }}\right) \\
& \dot{m}_{\text {hot }}\left(h_{\text {hot }}^{i, j}-h_{\text {hot }}^{i+1, j}\right)=Q_{i, j}=\dot{m}_{\text {cold }}\left(h_{\text {cold }}^{i, j+1}-h_{\text {cold }}^{i, j}\right)
\end{aligned}
$$

where,

$Q_{i, j}=$ heat transfer in region $[i, j], \mathrm{W}$,

$H S_{i, j}=$ overall heat transfer coefficient times area for region $[i, j], \mathrm{W} / \mathrm{K}$,

$\bar{T}_{h o t}=\frac{T_{h o t}^{i, j}+T_{h o t}^{i+1, j}}{2}=$ average hot side temperature in region $[i, j], \mathrm{K}$,

$\bar{T}_{\text {cold }}=\frac{T_{\text {cold }}^{i, j}+T_{\text {cold }}^{i, j+1}}{2}=$ average cold side temperature in region $[i, j], \mathrm{K}$,

$T_{\text {hot }}^{i, j}, T_{\text {cold }}^{i, j}=$ hot and cold side temperatures at node $(i, j)$, respectively, $\mathrm{K}$, 


$$
\begin{aligned}
& \dot{m}_{h o t}, \dot{m}_{\text {cold }}=\text { hot and cold side flow rates in region }[i, j], \text { respectively, } \mathrm{kg} / \mathrm{s}, \\
& h_{\text {hot }}^{i, j}, h_{\text {cold }}^{i, j}=\text { hot and cold side enthalpies at node }(i, j), \text { respectively, } \mathrm{J} / \mathrm{kg}-\mathrm{K} .
\end{aligned}
$$

The overall heat transfer coefficient is defined through the total thermal resistance on the hot and cold side and the resistance of the wall:

$$
H S_{i, j}=\frac{1}{r e s_{i, j}}=\frac{1}{r e s_{h o t}^{i, j}+r e s_{w}^{i, j}+r e s_{w}^{i, j}}
$$

while the resistance on each side is calculated through the heat transfer coefficient $(H T C)$, surface area $(S)$, and surface area efficiency $(\eta)$ on that side:

$$
\begin{aligned}
& \frac{1}{r e s_{\text {hot }}^{i, j}}=H T C_{\text {hot }}^{i, j} S_{\text {hot }}^{i, j} \eta_{\text {hot }}^{i, j} \\
& \frac{1}{\text { res }_{\text {cold }}^{i, j}}=H T C_{\text {cold }}^{i, j} S_{\text {cold }}^{i, j} \eta_{\text {cold }}^{i, j}
\end{aligned}
$$

The wall thermal resistance depends on the surface geometry. For a round tube, it is equal to:

where,

$$
\operatorname{res}_{w}^{i, j}=\frac{\ln \left(\frac{d_{o}}{d_{i}}\right)}{2 \pi k_{w}^{i, j} \Delta l_{i, j}}
$$

$d_{o}, d_{i}=$ outer and inner tube diameters, respectively, $\mathrm{m}$,

$k_{w}^{i, j}=$ average wall thermal conductivity in region $[i, j], \mathrm{W} / \mathrm{m}-\mathrm{K}$,

$\Delta l_{i, j}=$ tube length in region $[i, j], \mathrm{m}$.

In addition to the heat transfer equations above, the pressure drops are calculated in region $[i, j]$ for both fluids. Those pressure drops are used to calculate the pressure change in the node and, eventually, to relate the enthalpy change with the temperature change in the region to complete the heat transfer equations above.

The heat transfer equations above are listed in the code in an iterative fashion. First, based on the temperatures from previous iterations, the heat transfer coefficients and the amount of heat transfer are calculated for each region, along with the pressure drop. Then, the amount of heat transfer is used to re-calculate temperatures in each node, starting from inlet nodes. It was found, though, that this approach may lead to temperature cross-over, a conditions where hot side temperatures may drop below the cold side temperature in a particular region on a particular iteration, leading to a negative heat transfer and diverging iterations. To avoid these issues, a limit on the heat transfer is implemented to preclude temperature cross-over. As a result, the already slower calculations for a cross-flow heat exchanger are further slowed down due to limits on convergence speed.

There is, moreover, another source of computational speed reduction specific to the $\mathrm{sCO}_{2}$ cooler analysis in the cycle calculations. Previously, the cooler calculations in the PDC were set up to take advantage of the fact that the $\mathrm{CO}_{2}$ outlet temperature and pressure are known from the 
compressor-inlet conditions. Therefore, the cooler calculations in the PDC start from cold side and proceed towards the hot side. This approach has two benefits. First, the calculations start where the temperature difference between the two fluids is minimal, so the possibility of temperature cross-over is reduced. More importantly for $\mathrm{sCO}_{2}$ cooler applications, this approach ensures that $\mathrm{CO}_{2}$ conditions (both temperature and pressure) always stay above the critical point, since both temperature and pressure can only increase starting from the $\mathrm{CO}_{2}$ outlet. As Figure 4 demonstrates, however, this approach cannot be implemented with a cross-flow heat exchanger due to the fact that $\mathrm{CO}_{2}$ temperatures at the hot side outlet are different for different $\mathrm{CO}_{2}$ channels. Therefore, there is no single $\mathrm{CO}_{2}$ outlet temperature to start calculations from; the outlet temperatures for each channel are not known until the calculations for the entire heat exchanger are performed. A similar, but smaller, effect exists for the $\mathrm{CO}_{2}$ side pressures. Because of varying $\mathrm{CO}_{2}$ properties between the parallel channels, $\mathrm{CO}_{2}$ pressure drops and pressures would not be equal between the channels. For these reasons, the cross-flow heat exchanger calculations, even for the $\mathrm{CO}_{2}$ cooler, have to start from hot side inlet, and special attention (i.e., slower, more careful, iterations) needs to be paid to avoid conditions below the $\mathrm{CO}_{2}$ critical point.

There is another aspect of the cross flow heat exchanger which has a potential to complicate the calculations even further. As mentioned in the previous paragraph, a non-uniform temperature distribution results in different pressure conditions between the parallel channels on both sides. Therefore, if a uniform flow distribution is assumed, the pressures at each channel outlet will be different. In reality, though, these pressures have to be the same, for example, equal to the pressure of the outlet header on the $\mathrm{CO}_{2}$ side. Therefore, there would be a flow re-distribution between the channels (again, on both sides) to achieve a common outlet pressure. To avoid an additional layer of iterations to calculate flow re-distribution, an assumption of uniform flow distribution is currently made in the cross-flow heat exchanger code. Under this assumption, the flow rates are assumed to be the same for all channels and the calculations proceed independently to obtain outlet pressures for each channel. Then, the channel-outlet pressures are averaged to obtain a common outlet pressure as the header pressure. This assumption is partially justified by the fact that differences in pressure drops are not that large. In one of the cooler calculations described later in the report, it was found that the pressure drop on the $\mathrm{CO}_{2}$ side varied from $4.789 \mathrm{kPa}$ to $4.892 \mathrm{kPa}$ between the channels under a uniform-flow assumption, i.e. the difference in pressure drops was only about $2 \%$.

Another assumption currently implemented in the code is no intermixing between the air flows. In the finned tube designs described below, there would always be a space between the tube fins, such that there would be possibility for some air flow along the tubes, rather than across the tubes. It is believed, though, that the air flow rate along the tubes and air intermixing would be small compared to the air flow across the tubes, such that these effects can be ignored.

The last major assumption for the calculations described above is similar to that adopted for a counterflow heat exchanger in that it is assumed that there is no heat transfer inside the wall between two adjacent nodes. For some crossflow heat exchanger designs, this assumption also means no heat transfer in structure in the direction of air flow (such as between touching fins of different tubes). 
Because of the significant differences in the solution approach, a new subroutine was developed for the cross-flow heat exchangers, first as a stand-alone code, and later integrated into the PDC. Depending on the considered heat exchanger geometries, some design-specific differences in the solution approach were needed. Those differences are described in the following chapters. 


\section{Finned Tube Cross-Flow Heat Exchanger Analysis}

\subsection{General HX Description}

The schematic illustration of a finned tube heat exchanger is shown in Figure 5. For this aircooled $\mathrm{CO}_{2}$ cooler application, the $\mathrm{CO}_{2}$ flows inside of the horizontal tubes, while the air flow is vertical, from bottom to top, across the tubes, driven by air fans. The tubes have transverse fins on the outside (air) surface. The $\mathrm{CO}_{2}$ flow arrangement can be either single-pass or multi-pass; the example in Figure 5 shows a three-pass arrangement, where the tubes are divided into three groups and $\mathrm{CO}_{2}$ flow goes three times across the heat exchanger. The advantage of a multi-pass arrangement is that it increases the $\mathrm{CO}_{2}$ flow rate per tube, thus increasing the Reynolds number and the heat transfer coefficient. This is achieved, though, at the expense of higher pressure drop on the $\mathrm{CO}_{2}$ side; therefore, there would always be a trade-off between cycle efficiency (affected by $\mathrm{CO}_{2}$ pressure drop in the cooler) and cooler thermal performance and cost. The multi-pass arrangement can be done either in headers (as shown in Figure 5) or in tubes, where individual tubes will be connected by U-sections. The advantage of the header design in Figure 5 for this application is that the tubes are already long, about $18 \mathrm{~m}$ (61 feet), so a three-pass arrangement with U-tubes will require fabrication and bending of $50+\mathrm{m}$ tubes. The disadvantage of the header design is that it will require additional high-pressure $\mathrm{CO}_{2}$ headers.

Figure 5 shows four rows of tubes in the air flow direction. This is again a design choice affecting the heat exchanger size (foot print) and the air side pressure drop. The tubes can be either in a triangular lattice (as shown in Figure 5) or in a square lattice, where the tubes will be located directly above the previous row.

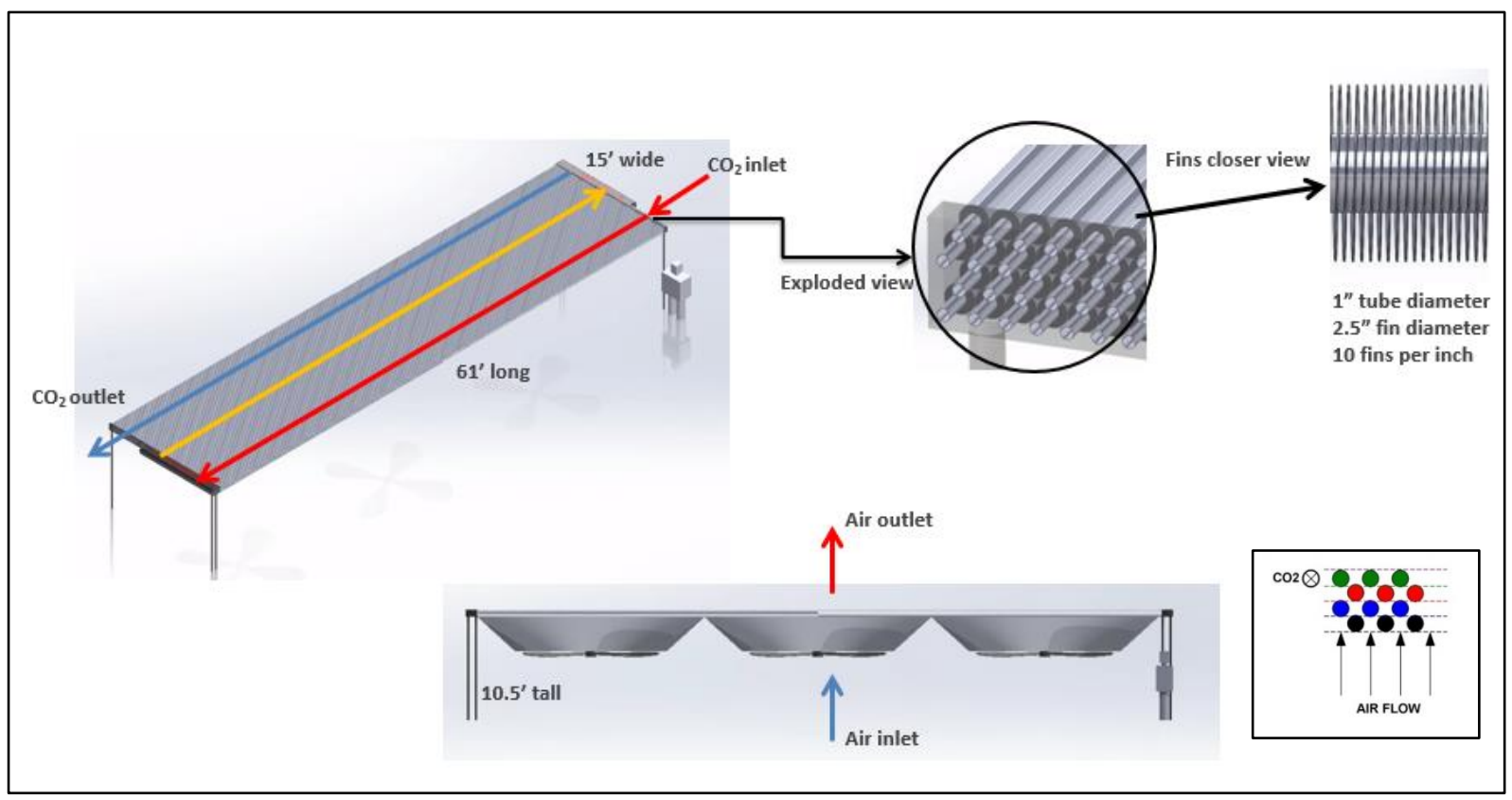

Figure 5. Finned Tube Cross Flow Heat Exchanger [1]. 
Figure 5 shows one heat exchanger module, while large-scale applications would require multiple units. For example, the Harsco quote for the AFR-100 design with a $137 \mathrm{MW} \mathrm{CO}_{2}$ cooler capacity needed 86 such units; the dimensions in Figure 5 are based on that Harsco design.

\subsection{Solution Approach}

The solution approach for the finned tube heat exchanger is based on the concept described in Section 2. The $\mathrm{CO}_{2}$ channels in Figure 4 are the tubes in one vertical section; the number of tubes is equal to the number of tube rows $\left(N_{\text {row }}\right)$ - four for the design in Figure 5 . There are $N_{\text {row }}+1$ vertical nodes on the air side. This means that $\mathrm{CO}_{2}$ conditions inside a tube and air conditions outside a tube are resolved for each tube. It is assumed that all parallel $\mathrm{CO}_{2}$ tubes in one pass will be identical from a heat transfer point of view, so the solution will be obtained for one vertical stack of tubes. The number of nodes in the direction of the $\mathrm{CO}_{2}$ flow will be determined later based on a trade-off between the required accuracy for $\mathrm{CO}_{2}$ properties and computational time.

As mentioned above, the tubes can be either in a triangular or square lattice, as shown in Figure 6. In Figure 6,

$$
\begin{aligned}
& d_{f}=\text { fin outer diameter, } \\
& d_{t}=\text { tube outer diameter, } \\
& p_{v}=\text { tube lattice vertical pitch, } \\
& p_{h}=\text { tube lattice horizontal pitch }
\end{aligned}
$$

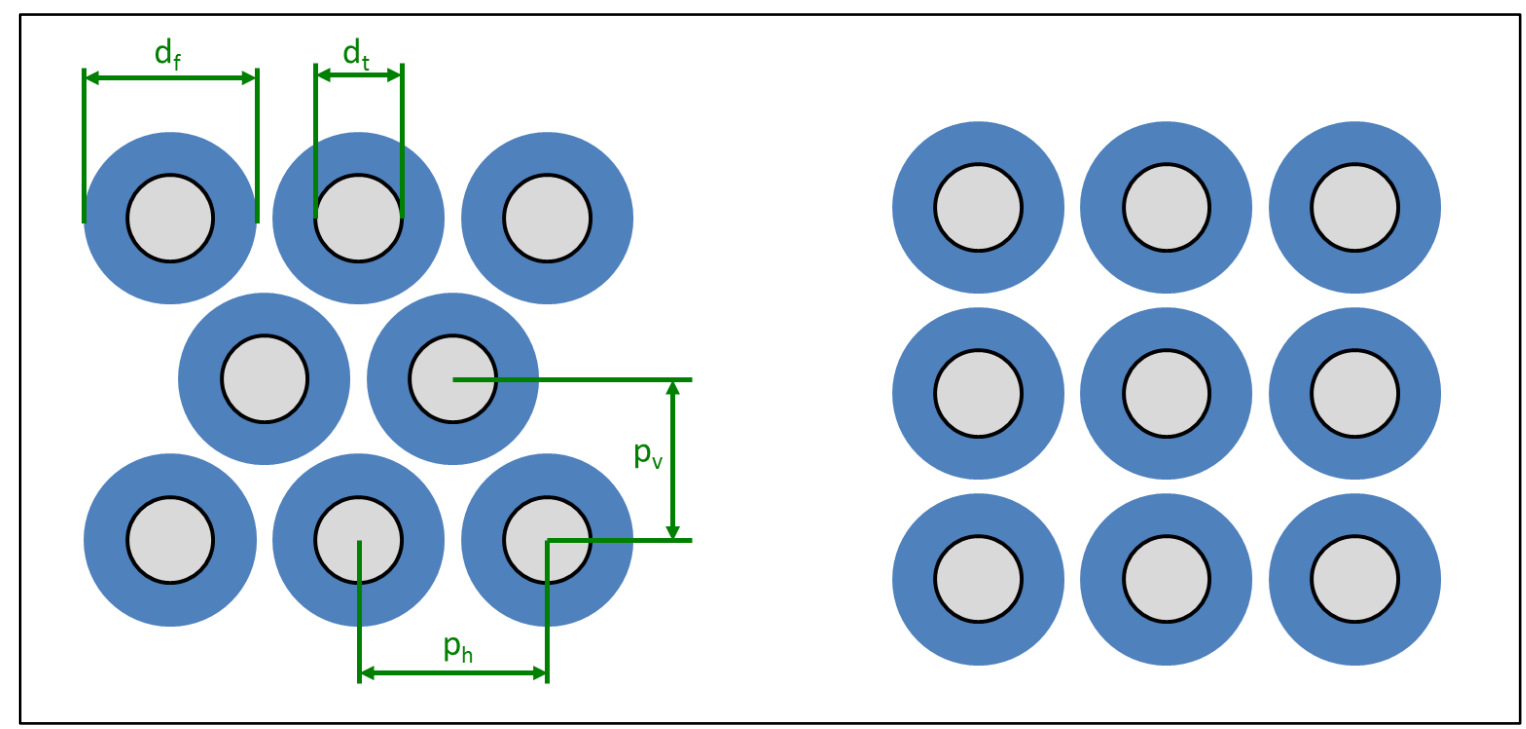

Figure 6. Tube Lattices: Triangular (Left) and Square (Right).

In the calculations, the off-centered arrangement of a triangular lattice is ignored; instead, it is assumed that tubes are located directly above each other, as in the square lattice. However, both the horizontal and vertical tube pitches in Figure 6 are input to the code (as pitch-to-diameter ratios), so the flow path length (height) on the air side is correctly accounted for both triangular and square lattice. 
To calculate the multi-pass arrangement on the hot $\left(\mathrm{CO}_{2}\right)$ side, the following approach is taken in the code (see Figure 7). In the modeled heat exchanger (top of Figure 7, a three-pass example is shown), the $\mathrm{CO}_{2}$ flow goes multiple times through the $\mathrm{HX}$ tubes. On the air side, though, the flows and temperatures for each tube are independent of each other. Also, each pass "sees" the same air inlet temperature. These facts mean that there are basically multiple heat exchangers, located in series, as demonstrated at the bottom of Figure 7. Except for the $\mathrm{CO}_{2}$ inlet conditions to each section, there is no other connection between these heat exchangers.

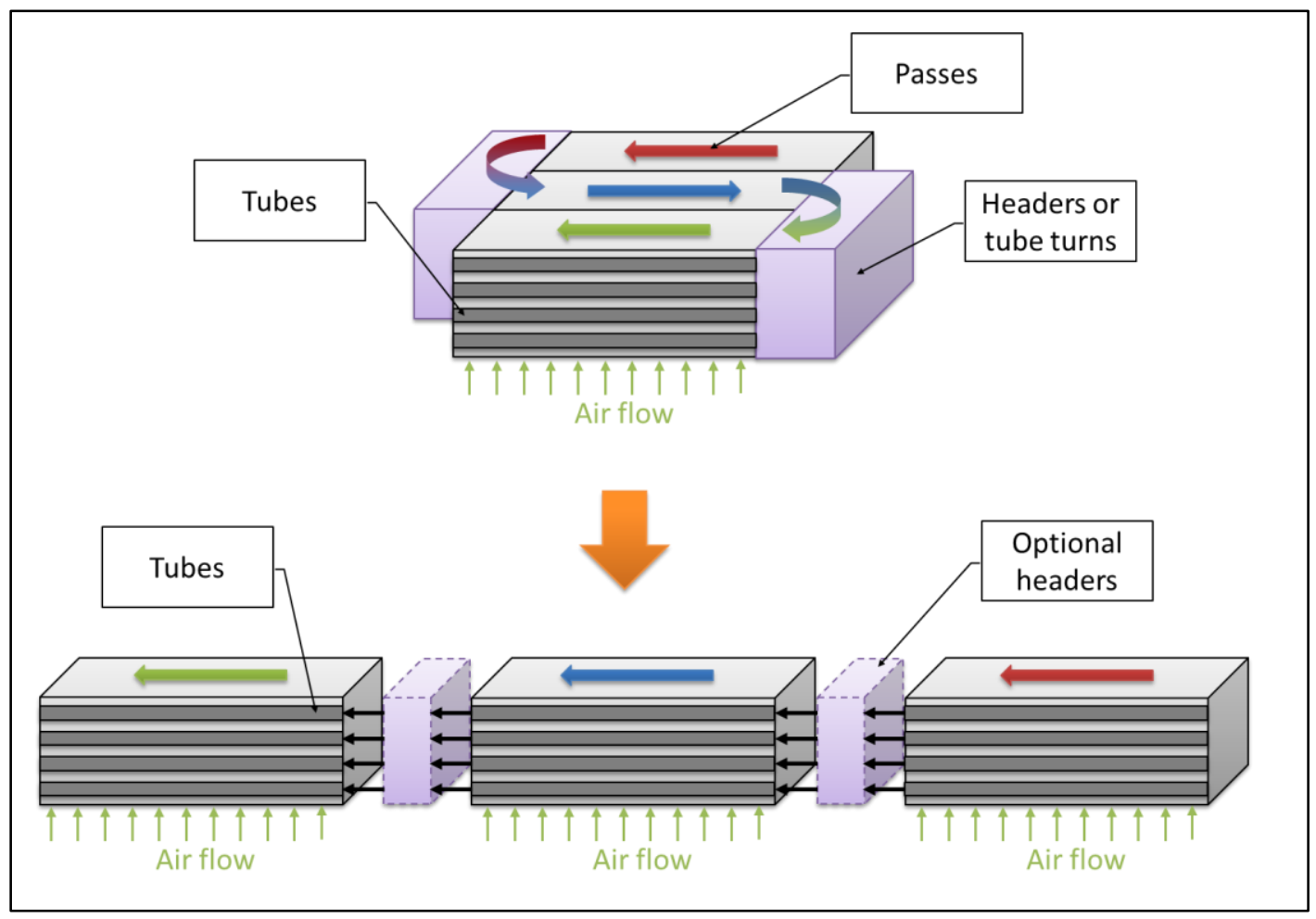

Figure 7. Treatment of Multi-Pass HX with Separate HXs.

Therefore, in the code, a multiple-pass heat exchanger is treated as a series of multiple heat exchangers. The number of tubes in each heat exchanger is equal to the number of tubes in each pass (1/3 of total number of tubes for the three-pass example in Figure 7). The inlet conditions on the air side are the same for all heat exchangers. The $\mathrm{CO}_{2}$ conditions at the first $\mathrm{HX}$ (first pass) inlet are the same as the given $\mathrm{CO}_{2}$ inlet conditions. When the calculations for the first $\mathrm{HX}$ are done, the $\mathrm{CO}_{2}$ outlet conditions for that $\mathrm{HX}$ are calculated. If the input specifies that pass connections are done in U-tube sections, those outlet conditions are transferred directly, tube-bytube, to the inlet of the next heat exchanger (possible temperature and pressure changes in the Usections of the tubes are ignored). In the case where the connection is done in headers, the outlet conditions from all tubes are combined to find the average conditions for this header. This averaging is done for the pressure (as discussed in the assumptions in Section 2) and for the enthalpy to preserve energy. The enthalpy-pressure pair is then used to define the rest of the $\mathrm{CO}_{2}$ properties in that header, which are used as the inlet conditions for the next HX section. These calculations are repeated for all passes. The outlet conditions at the last heat exchanger are always averaged to calculate the $\mathrm{CO}_{2}$ conditions at the heat exchanger outlet header. The air outlet 
conditions from all nodes in all heat exchanger sections are averaged (again, based on enthalpypressure averaging) to calculate the overall air outlet pressure and temperature.

\subsection{Geometric Parameters}

To determine the heat transfer and pressure drop in the finned tube cross-flow heat exchanger, some geometric parameters must be defined, including the flow area, surface area, heat transfer perimeter (surface area per unit length), hydraulic diameter, and etc. The definitions of these parameters for the air side will be discussed first.

When the air flows across the finned tubes, the free flow area varies. Depending on how the heat transfer and pressure drop correlations are developed, the air-side flow area can be defined differently. For the correlations currently adopted in the code, the air-side flow area is defined as the minimum free flow area when the air goes across the finned tube bank (and correspondingly the local air velocity will be the maximum). Specifically, it is defined as:

$$
A_{c, a}=\left[\left(p_{h}-d_{t, o}\right) L_{t}-\left(d_{f}-d_{t, o}\right) t_{f} N_{f}\right] N_{c}
$$

where,

$$
\begin{aligned}
& A_{c, a}=\text { air-side flow area, } \mathrm{m}^{2}, \\
& p_{h}=\text { horizontal tube pitch, } \mathrm{m}, \\
& d_{t, o}=\text { tube outer diameter, } \mathrm{m}, \\
& L_{t}=\text { tube length, } \mathrm{m}, \\
& d_{f}=\text { fin diameter, } \mathrm{m}, \\
& t_{f}=\text { fin thickness, } \mathrm{m} \\
& N_{f}=\text { number of fins per tube, } \\
& L_{t}=\text { tube length, } \mathrm{m}, \\
& N_{c}=\text { number of tube columns (number of tubes per row). }
\end{aligned}
$$

The air-side surface area (heat transfer area) includes that for both the fins and the bare tubes, and is defined as:

$$
A_{a}=\left[\pi d_{t, o}\left(L_{t}-t_{f} N_{f}\right)+\frac{\pi}{2}\left(d_{f}^{2}-d_{t, o}^{2}\right)\right] N_{c} N_{r}
$$

where,

$$
\begin{aligned}
& A_{a}=\text { air-side surface area, } \mathrm{m}^{2}, \\
& N_{r}=\text { number of tube rows. }
\end{aligned}
$$

It should be noted that the circumferential surface of the fins have been ignored in the above definition. The main reason is that the fins are touching with each other in some designs, such that part of that surface will not participate in heat transfer. In additional, the fin circumferential area is negligible compared to its side surface area, which is the second term in the above definition. Therefore, ignoring the fin circumferential area will not affect the heat transfer calculation. 
With the air-side surface area defined, the air-side heat transfer perimeter can be defined as:

$$
H T P_{a}=A_{a} L_{L_{t}}
$$

where,

$$
H T P_{a}=\text { air-side heat transfer perimeter, } \mathrm{m} .
$$

Heat transfer and pressure drop correlations for cross flow over a finned tube bank are available from preceding researches. However, these correlations were developed based on different definitions of hydraulic diameter. For the Briggs and Young [14] (heat transfer) and Robinson and Briggs [15] (pressure drop) correlations adopted in the code, the hydraulic diameter is selected to be the tube outer diameter. For the Kays and London [16] (heat transfer and pressure drop) correlations that have been adopted, the hydraulic diameter is defined as:

$$
D_{h, a}=4 \frac{A_{c, a}}{A_{a}} L_{a}
$$

where $D_{h, a}$ is the air-side hydraulic diameter $(\mathrm{m}) ; L_{a}$ is the air-side flow length $(\mathrm{m})$ and is defined as:

$$
L_{a}=p_{v} N_{r}
$$

where,

$$
p_{v}=\text { vertical tube pitch, } \mathrm{m} \text {. }
$$

The use of fins in the finned tube cross-flow heat exchanger helps to enhance the air-side heat transfer through the creation of an extended heat transfer surface. However, considering the heat flow path from the tube-side fluid through the tube wall and fins, and eventually into the air, there is clearly an additional thermal resistance due to the fins, compared to plain tubes. To account for this resistance in heat transfer calculations, a fin efficiency is defined in the following manner: fin efficiency is the ratio of the total heat transferred from the actual fins to the total heat that would be transferred if the fins were isothermal at the tube temperature. Correlations to determine the fin efficiency will be discussed in the following section. With the fin efficiency determined, the airside surface area efficiency can be calculated as:

$$
\eta_{a}=1-\frac{A_{f}}{A_{a}}\left(1-\eta_{f}\right)
$$

where,

$\eta_{a}=$ air-side surface area efficiency,

$\eta_{f}=$ fin efficiency,

$A_{f}=$ fin surface area, $\mathrm{m}^{2}$, and is defined as:

$$
A_{f}=\frac{\pi}{2}\left(d_{f}^{2}-d_{t, o}^{2}\right) N_{c} N_{r}
$$


It should be noted that the circumferential surface area of the fins has been neglected in the above definition, to be consistent with the definition of the total air-side surface area.

For the tube side, no interior fins are adopted in the present design. Therefore, the definitions of the geometric parameters for the tube side are quite straightforward, summarized as follows:

$$
\begin{aligned}
& A_{c, t}=\frac{\pi}{4} d_{t, i}^{2} N_{c} N_{r} \\
& A_{t}=\pi d_{t, i} L_{t} N_{c} N_{r} \\
& H_{T P} P_{t}=A_{t} /_{L_{t}}=\pi d_{t, i} N_{c} N_{r} \\
& D_{h, t}=d_{t, i}
\end{aligned}
$$

where,

$$
\begin{aligned}
& A_{c, t}=\text { tube-side flow area, } \mathrm{m}^{2} \\
& d_{t, i}=\text { tube inner diameter, } \mathrm{m}, \\
& A_{t}=\text { tube-side total surface area, } \mathrm{m}^{2} \\
& H T P_{t}=\text { tube-side heat transfer perimeter, } \mathrm{m}, \\
& D_{h, t}=\text { tube-side hydraulic diameter, } \mathrm{m} .
\end{aligned}
$$

\subsection{Heat Transfer and Pressure Drop Correlations}

Previously, a design and a quote for a $\mathrm{SCO}_{2}$-air cooler were received from Harsco, which features a finned tube design to enhance the air-side heat transfer. The quoted air cooler is a modular design with a nominal heat removal capability of approximately $1.69 \mathrm{MW}$ per unit. A total of 86 such units are expected to meet the cooling requirement for the AFR-100 $\mathrm{SCO}_{2}$ power cycle in Figure 3. To confirm the performance and sizing of the quoted air cooler by Harsco, an engineering equation solver (EES) model was previously developed to model the air cooler [1]. In EES, heat transfer and pressure drop correlations are available for the air-side analysis, but only for a limited selection of finned tube geometries. Among these correlations, the ones for a finned tube geometry (named the Kays and London design, and the corresponding heat transfer and pressure drop correlations named Kays and London correlations [16] in the remainder of the report) that is closest to the Harsco design were adopted in the present code. However, it has been found that the air-side heat transfer and pressure drop characteristics can vary significantly when the finned tube geometry changes. Therefore, the use of the Kays and London correlations for the air-side analysis of the Harsco design may cause errors, leading to the efforts of identifying more general correlations that take into account the geometric features of the finned tube. In this section, the Kays and London correlations and the new correlations will be discussed, along with comparisons between them. In addition, correlations for calculating the fin efficiency are also discussed. 


\subsubsection{Heat Transfer}

In the Kays and London method, the heat transfer coefficient for cross flow over a finned tube bank is calculated based on the Colburn $j$ factor [16]. For a fixed finned tube geometry, the $j$ factor is only dependent on Reynolds number:

$$
j=F(\mathrm{Re})
$$

where Re is the Reynolds number and is defined as:

$$
\operatorname{Re}=\frac{G_{a} D_{h, a}}{\mu_{a}}
$$

Here,

$G_{a}=$ air mass flux based on $A_{c, a}, \mathrm{~kg} / \mathrm{m}^{2}-\mathrm{s}$,

$D_{h, a}=$ air-side hydraulic diameter defined in Section 3.3,

$\mu_{a}=$ dynamic viscosity of air, Pa-s.

As mentioned above, the $j$ factor may vary significantly for different finned tube geometries. For the air-side heat transfer analysis of the Harsco design, the $j$ factor for the Kays and London design (CF-8.8-1.0J-A) [16] was adopted. For a comparison, some key parameters of the two finned tube geometries are summarized in Table 1. It should be noted that the $j$ factor for the Kays and London design assumes an infinitely large tube bank. In the following discussions, it is assumed that the same number of passes, number of rows, number of tubes per row, and tube length as those in the Harsco design are adopted for the EES geometry.

Table 1. Comparison between the Harsco Design and the Kays and London Design [1]

\begin{tabular}{|l|c|c|}
\hline Variable & Harsco Design & $\begin{array}{c}\text { Kays and London Design } \\
(\mathrm{CF}-8.8-1.0 \mathrm{~J}-\mathrm{A})\end{array}$ \\
\hline Fin Thickness $(\mathrm{mm})$ & 0.4064 & 0.3048 \\
\hline Fin Pitch (fins/m) & 393.7 & 346 \\
\hline Fin Diameter $(\mathrm{mm})$ & 57.15 & 44.12 \\
\hline Tube Outer Diameter $(\mathrm{mm})$ & 25.4 & 26.01 \\
\hline Horizontal Spacing $(\mathrm{mm})$ & 57.15 & 49.76 \\
\hline Vertical Spacing $(\mathrm{mm})$ & 49.49 & 52.4 \\
\hline Number of Passes & 3 & -- \\
\hline Number of Rows & 4 & -- \\
\hline Number of Tubes per Row & $81,80,81,80$ & -- \\
\hline Tube Length (m) & 18.29 & -- \\
\hline
\end{tabular}

The $j$ factor for the Kays and London design is plotted against the Reynolds number as shown in Figure 8 . The original $j$ factor presented by Kays and London [16] was in the form of charts, based on which separate values shown in Figure 8 were generated through a digitizing process. A fitting curve that correlates the $j$ factor with the Reynolds number is also provided as shown in Figure 8 . 


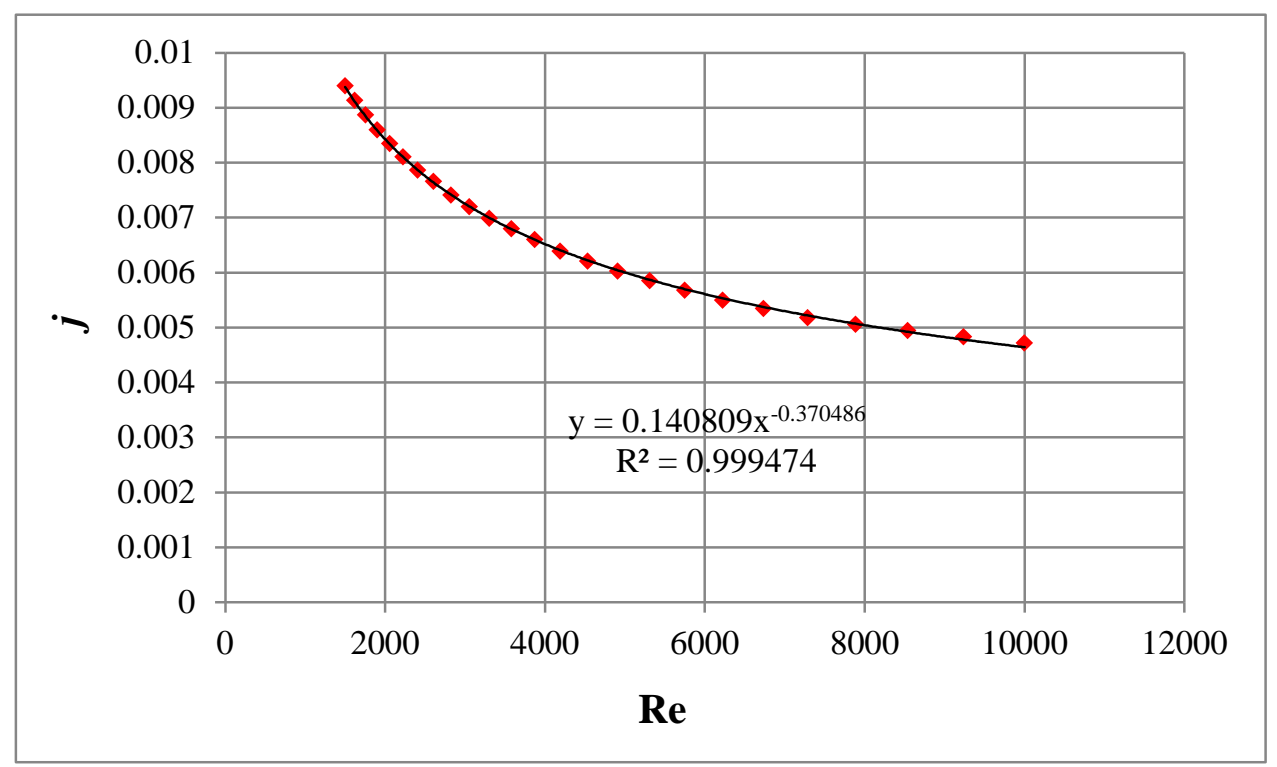

Figure 8. $j$ Factor for the Kays and London geometry.

With the $j$ factor determined, the heat transfer coefficient for cross flow over a finned tube bank can be calculated as:

$$
\begin{aligned}
& \mathrm{Nu}=j \operatorname{RePr}_{a}^{1 / 3} \\
& h_{a}=\frac{\mathrm{Nu} D_{h, a}}{k_{a}}
\end{aligned}
$$

where,

$\mathrm{Nu}=$ Nusselt number,

$h_{a}=$ air-side heat transfer coefficient, $\mathrm{W} / \mathrm{m}^{2}-\mathrm{K}$,

$k_{a}=$ thermal conductivity of air, $\mathrm{W} / \mathrm{m}-\mathrm{K}$,

$\operatorname{Pr}_{a}=$ Prandtl number of air, and is defined as:

$$
\operatorname{Pr}_{a}=\frac{c_{p, a} \mu_{a}}{k_{a}}
$$

where,

$$
c_{p, a}=\text { specific heat of air, } \mathrm{J} / \mathrm{kg}-\mathrm{K} \text {. }
$$

As can be seen from Table 1, even though the Kays and London design is the closest one to the Harsco design, there are still appreciable differences, which may cause errors when using the $j$ factor to analyze the air-side heat transfer for the Harsco design. Therefore, an effort was made to search for a more general heat transfer correlation that takes into account the finned tube geometry, leading to the finding of the Briggs and Young correlation [14]:

$$
\frac{h_{a} d_{t, o}}{k_{a}}=0.134\left(\frac{G_{a} d_{t, o}}{\mu_{a}}\right)^{0.681} \operatorname{Pr}_{a}^{1 / 3}\left(\frac{H_{f}}{s_{f}}\right)^{-0.2}\left(\frac{t_{f}}{s_{f}}\right)^{-0.1134}
$$


where,

$H_{f}=$ fin height, $\mathrm{m}$, and is defined as:

$H_{f}=\frac{d_{f}-d_{t, o}}{2}$

$s_{f}=$ fin spacing, $\mathrm{m}$, and is defined as:

$S_{f}=\frac{L_{t}}{N_{f}}-t_{f}$

For a comparison, both the Briggs and Young correlation and Kays and London $j$ factor are applied to the Kays and London design, with the results shown in Figure 9. The percent difference is defined as:

$$
\frac{h_{B Y}-h_{K L}}{h_{K L}} \times 100
$$

where,

$h_{B Y}=$ heat transfer coefficient predicted by Briggs and Young correlation, $\mathrm{W} / \mathrm{m}^{2}-\mathrm{K}$, $h_{K L}=$ heat transfer coefficient predicted by Kays and London correlation, $\mathrm{W} / \mathrm{m}^{2}-\mathrm{K}$.

As can be seen, the difference in the heat transfer coefficients predicted by these two correlations is in the order of $10 \%$, which is small considering the uncertainties in these correlations (e.g., $5.1 \%$ standard deviation for the Briggs and Young correlation [14]).

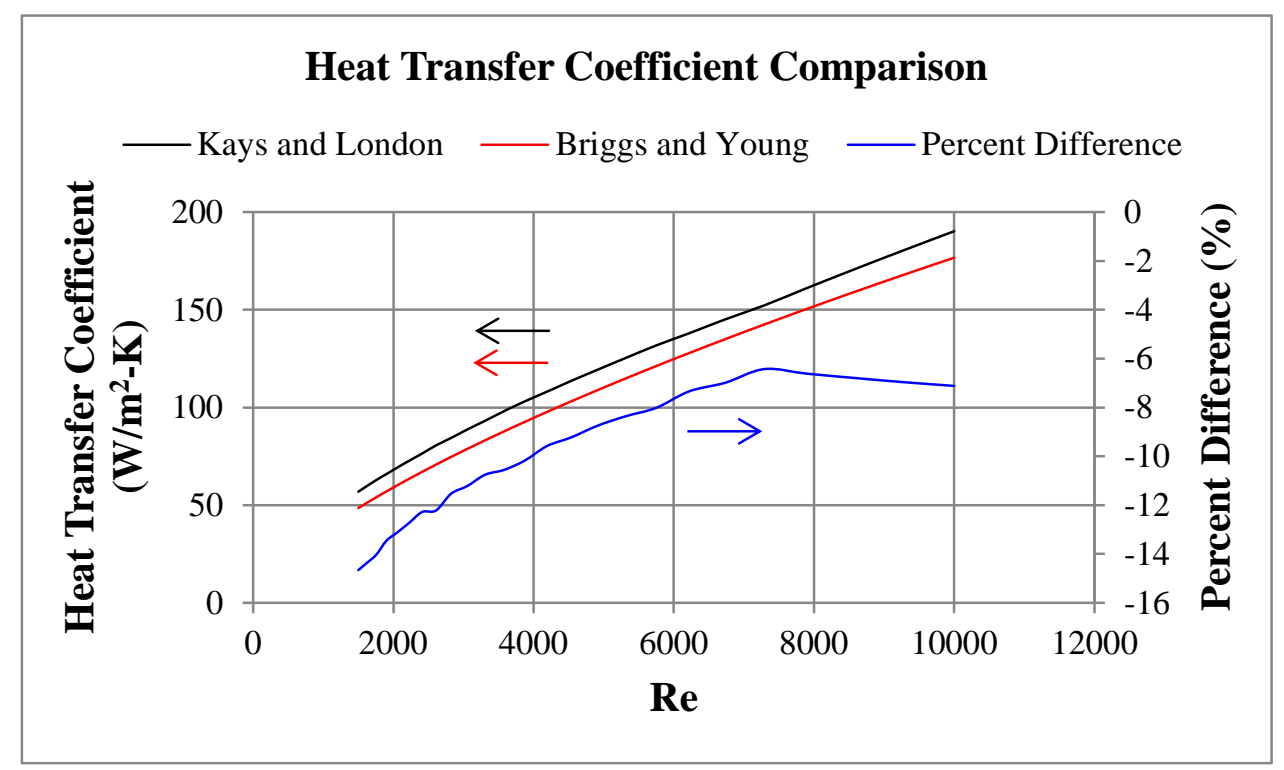

Figure 9. Comparison between the Kays and London, and Briggs and Young Correlations. 


\subsubsection{Pressure Drop}

In the Kays and London method the pressure drop for cross flow over a finned tube bank is calculated based on the friction factor $f$ [16]. For the Kays and London design shown in Table 1, the $f$ factor exhibits a relationship with the Reynolds number as plotted in Figure 10. Similar to the $j$ factor, the original data of the $f$ factor was in the form of charts. A digitizing procedure has been performed to generate the discrete points shown in Figure 10, along with a fitting curve.

With the $f$ factor determined, the air-side pressure drop can be calculated as:

$$
\Delta p_{a}=\frac{G_{a}^{2}}{2 \rho_{a}} f \frac{A_{a}}{A_{c, a}}
$$

where,

$\Delta p_{a}=$ air-side pressure drop, $\mathrm{Pa}$, $\rho_{a}=$ density of air, $\mathrm{kg} / \mathrm{m}^{3}$.

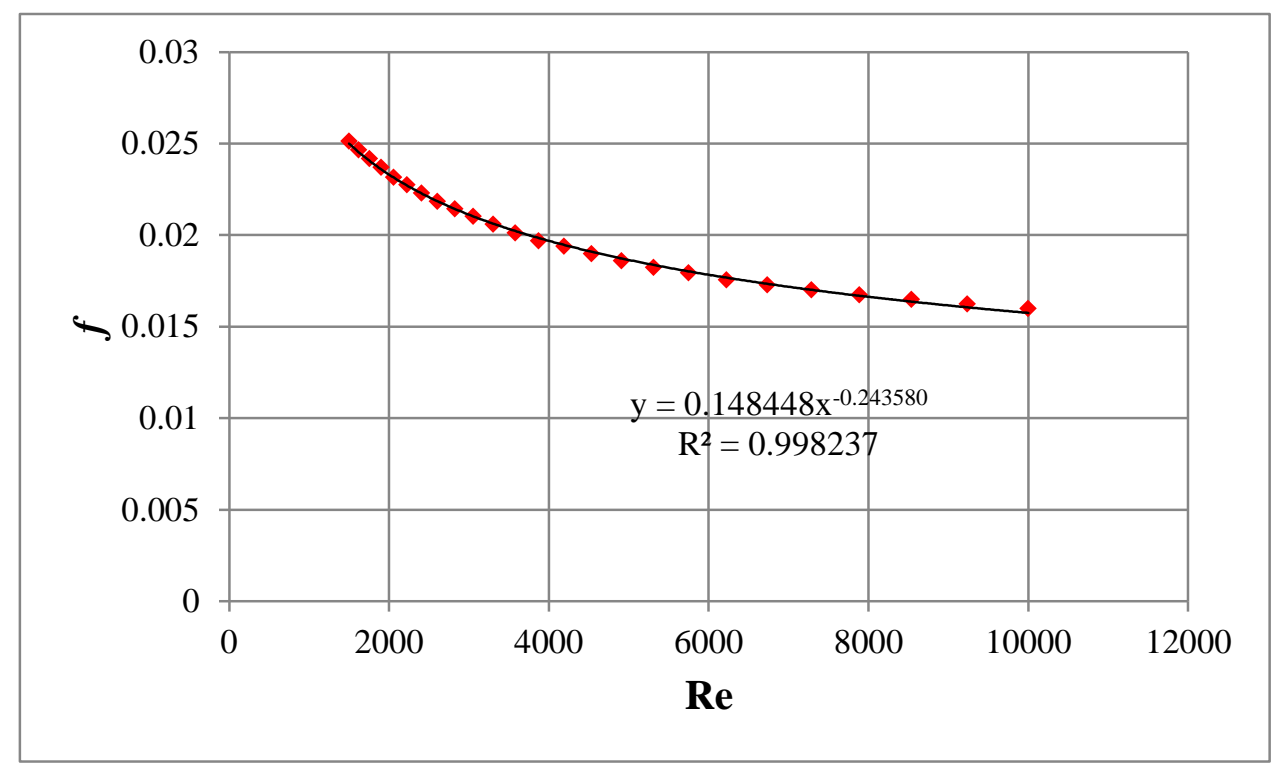

Figure 10. $f$ Factor by Kays and London [16].

Similar to the heat transfer, efforts have been made to identify a more general pressure drop correlation. Robinson and Briggs [15] developed a general pressure drop correlation that takes into account the finned tube geometry, written as:

$$
f_{r}=18.93\left(\frac{G_{a} d_{t, o}}{\mu_{a}}\right)^{-0.316}\left(\frac{p_{h}}{d_{t, o}}\right)^{-0.927}\left(\frac{p_{h}}{p_{v}}\right)^{-0.515}
$$

where,

$$
f_{r}=\text { friction factor by Robinson and Young [15]. }
$$

The total pressure drop for cross air flow over the finned tube bank is calculated based on $f_{r}$ as: 


$$
\Delta p_{a}=\frac{G_{a}^{2}}{\rho_{a}} f_{r} N_{r}
$$

A comparison is made between the above two pressure drop correlations by applying them to the Kays and London design, with the results shown in Figure 11. In the present calculation, four rows of the selected finned tubes are assumed. The percent difference shown in Figure 11 is defined in the same way as the heat transfer, with the Kays and London correlation as the reference. As can be seen, the percent difference of the pressure drop comparison is much larger than that of the previous heat transfer comparison. At the low Reynolds number end, this difference is as high as 35\%, much larger than the standard deviation of the Robinson and Briggs correlation, which is $10.7 \%$ [15]. Because of this large difference, the two correlations used were double checked. It is found that the Robinson and Briggs correlation was developed from their original work, while Kays and London developed their correlation based on the original work by Jameson [17]. Therefore, the original pressure drop correlation by Jameson was also investigated.

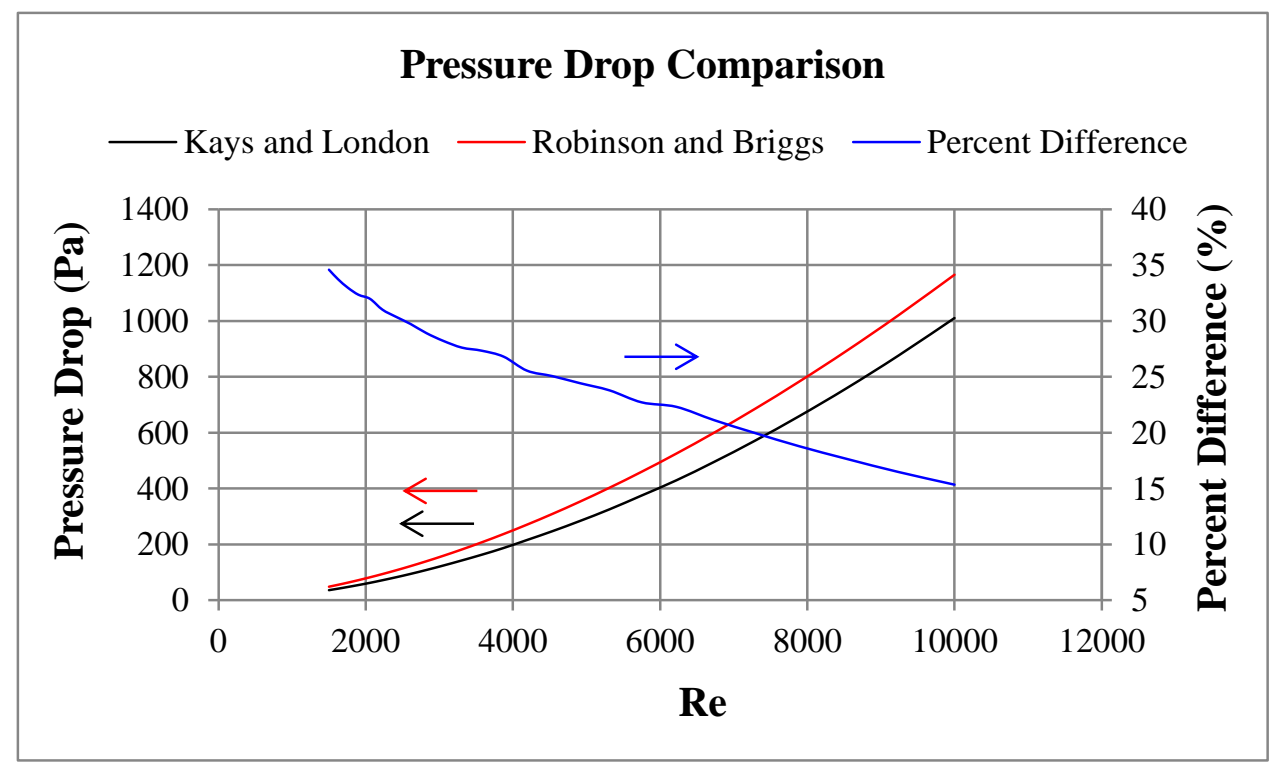

Figure 11. Comparison between the Kays and London, and Robinson and Briggs Correlations.

The pressure drop correlation developed by Jameson is written as:

$$
f_{J}=1.532 \mathrm{Re}_{e q}^{-0.25}
$$

where,

$f_{J}=$ friction factor by Jameson,

$\operatorname{Re}_{e q}=$ Reynolds number based on an equivalent diameter for the finned tube bank, and is defined as:

$$
\operatorname{Re}_{e q}=\frac{G_{a} D_{e q}}{\mu_{a}}
$$

where,

$$
D_{e q}=\text { equivalent diameter for the finned tube bank, } \mathrm{m} .
$$


An empirical relation for the $D_{e q}$ was given by Jameson [17] as:

$$
D_{e q}=\frac{d_{e q}}{\left[\left(\frac{H_{f}}{2 s_{f}}\right)^{0.4}\left(\frac{1}{2 \sqrt{p_{h} / d_{e q-1}}}+\frac{1}{2 \sqrt{p_{d} / d_{e q-1}}}\right)\right]^{4}}
$$

where,

$d_{e q}=$ equivalent diameter for a single finned tube, $\mathrm{m}$,

$p_{d}=$ diagonal tube pitch, $\mathrm{m}$.

$d_{e q}$ and $p_{d}$ are defined respectively as:

$$
\begin{aligned}
& d_{e q}=\frac{2 A}{\pi B} \\
& p_{d}=\sqrt{\left(p_{h} / 2\right)^{2}+\left(p_{v}\right)^{2}}
\end{aligned}
$$

where,

$A=$ total surface area of a single finned tube, $\mathrm{m}^{2}$,

$B=$ projected perimeter of a single tube, $\mathrm{m}$.

$A$ and $B$ are defined respectively as:

$$
\begin{aligned}
& A=\frac{A_{a}}{N_{c} N_{r}} \\
& B=2 L_{t}+4 H_{f} N_{f}
\end{aligned}
$$

It should be noted that, with the above definitions, $d_{e q}$ reduces to its outer diameter for a plain tube. With the friction factor determined, the total air-side pressure drop can be calculated as:

$$
\Delta p_{a}=\frac{2 G_{a}^{2}}{\rho_{a}} f_{J} N_{r}
$$

As can be seen, the Jameson correlation was developed in a similar way to the Robinson and Briggs correlation, with the only difference of a factor of 2. The Jameson correlation was applied to the Kays and London design and was compared with the previous results, as shown in Figure 12. As can be seen, the Jameson correlation agrees better with the Robinson and Briggs correlation than the Kays and London correlation in predicting the air-side pressure drop for the Kays and London design. In addition, the percent difference of the pressure drops predicted by the Jameson, and Robinson and Briggs correlation, shown in Figure 12, is of the same order of magnitude as the standard deviation of the latter correlation. In the present code, all the three pressure drop correlations have been implemented. 


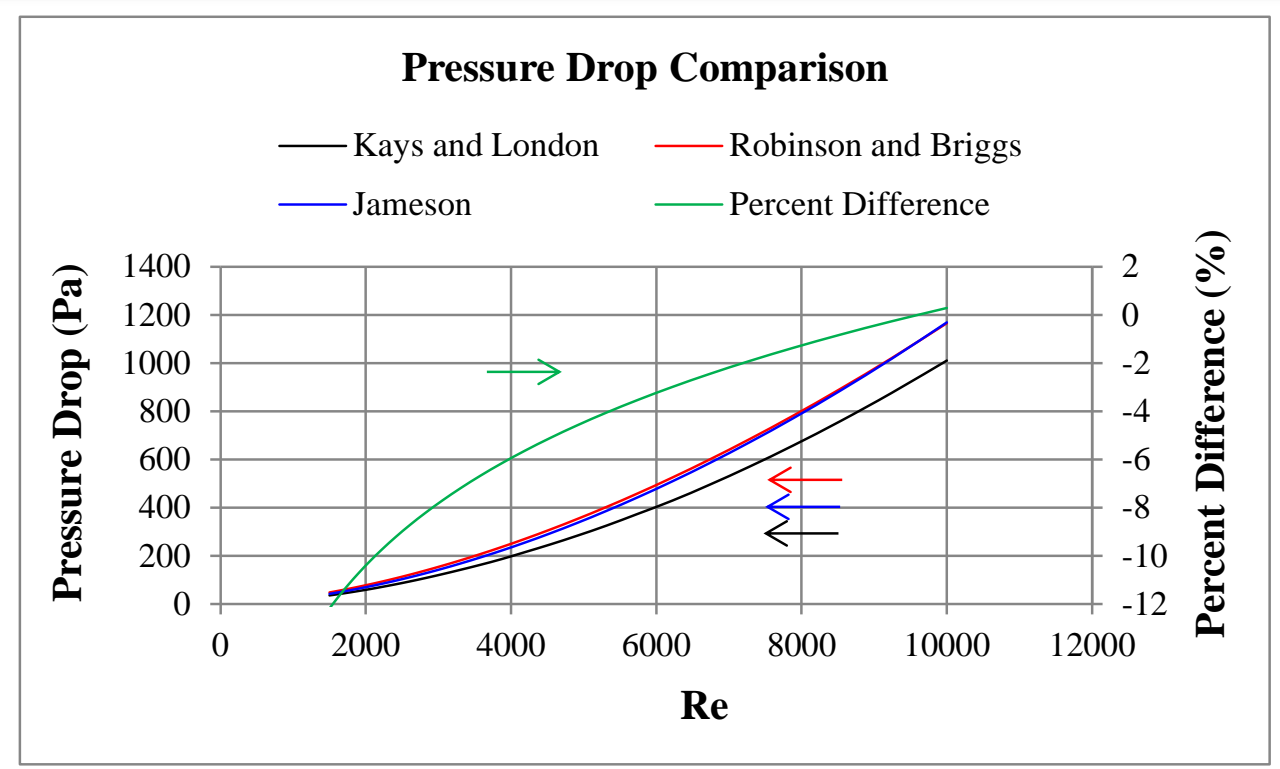

Figure 12. Comparison of the Three Pressure Drop Correlations.

\subsubsection{Fin Efficiency}

For fined tubes with circular fins, the fin efficiency can be calculated based on a complex analytical derivation by Kern and Kraus [18]:

$$
\eta_{f}=\frac{4 d_{t, o}}{m\left(d_{f}^{2}-d_{t, o}^{2}\right)}\left[\frac{I_{1}\left(m d_{f} / 2\right) K_{1}\left(m d_{t, o} / 2\right)-K_{1}\left(m d_{f} / 2\right) I_{1}\left(m d_{t, o} / 2\right)}{I_{0}\left(m d_{t, o} / 2\right) K_{1}\left(m d_{f} / 2\right)+I_{1}\left(m d_{f} / 2\right) K_{0}\left(m d_{t, o} / 2\right)}\right]
$$

where,

$I_{1}=$ first order modified Bessel function of the first kind,

$I_{0}=$ zero $^{\text {th }}$ order modified Bessel function of the first kind,

$K_{1}=$ first order modified Bessel function of the second kind,

$K_{0}=$ zero $^{\text {th }}$ order modified Bessel function of the second kind,

$m=$ a geometric parameter $\left(\mathrm{m}^{-1}\right)$ defined as:

$$
m=\sqrt{\frac{2}{\left(\frac{1}{h_{a}}+R_{f, a}\right) k_{f} t_{f}}}
$$

where,

$R_{f, a}=$ air-side fouling resistance, $\mathrm{m}^{2}-\mathrm{K} / \mathrm{W}$, if present,

$k_{f}=$ thermal conductivity of the fin, $\mathrm{W} / \mathrm{m}-\mathrm{K}$.

The above analytical formulation for the fin efficiency, although accurate, is relatively difficult to be implemented in Fortran, due to the Bessel functions. An empirical correlation that approximates the above analytical solution well, but much simpler to implement in Fortran, has been identified: 


$$
\eta_{f}=\frac{1}{1+\frac{\left(m H_{f}\right)^{2}}{3} \sqrt{\frac{d_{f}}{d_{t, o}}}}
$$

In the present application (as well as most other applications), the air-side heat transfer coefficient is expected to lie in the range of $\sim 0-200 \mathrm{~W} / \mathrm{m}^{2}-\mathrm{K}$. Over this range, the fin efficiencies are calculated using the above two equations, assuming no fouling resistance for the air side. The results are shown in Figure 13. As can be seen, over the potential range of the heat transfer coefficient, the empirical correlation approximates the analytical solution very well (with maximum relative error less than $2.5 \%$ ), and thus is adopted in the code.

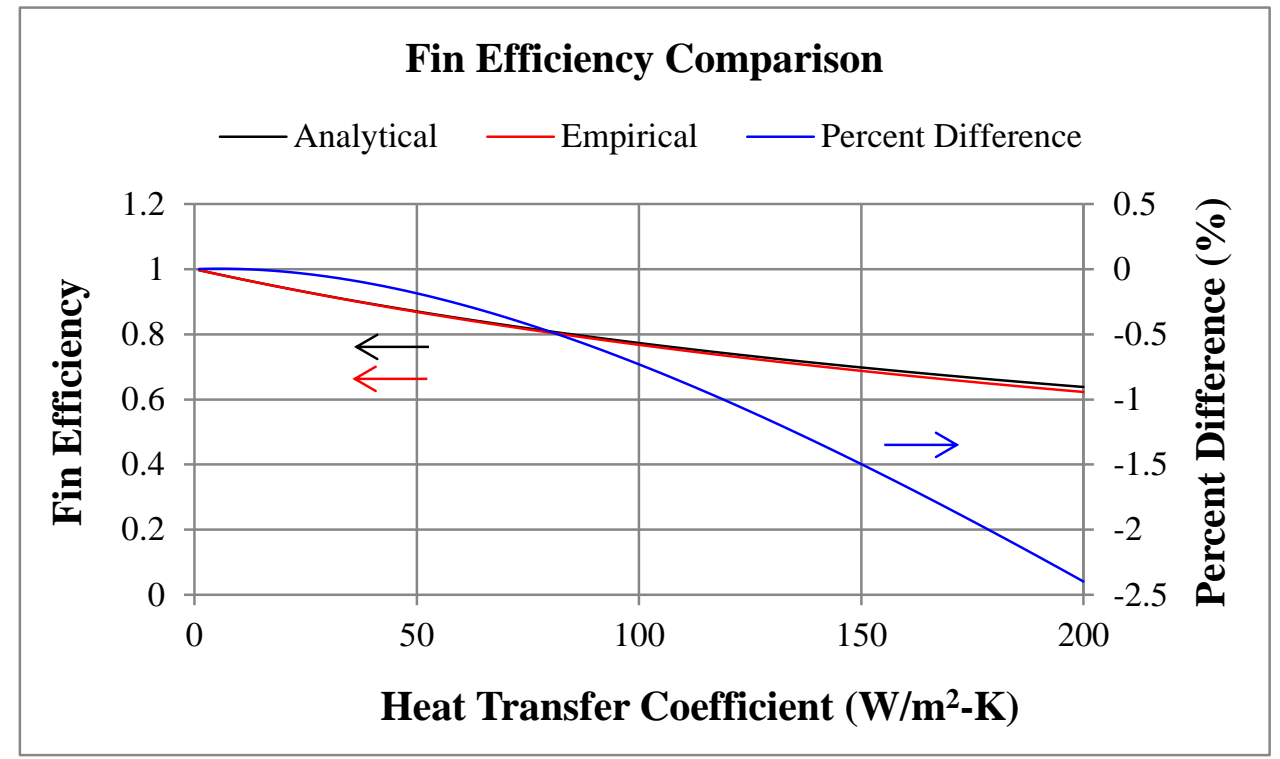

Figure 13. Fin Efficiency Comparison Results.

\subsection{HX Analysis}

Along with the quote from Harsco, design results were also provided by the vendor. To confirm the performance of the quoted Harsco design under the specified operation conditions, the developed Fortran code was applied to the Harsco design. The rating results with different combinations of heat transfer and pressure drop correlations were compared with the quoted results, and the correlations that yielded the best agreement were identified. With the selected correlations, the code was further applied to investigate other design options for the finned tube cross-flow heat exchanger, in terms of number of rows, number of passes, header design vs. U tube design, and finned tube geometry.

\subsubsection{Comparison with Harsco Quote}

Table 2 summarizes the key rating results of the Harsco design with different heat transfer and pressure drop correlations. The design results provided by the vendor are also shown in Table 2 , as a reference. In the present code, a fan efficiency of $90 \%$ was assumed when calculating the fan 
power. As can be clearly seen, the use of the Briggs and Young correlation for heat transfer and Kays and London correlation for pressure drop yields the best agreement with the vendor results, in terms of the $\mathrm{sCO}_{2}$-side conditions and fan power. It should be noted that, this conclusion is based upon the assumption of $90 \%$ fan efficiency, which is selected to the best knowledge of the authors.

Table 2. Rating Results of the Harsco Design

\begin{tabular}{|l|c|c|c|c|c|c|}
\hline & $\begin{array}{c}\dot{\boldsymbol{Q}} \\
(\mathbf{M W})\end{array}$ & $\begin{array}{c}\boldsymbol{T}_{\mathbf{C o}_{2}, \boldsymbol{i}} \\
\left({ }^{\mathbf{0}} \mathbf{C}\right)\end{array}$ & $\begin{array}{c}\boldsymbol{T}_{\mathbf{C o}}, \boldsymbol{o} \\
\left({ }^{\mathbf{o}} \mathbf{C}\right)\end{array}$ & $\begin{array}{c}\Delta \boldsymbol{p}_{\mathbf{C o}_{2}} \\
(\mathbf{k P a})\end{array}$ & $\begin{array}{c}\Delta \boldsymbol{p}_{\text {air }} \\
(\mathbf{P a})\end{array}$ & $\begin{array}{c}\text { Fan } \\
\text { Power } \\
(\mathbf{M W})\end{array}$ \\
\hline Vendor & 145.42 & 89.6 & 32.70 & 6.89 & -- & 5.0 \\
\hline BY \& RB & 137.46 & 89.6 & 32.65 & 6.72 & 104 & 2.7 \\
\hline KL \& KL & 145.88 & 89.6 & 32.53 & 6.43 & 191 & 5.0 \\
\hline BY \& KL & 137.47 & 89.6 & 32.65 & 6.72 & 190 & 5.0 \\
\hline KL \& RB & 145.88 & 89.6 & 32.53 & 6.43 & 105 & 2.7 \\
\hline BY \& Ja & 137.47 & 89.6 & 32.65 & 6.72 & 161 & 4.2 \\
\hline KL \& Ja & 145.88 & 89.6 & 32.53 & 6.43 & 162 & 4.2 \\
\hline
\end{tabular}

It should also be noted that, although predicting the $\mathrm{sCO}_{2}$-side outlet temperature accurately, the Briggs and Young correlation did not predict the total heat transfer rate very well, as seen from Table 2. One possible reason is due to the incorrect $\mathrm{sCO}_{2}$-side inlet pressure used by the vendor. In the present analysis, the $\mathrm{sCO}_{2}$-side inlet pressure has been fixed at $7.635 \mathrm{MPa}$, which is dictated by the $\mathrm{sCO}_{2}$ cycle operating conditions, as shown in Figure 3. However, the vendor used 1,122 psia $(7.736 \mathrm{MPa})$ as the $\mathrm{sCO}_{2}$-side inlet pressure in their design. To examine the effects of the $\mathrm{sCO}_{2}$-side inlet pressure, and accordingly the $\mathrm{sCO}_{2}$ properties, on the total heat transfer rate, a rerating process was performed, with a $\mathrm{sCO}_{2}$-side inlet pressure of $7.736 \mathrm{MPa}$. The results are shown in Table 3. As can be seen, the rated total heat transfer rate with the adjusted $\mathrm{sCO}_{2}$-side inlet pressure agrees much better with the vendor results, though the $\mathrm{sCO}_{2}$-side outlet temperature deviates more. These results are probably due to different $\mathrm{CO}_{2}$ properties subroutines used by the vendor.

Table 3. Rating Results with a sCO $\mathrm{S}_{2}$-side Inlet Pressure of 7.736 MPa

\begin{tabular}{|l|c|c|c|c|c|c|}
\hline & $\begin{array}{c}\dot{\boldsymbol{Q}} \\
(\mathbf{M W})\end{array}$ & $\begin{array}{c}\boldsymbol{T}_{\boldsymbol{C o}_{2}, \boldsymbol{i}} \\
\left({ }^{\mathbf{o}} \mathbf{C}\right)\end{array}$ & $\begin{array}{c}\boldsymbol{T}_{\boldsymbol{C o}_{\mathbf{2}}, \boldsymbol{o}} \\
\left({ }^{\mathbf{o}} \mathbf{C}\right)\end{array}$ & $\begin{array}{c}\Delta \boldsymbol{p}_{\boldsymbol{C o}_{\mathbf{2}}} \\
(\mathbf{k P a})\end{array}$ & $\begin{array}{c}\Delta \boldsymbol{p}_{\text {air }} \\
(\mathbf{P a})\end{array}$ & $\begin{array}{c}\text { Fan Power } \\
(\mathbf{M W})\end{array}$ \\
\hline Vendor & 145.42 & 89.6 & 32.70 & 6.89 & -- & 5.0 \\
\hline BY \& KL & 144.68 & 89.6 & 33.14 & 6.46 & 191 & 5.0 \\
\hline
\end{tabular}

Before proceeding to the investigation of the design options for the finned tube cross-flow heat exchanger, a mesh convergence study was performed to make sure the sizing results were grid- 
independent. In the above calculations, 50 axial mesh cells were applied to each pass for the $\mathrm{sCO}_{2}$ side. For the air side, each row of tubes in each pass was treated as one mesh cell. The mesh convergence study focuses on the $\mathrm{sCO}_{2}$ side. By varying the $\mathrm{sCO}_{2}$-side meshes from 10 to 50 mesh cells per pass, with an increment of 10 for each case, the sizing results are summarized in Table 4. BY and KL correlations have been adopted in the mesh convergence study. As can be clearly seen, as the number of mesh cells for the $\mathrm{sCO}_{2}$ side increases to 40 mesh cells per pass, the sizing results converge to constant values. Therefore, for the remaining of the report, 50 mesh cells per pass have been selected for the $\mathrm{SCO}_{2}$ side.

Table 4. Mesh Convergence Study Results

\begin{tabular}{|l|c|c|c|c|c|c|}
\hline & $\begin{array}{c}\dot{\boldsymbol{Q}} \\
(\mathbf{M W})\end{array}$ & $\begin{array}{c}\boldsymbol{T}_{\mathbf{C o}_{2}, \boldsymbol{i}} \\
\left({ }^{\mathbf{o}} \mathbf{C}\right)\end{array}$ & $\begin{array}{c}\boldsymbol{T}_{\boldsymbol{C o}_{2}, \boldsymbol{o}} \\
\left({ }^{\mathbf{O}} \mathbf{C}\right)\end{array}$ & $\begin{array}{c}\Delta \boldsymbol{p}_{\boldsymbol{C o}_{2}} \\
(\mathbf{k P a})\end{array}$ & $\begin{array}{c}\Delta \boldsymbol{p}_{\text {air }} \\
(\mathbf{P a})\end{array}$ & $\begin{array}{c}\text { Fan Power } \\
(\mathbf{M W})\end{array}$ \\
\hline 50 Meshes & 137.47 & 89.6 & 32.654 & 6.72 & 190 & 5.0 \\
\hline 40 Meshes & 137.47 & 89.6 & 32.654 & 6.72 & 190 & 5.0 \\
\hline 30 Meshes & 137.48 & 89.6 & 32.654 & 6.72 & 190 & 5.0 \\
\hline 20 Meshes & 137.50 & 89.6 & 32.653 & 6.72 & 190 & 5.0 \\
\hline 10 Meshes & 137.61 & 89.6 & 32.651 & 6.71 & 190 & 5.0 \\
\hline
\end{tabular}

\subsubsection{Design Options}

Different design options for the finned tube cross-flow heat exchanger, in terms of number of rows, number of passes, header design vs. U tube design, and finned tube geometry, were investigated. The design results are summarized in Table 5. Based on previous studies, the B \& Y and $\mathrm{K} \& \mathrm{~L}$ correlations have been selected in all the calculations except for the last case, where the K \& L correlations are adopted for both heat transfer and pressure drop. The overall HX size, represented by the number of PCHE units, and the air flow rate are selected to:

- Meet the $\mathrm{CO}_{2}$ inlet and outlet conditions for the reference $\mathrm{sCO}_{2}$ cycle design with 31.25

${ }^{\circ} \mathrm{C}$ and 7.4 MPa compressor inlet temperature and pressure, and

- Maintain 5 MWe (5\% gross AFR-100 generator output) air circulation power under assumption of $90 \%$ air fan efficiency. 
Table 5. Results of Finned Tube Cross-flow Heat Exchanger Calculations

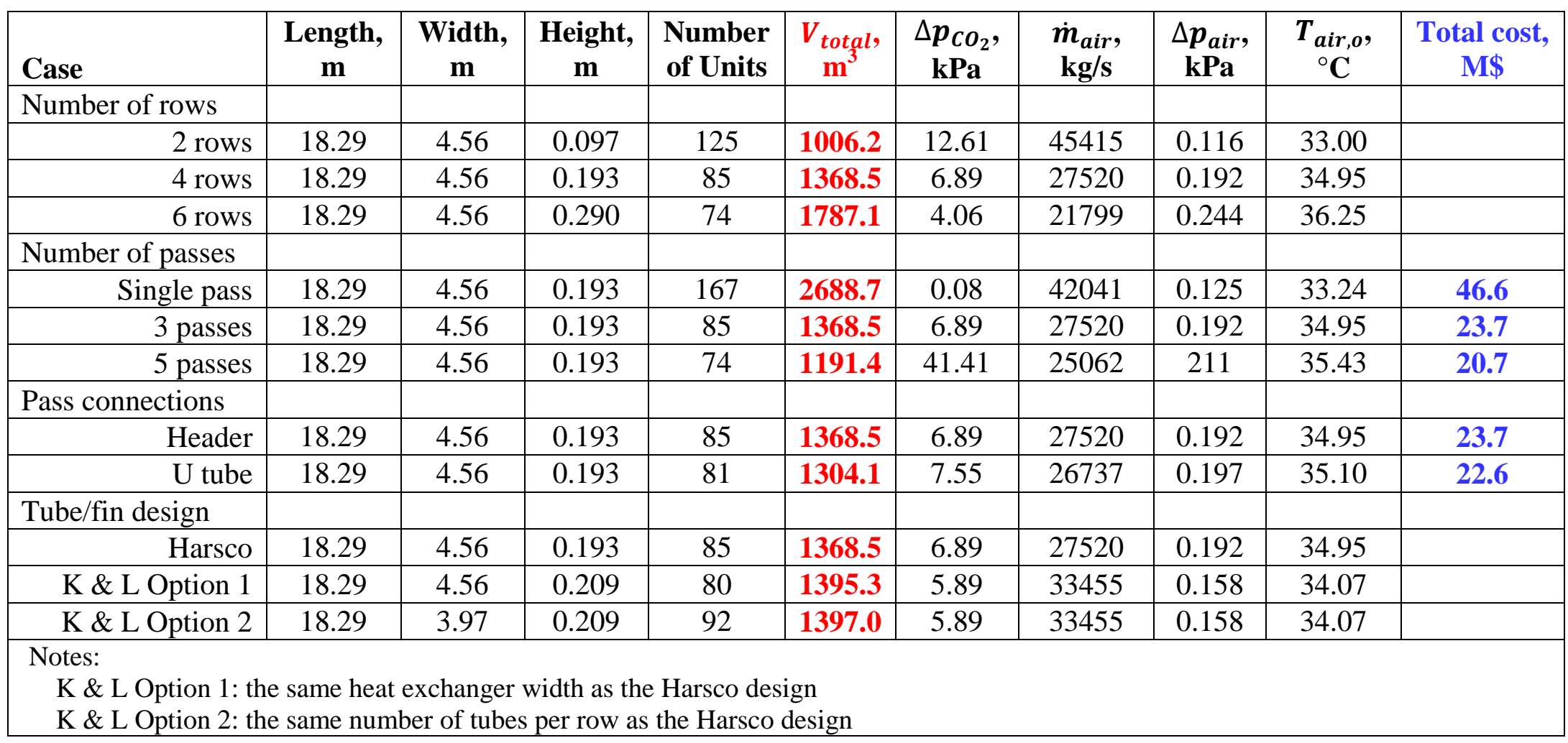


In Table 5, the total volume and total cost are defined respectively as:

$V_{\text {total }}=L \times W \times H \times N$

Total Cost $=$ Cost $/$ Unit $\times N$

where,

$V_{\text {total }}=$ total volume of the heat exchangers, $\mathrm{m}^{3}$,

$L=$ heat exchanger length, $\mathrm{m}$,

$W=$ heat exchanger width, $\mathrm{m}$,

$H=$ tube bank height, $\mathrm{m}$,

$N=$ number of units,

Cost $/$ Unit $=$ cost per unit based on Harsco quote.

The first set of results in Table 5 examines the design options of various number of tube rows, while keeping the other design parameters the same as the Harsco design (i.e., three passes, header design, and Harsco tube/fin design). As can be, as the number of rows in each unit increases, the total number of units decreases, which is understandable for a fixed heat transfer rate. However, the total number of tubes increases with the increase of number of rows, leading to the increase of the total heat exchanger volume. In addition, the increase of the total number of tubes has also caused a decrease of the $\mathrm{SCO}_{2}$ flow in each tube, and correspondingly a decrease of the $\mathrm{sCO}_{2}$-side pressure drop. At this point, the optimal design cannot be selected because no detailed cost information is available to compare heat exchangers of different designs, such as with different number of tubes.

The second set of results in Table 5 examines the design options of various numbers of passes. It can be seen that, less units are needed with more passes employed in one unit. Due to the fixed width for each unit, the number of tubes in each pass is reduced with more passes. The decrease of the number of tubes in each pass, along with the reduction of the total number of units as the number of passes increases, results in a significant increase in the $\mathrm{sCO}_{2}$ flow in each tube, and correspondingly a significant increase in the $\mathrm{sCO}_{2}$-side pressure drop. As can be seen, as the pass number changes from 3 to 5 , the total cost is not reduced much; however, the $\mathrm{sCO}_{2}$-side pressure drop increases significantly. Therefore, the design with three passes (the one selected by the vendor) is confirmed as optimal.

The third set of results in Table 5 investigates the different design options for pass connections, header vs $U$ tube. With the header design, the fluids exiting the parallel tubes in one pass will first mix in the header before entering the next pass. However, with the $U$ tube design, the fluids are always constrained in their individual tubes and will not mix at the pass connections. As can be seen, there is not much difference between the two design options. With the header design, four more units are required to achieve the same total heat transfer rate, leading to a slight increase in both the total volume and cost. However, the header design also exhibits lower pressure drop for the $\mathrm{sCO}_{2}$ side (notice that pressure drop in both headers and $\mathrm{U}$ tube section is ignored in both calculations). Because there is not much different in performance, the header design is considered a better option since it does not require three-fold longer tubes. 
The last set of results in Table 5 refers to the design options of different tube/fin geometry, as described in Table 1 . The $\mathrm{K} \&$ L Option 1 employs a smaller pitch than the Harsco design, thus more tubes can be fit into the same unit volume. Because of this, fewer units are required for the $\mathrm{K} \& \mathrm{~L}$ design than for the Harsco design. However, the net effect of the tube pitch and total number of units still results in more tubes used for the K \& L Option 1, and correspondingly a larger total volume. Nevertheless, the two designs are similar in terms of the total volume and other performance characteristics. A slightly modified version of $\mathrm{K} \& \mathrm{~L}$ Option 1, i.e., $\mathrm{K} \& \mathrm{~L}$ Option 2, has also been examined. In K \& L Option 2, the same number of tubes per row as in the Harsco design (81 tubes per row) is used. Due to the smaller pitch mentioned earlier, the K \& L Option 2 is narrower than the $\mathrm{K} \& \mathrm{~L}$ Option 1, leading to more units required. Except for these two differences, the two $\mathrm{K} \& \mathrm{~L}$ designs are almost exactly the same in all the other aspects, as shown in Table 5. The main reason for that is because the multiple units are connected in parallel, which is exactly the same way as how the individual tubes are connected in a single unit.

Therefore, taking part of the tubes from each unit and forming them into more units that are still connected in parallel will not affect the performance, which is exactly how K \& L Option 2 was modified based on K \& L Option 1. 


\section{Cross-Flow PCHE Option}

Since the cross-flow finned tube heat exchanger proved to be a practical and cost effective option for the $\mathrm{sCO}_{2}$ air cooler application, the analysis was extended to investigate the feasibility of a cross-flow compact Printed Circuit Heat Exchanger (PCHE). It needs to be pointed out, though, that unlike the design described in the previous section, the heat exchanger design and corresponding analysis described below is just a concept investigated by the authors. It has not been proposed or quoted by a heat exchanger manufacturer. For these reasons, the proposed design may not be optimal (or practical) for this particular application. For the same reasons, the heat exchanger cost estimate presented below is carried out by the authors based on scaling of previous and different design of similar heat exchangers. Significantly, the costs are dated and would likely be different (likely less) today. Therefore, the analysis presented below is only a preliminary investigation of this type of a heat exchanger for this application.

\subsection{General HX Description}

The cross-flow PCHE air cooler concept is schematically illustrated in Figure 14. The $\mathrm{CO}_{2}$ side consists of conventional semi-circular zigzagged etched channels in a metal plate. The channel and plate dimensions (with the exception of plate width) are retained from the water cooler PCHE design analyzed in previous ANL work. In a simplest configuration, there would be a simple pass of $\mathrm{CO}_{2}$ channels across the plate. However, as Figure 14 demonstrates, this technology allows for a multi-pass channel configuration on the plate, without a need of external headers. Figure 14 shows just one example of three-pass arrangement on the $\mathrm{CO}_{2}$ side; other options are possible.

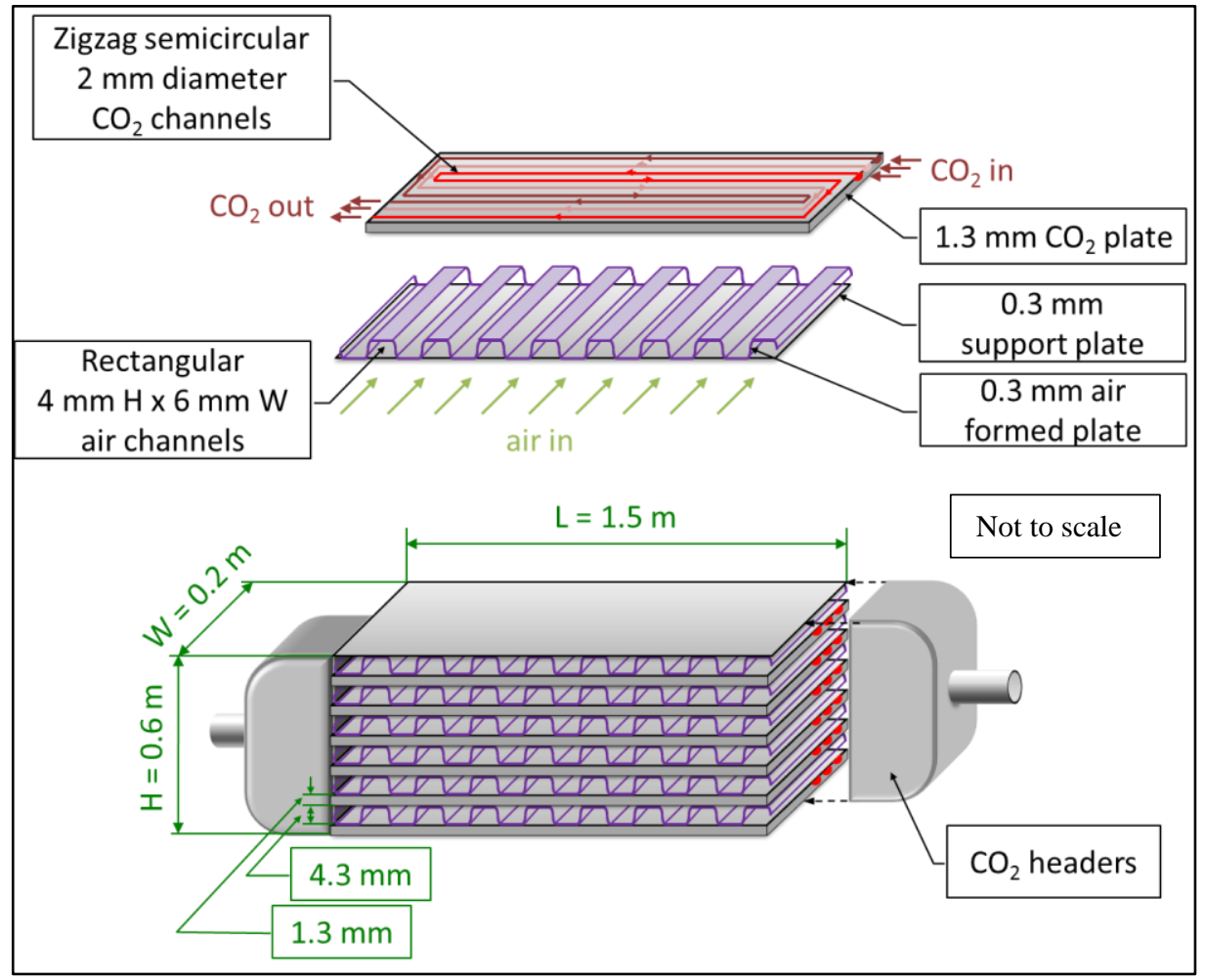

Figure 14. Concept of Cross-Flow PCHE. 
On the air side, Heatric's formed plate concept with large channel sizes is adopted to increase the flow area and, hopefully, reduce the pressure drop on the air side. The channels are formed by a deformed plate. The air channel dimensions assumed in this analysis are $4 \mathrm{~mm}$ tall by $6 \mathrm{~mm}$ wide with the plate thickness of $0.3 \mathrm{~mm}$. The air channels could be straight or have small zigzag angle to promote turbulence. The air flow is perpendicular to the general direction of the $\mathrm{CO}_{2}$ flow, i.e. the air flow is in the direction of the heat exchanger width. In order to reduce the pressure drop on the air side to minimize the air circulation power, a heat exchanger width of $0.2 \mathrm{~m}$ is assumed, which is about the same as the tube bank height in the finned tube concept described in the previous section.

As shown in Figure 14, there would be $\mathrm{CO}_{2}$ inlet and outlet headers on each side of the heat exchanger. The air side does not need headers and could be open to the environment as long as it is connected by a duct to the air fans, much like the finned tube design in previous section. Also, since the air flow and pressure drop for these heat exchangers are similar to those for finned tube design described in the previous section, the same, or very similar, air fans could be used.

In this heat exchanger configuration, there would still be a cross-flow pattern between the $\mathrm{CO}_{2}$ and air sides. So, the concept described in Section 2 would still be applicable to this geometry. The difference from the finned tube arrangement in previous section is that the $\mathrm{CO}_{2}$ channels in one plate will include channels from all passes. Therefore, logic, specific to this design, was included in the code to calculate inlet conditions for each additional pass based on what channel in the previous pass this channel is connected to. For example, in Figure 14, the inlet conditions for the fourth from the far side channel (red left-to-right channel) are equal to the outlet conditions of the third channel. To simplify the calculations, an assumption is made to ignore any heat transfer and conditions change in the sections connecting the channels, such that pure crossflow configuration is analyzed.

Because of this flow arrangement, the number of regions in the direction of the air flow is selected to be equal to the total number of $\mathrm{CO}_{2}$ channels in each plate, such that the $\mathrm{CO}_{2}$ conditions in each individual channel will be resolved (which for $0.2 \mathrm{~mm}$ wide plates and a 1.3 mm channel diameter would mean around 100 points in that direction). In the direction of HX length, the number of points selection is arbitrary and, similar to other options, should be based on a trade-off between accuracy and computational speed. Under an assumption of a uniform flow distribution, all the plate pairs are identical, so the calculations are performed to calculate heat transfer between one $\mathrm{CO}_{2}$ plate and one air plate; the results for all other plates would be identical.

Similar to the finned tube concept, the $\mathrm{CO}_{2}$ conditions are the outlet of last pass's channels are averaged to calculate average cooler-outlet conditions. Similarly, the conditions on the outlet of all air channels are averaged to calculate air outlet conditions.

\subsection{Geometric Parameters}

Since the channel configurations on both the $\mathrm{CO}_{2}$ and air sides are exactly the same as in the previously modeled PCHE concepts, no changes were needed in the calculation of parameters, such as hydraulic diameter, flow areas, surface areas, etc. The only change needed for the cross- 
flow arrangement is that the heat transfer equations in Section 2 are now solved on a per-region, rather than a per-unit length basis. So, instead of calculating a heat transfer perimeter, a heat transfer area for each region now needs to be calculated for both sides. However, to retain similarity with the counter-flow subroutines, a concept of heat transfer perimeter is retained, which is now defined as the heat transfer surface area per unit length, where the unit length is measured along the heat exchanger length, which is the same direction as the $\mathrm{CO}_{2}$ flow.

Since nodalization is selected to represent each $\mathrm{CO}_{2}$ channel, the $\mathrm{CO}_{2}$ flow rate per node is equal to the $\mathrm{CO}_{2}$ flow rate per physical channel. The air flow rate per region is the total air flow rate per plate divided by number of regions across the heat exchanger length.

\subsection{Heat Transfer and Pressure Drop Correlations}

Similar to the geometric parameters, no changes were needed for the heat transfer and pressure drop correlations. The correlations developed previously by ANL for the PCHE channels [19] are directly applied for both the $\mathrm{CO}_{2}$ and air sides.

\subsection{HX Analysis}

Figure 15 shows the calculated temperature profiles for a three-pass cross-flow $\mathrm{PCHE}$ on the $\mathrm{CO}_{2}$ and air sides. In this case, the plate dimensions were $1.5 \mathrm{~m}$ long (in the $\mathrm{CO}_{2}$ flow direction) by 0.2 $\mathrm{m}$ wide (in the air flow direction). There were twenty $\mathrm{CO}_{2}$ channels in each pass for a total of 60 channels in a plate. Figure 15 demonstrates the clearly two-dimensional temperature profiles in this heat exchanger and also the effect of the $\mathrm{CO}_{2}$ properties variation as it approaches the critical point. Most of the $\mathrm{CO}_{2}$ temperature change (and also the air temperature change) occurs in the first pass. In the third pass, the $\mathrm{CO}_{2}$ temperature change is less than $1{ }^{\circ} \mathrm{C}$ for all channels, which is the result of both increased $\mathrm{CO}_{2}$ heat capacity and also the fact that this pass faces the coldest part of the air flow. Because the $\mathrm{CO}_{2}$ temperature is very low for the entire third pass, the heat transfer rate and air temperature rise are small in this region. The air temperature rise is limited to $1{ }^{\circ} \mathrm{C}$ or less in this pass. These results confirm that in practice a close temperature approach can be achieved for all channels in the cross-flow configuration. In these particular results, the $\mathrm{CO}_{2}$ inlet temperature at the outlet of all channels varied from $32.62{ }^{\circ} \mathrm{C}$ to $32.70{ }^{\circ} \mathrm{C}$. On the air side, though, the temperature distribution is highly non-uniform at the HX exit: Figure 15 shows that this temperature ranges from $33.5{ }^{\circ} \mathrm{C}$ to $45^{\circ} \mathrm{C}$. 


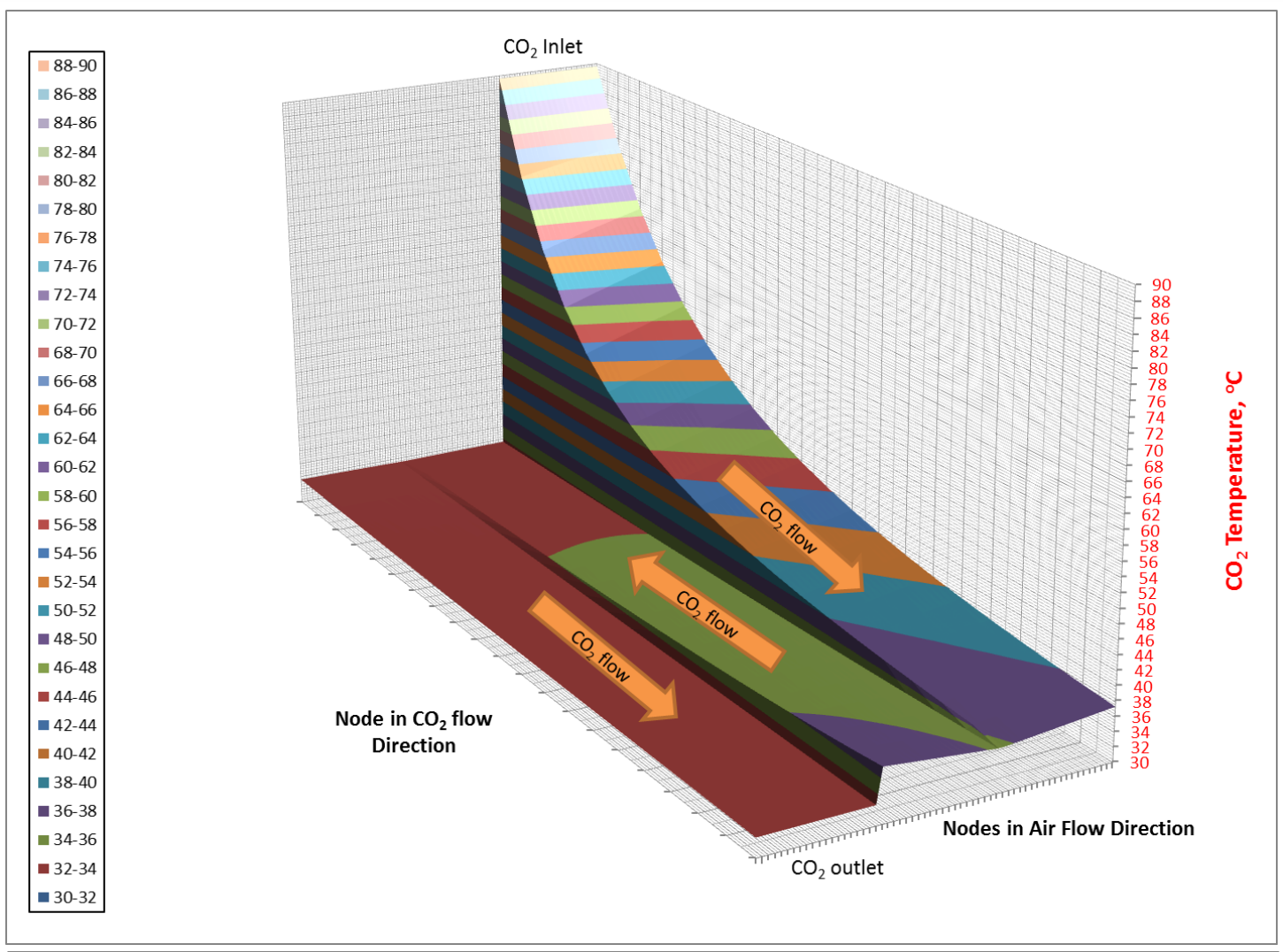

\begin{tabular}{|c|}
\hline$=45-46$ \\
\hline $44-45$ \\
\hline$=43-44$ \\
\hline$=42-43$ \\
\hline$=41-42$ \\
\hline - 40-41 \\
\hline = $39-40$ \\
\hline = \\
\hline$=37-38$ \\
\hline = 36-37 \\
\hline$=35-36$ \\
\hline$=34-35$ \\
\hline = 33-34 \\
\hline | $32-33$ \\
\hline = 31-32 \\
\hline$=30-31$ \\
\hline
\end{tabular}
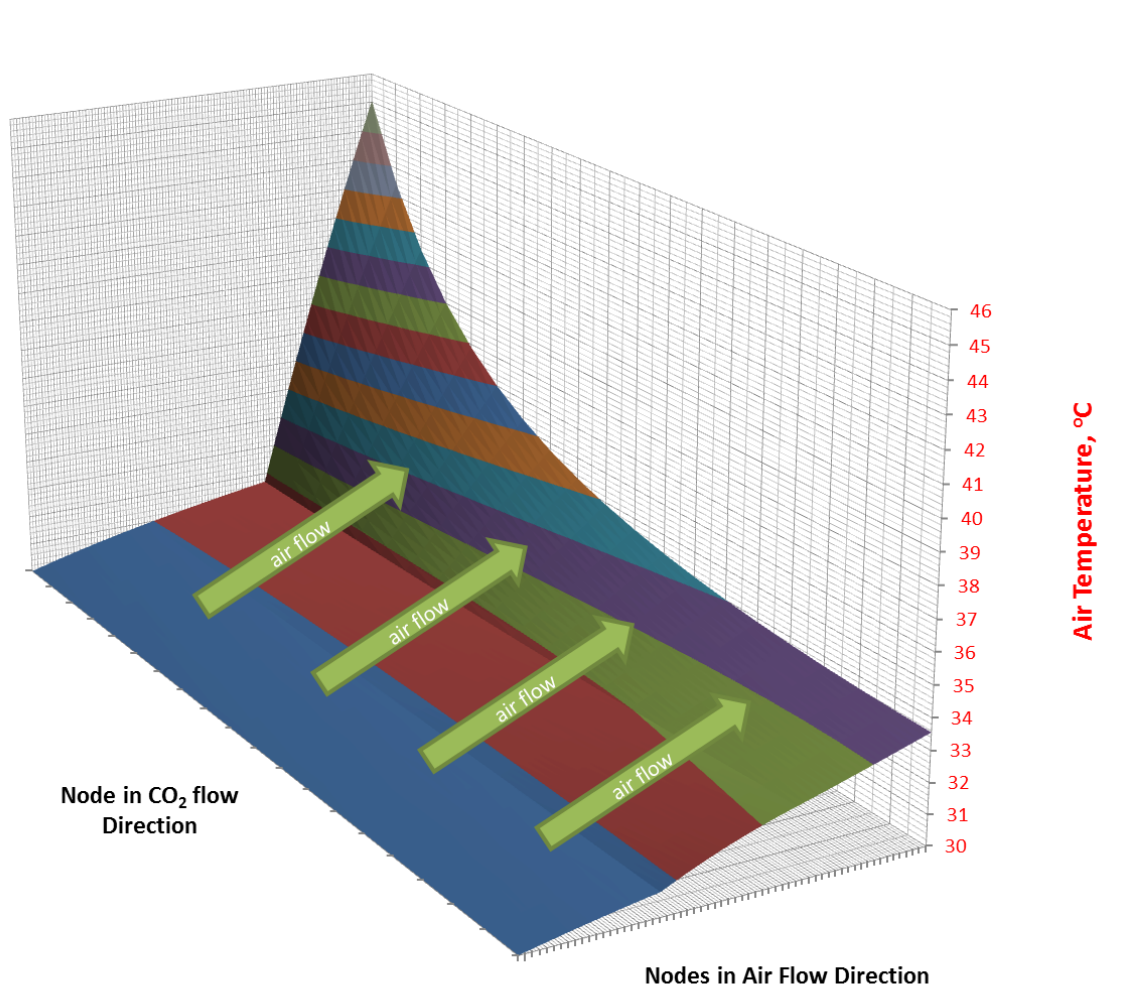

Figure 15. Temperature Profiles in a Three-Pass Cross-Flow PCHE: $\mathrm{CO}_{2}$ (Top) and Air (Bottom). 
The rest of results of the cross-flow PCHE analysis for a $\mathrm{sCO}_{2}$ cooler application are presented in Table 6. The first line in this table repeats the results for a finned tube heat exchanger from the previous section. The second line shows the results for a counter-flow PCHE cooler, which were obtained from scaling the results in the previous work [4] to the AFR-100 137 MW cooler capacity. These two lines are shown in Table 6 for comparison.

The results shown in Table 6 are the results of HX sizing calculations. The overall HX size, represented by the number of PCHE units, and the air flow rate are selected to:

- Meet the $\mathrm{CO}_{2}$ inlet and outlet conditions for the reference $\mathrm{sCO}_{2}$ cycle design with a 31.25 ${ }^{\circ} \mathrm{C}$ and 7.4 $\mathrm{MPa}$ compressor inlet temperature and pressure, and

- Maintain a 5 MWe (5\% gross AFR-100 generator output) air circulation power under assumption of $90 \%$ air fan efficiency.

The first set of data shows the effect of air channel angle with a single-pass design on the $\mathrm{CO}_{2}$ side. The most compact design (in terms of total HX volume) is achieved with a small angle of $30^{\circ}$.

The second set of results in Table 6 demonstrates the effect of number of passes on $\mathrm{CO}_{2}$ side. As the number of passes increases, the total $\mathrm{HX}$ volume decreases. However, due to longer path on the $\mathrm{CO}_{2}$ side, the $\mathrm{CO}_{2}$ side pressure drop increases significantly with the number of passes. It appears from Table 6 that the optimal design is with three passes, since beyond that the HX volume does not decrease much, but the $\mathrm{CO}_{2}$ side pressure drop increases significantly. 
Table 6. Results of Cross-Flow PCHE Calculations

\begin{tabular}{|c|c|c|c|c|c|c|c|c|c|c|}
\hline Case & $\begin{array}{c}\text { Length, } \\
\text { m }\end{array}$ & $\begin{array}{c}\text { Width, } \\
\text { m }\end{array}$ & $\begin{array}{c}\text { Height, } \\
\text { m }\end{array}$ & $\begin{array}{l}\text { Number } \\
\text { of Units }\end{array}$ & $\begin{array}{c}V_{\text {total }}, \\
\mathbf{m}^{3}\end{array}$ & $\begin{array}{c}\Delta \boldsymbol{p}_{\mathrm{CO}_{2}} \\
\mathbf{k P a}\end{array}$ & $\underset{\mathrm{kg} / \mathrm{s}}{\dot{m}_{\text {air }}}$ & $\begin{array}{c}\Delta \boldsymbol{p}_{\text {air }}, \\
\mathbf{k P a}\end{array}$ & $\begin{array}{c}\boldsymbol{T}_{\text {air }, o}, \\
{ }^{\circ} \mathbf{C}\end{array}$ & $\begin{array}{c}\text { Total } \\
\text { cost, M\$ }\end{array}$ \\
\hline Finned tube Harsco design & 18.29 & 4.56 & 0.193 & 85 & 1368.5 & 6.89 & 27520 & 0.192 & 34.95 & 23.7 \\
\hline Counter-flow & 0.638 & 0.6 & 0.6 & 11654 & 2676.7 & & 9638 & & & 569.3 \\
\hline \multicolumn{11}{|l|}{$\begin{array}{l}\text { Single pass, Air channel } \\
\text { zigzag angle }\end{array}$} \\
\hline $0^{\circ}$ (straight) & 1.5 & 0.2 & 0.6 & 4900 & 882 & 0.267 & 37968 & 0.139 & 35.24 & 234.6 \\
\hline $30^{\circ}$ & 1.5 & 0.2 & 0.6 & 4663 & 839.3 & 0.291 & 26000 & 0.204 & 35.24 & 223.3 \\
\hline $60^{\circ}$ & 1.5 & 0.2 & 0.6 & 5445 & 980.1 & 0.225 & 20650 & 0.255 & 36.6 & 260.7 \\
\hline $90^{\circ}$ & 1.5 & 0.2 & 0.6 & 6732 & 1211.8 & 0.159 & 16100 & 0.328 & 38.47 & 322.4 \\
\hline \multicolumn{11}{|l|}{ Number of passes } \\
\hline Single pass & 1.5 & 0.2 & 0.6 & 4663 & 839.3 & 0.291 & 26000 & 0.204 & 35.24 & 223.3 \\
\hline 3 passes & 1.5 & 0.2 & 0.6 & 3931 & 707.6 & 6.704 & 22100 & 0.24 & 36.17 & 188.2 \\
\hline 5 passes & 1.5 & 0.2 & 0.6 & 3610 & 649.8 & 29.949 & 21300 & 0.248 & 36.41 & 172.9 \\
\hline \multicolumn{11}{|l|}{ HX width } \\
\hline $0.1 \mathrm{~m}$ & 1.5 & 0.1 & 0.6 & 7450 & 670.5 & 10.946 & 47817 & 0.111 & 32.85 & 343.8 \\
\hline $0.2 \mathrm{~m}$ & 1.5 & 0.2 & 0.6 & 3931 & 707.58 & 6.704 & 22100 & 0.24 & 36.17 & 188.2 \\
\hline $0.3 \mathrm{~m}$ & 1.5 & 0.3 & 0.6 & 3280 & 885.6 & 3.965 & 15829 & 0.336 & 38.61 & 162.8 \\
\hline $0.4 \mathrm{~m}$ & 1.5 & 0.4 & 0.6 & 3080 & 1108.8 & 2.502 & 13039 & 0.405 & 40.46 & 158.2 \\
\hline $0.5 \mathrm{~m}$ & 1.5 & 0.5 & 0.6 & 3085 & 1388.3 & 1.607 & 11518 & 0.457 & 41.84 & 163.9 \\
\hline $0.6 \mathrm{~m}$ & 1.5 & 0.6 & 0.6 & 3250 & 1755 & 0.978 & 10586 & 0.5 & 42.88 & 178.3 \\
\hline
\end{tabular}


The last set of results in Table 6 refers to the parametric study on the PCHE block width (dimension in the air flow direction). The results are also plotted in Figure 16. The most compact design in terms of total $\mathrm{HX}$ volume is obtained with $0.1 \mathrm{~m}$ wide block, but this design requires the largest number of those small units. As the PCHE cost estimate is based in part on the fabrication cost which is assumed to be proportional to the number of blocks [11,1], a $0.1 \mathrm{~m}$ wide HX turns out to be the most expensive option. The least expensive design is achieved with $0.4 \mathrm{~m}$ wide units, but there is a significant uncertainty in the PCHE cost estimate since it was developed based on scaling of earlier and different designs, rather than an actual manufacturer's current cost quote.

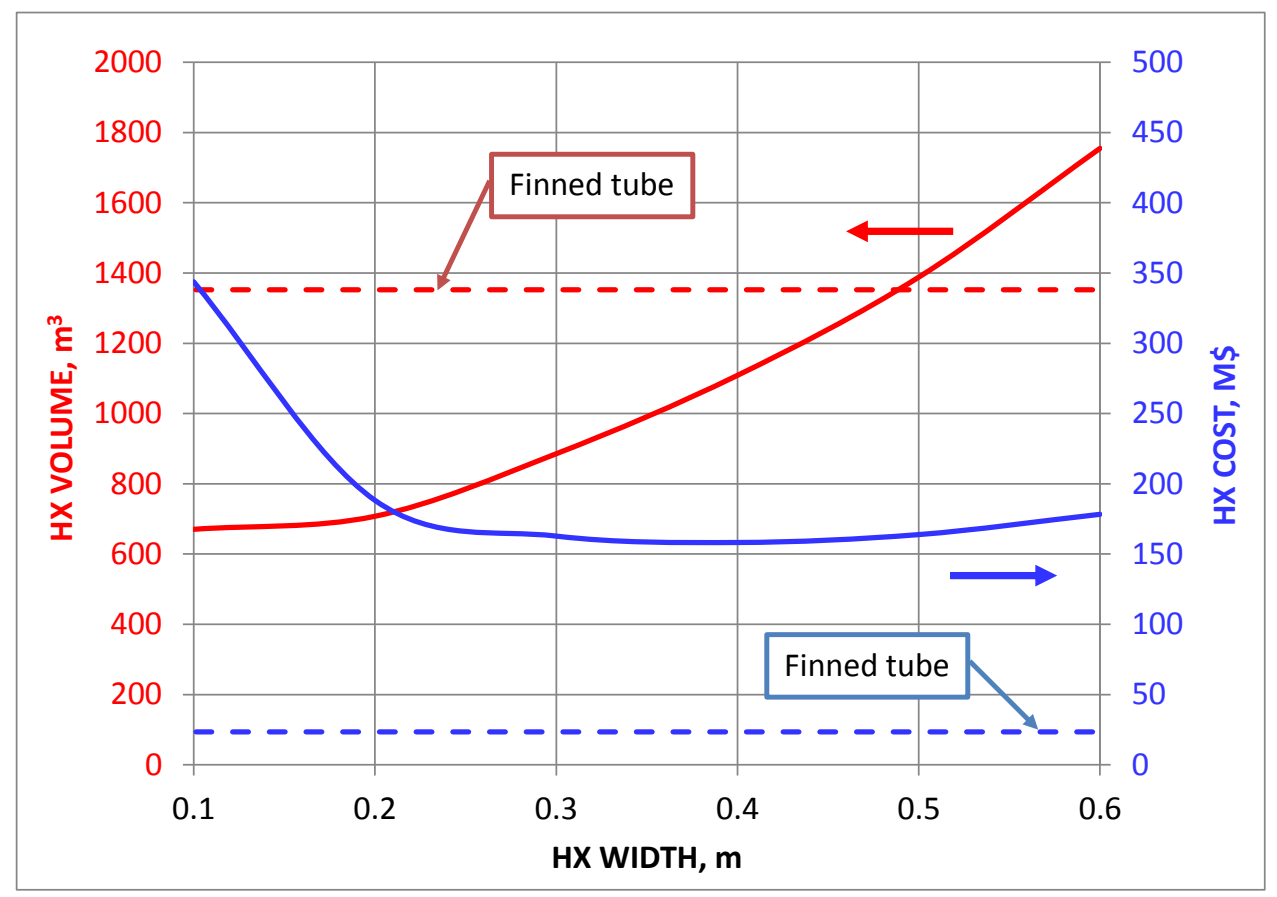

Figure 16. Parametric Study of Cross-Flow PCHE Cooler Width.

As it can be seen from Table 6, there are significant benefits of the cross-flow PCHE arrangement, compared to previous results for the counter-flow design, in terms of both total $H X$ volume and estimated cost. For example, the design with $0.2 \mathrm{~m}$ wide units with three $\mathrm{CO}_{2}$ passes shows about factor of four reduction in the HX total volume and about factor of three reduction in HX cost. These results confirm that one of the assumptions in the previous work - the counter flow configuration for the air cooler - was not the optional one and the cross-flow configuration is much better in this case. This is again due to the fact that for this application and the low density of cooling air, the pressure drop on the air side is important to maintaining a reasonable pumping power. For the same channel geometry, there are two ways to reduce the pressure drop decrease the flow path length or increase flow area. Both of these targets are better achieved with the cross-flow HX configuration.

At the same time, the results in Table 6 and Figure 16 show that although the cross-flow PCHE design offers about a factor of two reduction in total HX volume, compared to the finned tube design, it is a much more expensive option. Even the least costly PCHE option in Table 6 is about six times more expensive than the Harsco quote for the same $\mathrm{CO}_{2}$ conditions, heat duty, and air 
circulation power requirement. Even if the PCHE cost estimate and/or recent improvement in PCHE technology can achieve a 50\% cost reduction, these HXs will still be factor of three more expensive than the finned tube design for this application. The main reason for these results is that the fundamental feature of the PCHE heat exchangers which give them advantages for other applications - small channel size - is not well suited for the air cooling application where a small pressure drop on the air side is critical to maintaining reasonable requirements for the air circulation power.

Because of these results, the commercially available modular finned tube cross-flow heat exchanger is currently believed to be the best (i.e., the least expensive) option for the $\mathrm{CO}_{2}$ air cooler application and is selected for the system-level analysis presented in the next section of this report. 


\section{$5 \mathrm{sCO}_{2}$ Cycle Integration and Analysis}

\subsection{ANL Plant Dynamics Code Modifications}

The modeling for the cross-flow heat exchanger calculation subroutine described in the previous sections was directly integrated into the PDC code and is called if the input file specifies the cross-flow configuration for the cooler (this input selection is done by the HX type: 5 means cross-flow PCHE, 6 - cross-flow finned tube HX). Along with the HX subroutine, the heat transfer, pressure drop, and fin efficiency correlations were directly copied into the PDC. Also, the input files were modified to allow the additional input needed for the cross flow heat exchangers, such as number of passes, number of tube rows, etc.

Also, options to iterate on the air flow rate or the number of cooler units, rather than on the cooler length, to obtain required $\mathrm{CO}_{2}$ conditions were added to the PDC similar to the results discussed in Sections 2 and 3 above.

As discussed in Section 2, the cross-flow calculations are much slower than those for counterflow, especially for the cooler application close to the $\mathrm{CO}_{2}$ critical point. To partially compensate for this slowdown, the cooler design calculations are moved outside of the cycle iterations. That code modification was possible due to the fact that the $\mathrm{CO}_{2}$ inlet and outlet temperatures as well as the outlet pressure are known in the cycle analysis either from the compressor-inlet conditions or from the low temperature recuperator outlet conditions. The only result from the cooler design calculations that affects the cycle calculations then is the pressure drop on the $\mathrm{CO}_{2}$ side (air side conditions affect $\mathrm{HX}$ size and pumping power, but not $\mathrm{CO}_{2}$ conditions in the cycle). Since the $\mathrm{CO}_{2}$ side pressure drop is not expected to change much during the iterations, the cycle and cooler calculations could be separated so that the cooler design subroutine is called less frequently. The cooler design and conditions are now updated together with $\mathrm{CO}_{2}$ conditions in the reactor heat exchanger outside of the cycle internal iterations.

Even with this modification, there was a noticeable decrease in computational speed of the code with the cross-flow cooler option. Still, the entire steady-state calculations are done in less than a minute of real time. The effect on the dynamic calculations will be investigated later. So far, no modifications to the dynamic part of the code to allow two-dimensional cooler calculations have been implemented into the PDC.

\subsection{Results of the Steady-State Analysis}

\subsubsection{Air Cooler Design at Reference AFR-100 Conditions}

Figure 17 shows the results of $\mathrm{sCO}_{2}$ cycle calculations with the integrated cross-flow cooler design for the same $\mathrm{sCO}_{2}$ cycle (compressor-inlet) conditions as the AFR-100 reference design in Figure 3. For these results, 84 Harsco units were simulated and the code was requested to iterate on the air flow rate to match the $\mathrm{CO}_{2}$ conditions. The main results - air flow rate and fan powerare very close to the stand-alone calculations reported in Section 3. The small differences are due 
to rounding off the $\mathrm{CO}_{2}$ conditions (pressures and temperatures) for the stand-alone code input, while the integrated calculations in the PDC use the exact values from the code. Compared to Figure 3 , the $\mathrm{SCO}_{2}$ cycle conditions are almost exactly the same due to the fact that the $\mathrm{CO}_{2}$ pressure drop in both the water PCHE counter-flow cooler and the air finned tube cross-flow cooler are about $7 \mathrm{kPa}$.

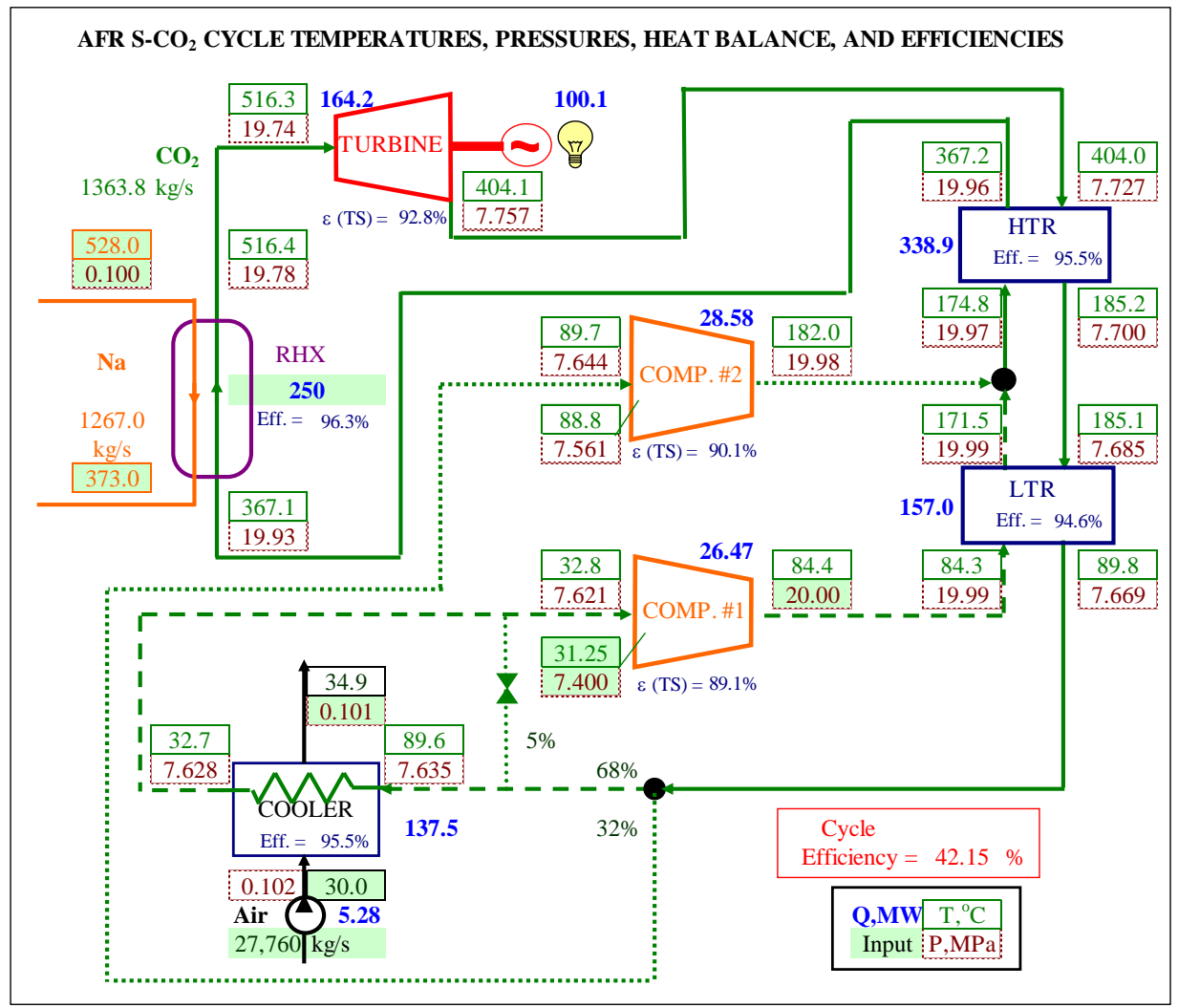

Figure 17. $\mathrm{sCO}_{2}$ Cycle Conditions with Cross-Flow Finned Tube Cooler.

\subsubsection{Air Cooler Design Optimization at Reference AFR-100 Conditions}

Once satisfactory core results were obtained at the reference conditions, the cooler design can be optimized. For the Harsco quote, it was specified that the air fan power is to be no more than 5 MWe (5\% of the total plant output). This value, however, was just a first guess for the cooler design. The fan power can be reduced by decreasing the air pressure drop, if more cooler units are used. Thus, there is a tradeoff between the cooler cost and lost plant output needed for air circulation.

To find the optimal cooler size, the cost-optimization technique previously developed at ANL for optimization of other heat exchangers [11] was applied to the cooler design. The goal of this optimization is to minimize the plant capital cost per unit electrical output $(\$ / \mathrm{kWe})$. Adding more cooler units increases the plant capital cost, but reduces the air fan power requirement so that the net plant output is increased. 
The results of the cooler cost-based optimization are shown in Figure 18. The same assumptions about the reactor capital cost as in the previous work [11] are used in this analysis. The cooler cost is assumed to be proportional to the number of units and the cost per unit is calculated based on the Harsco quote. The results in Figure 18 are normalized to the $\$ / \mathrm{kWe}$ value obtained with direct water cooling. Figure 18 also shows the results for air cooling towers which simply add the cost of these towers and required air circulation power obtained from a cooling tower manufacturer's quote. No optimization for the cooling tower design was carried out for the comparison in Figure 18.

The results in Figure 18 show that as number of cooler units increases, the cycle efficiency, which is only affected by the $\mathrm{CO}_{2}$ side pressure drop in the cooler does not change much. However, the plant efficiency increases significantly due to reduction in air flow rate and air pumping power requirements for the larger $\mathrm{HX}$.

The results in Figure 18 show that the air cooling option adds about $7 \%$ to the plant capital cost per unit electrical output, compared to direct water cooling and about $5 \%$ compared to the cooling tower option. These results again confirm the benefits of this type of the heat exchanger for air cooling applications - in previous work [4] at least a $40 \%$ increase was calculated. Even these results show that implementing dry air cooling is not going to affect the overall cost of a power plant with a $\mathrm{sCO}_{2}$ cycle significantly.

The other important result from Figure 18 is that the optimal number of coolers for these conditions, which minimizes the plant $\$ / \mathrm{kWe}$ cost is equal to 114 units. Even though it makes the cooler larger and more expensive, the resulting air fan power of $2.23 \mathrm{MWe}$ is much smaller than 5.3 MWe with 84 units in Figure 17 such that the net plant output increases from 100.1 MWe to 103.2 MWe, effectively reducing the reactor and the rest-of-the-cycle $\$ / \mathrm{kWe}$ cost. The $\mathrm{sCO}_{2}$ cycle conditions with the optimal cooler design with 114 units are shown in Figure 19. 


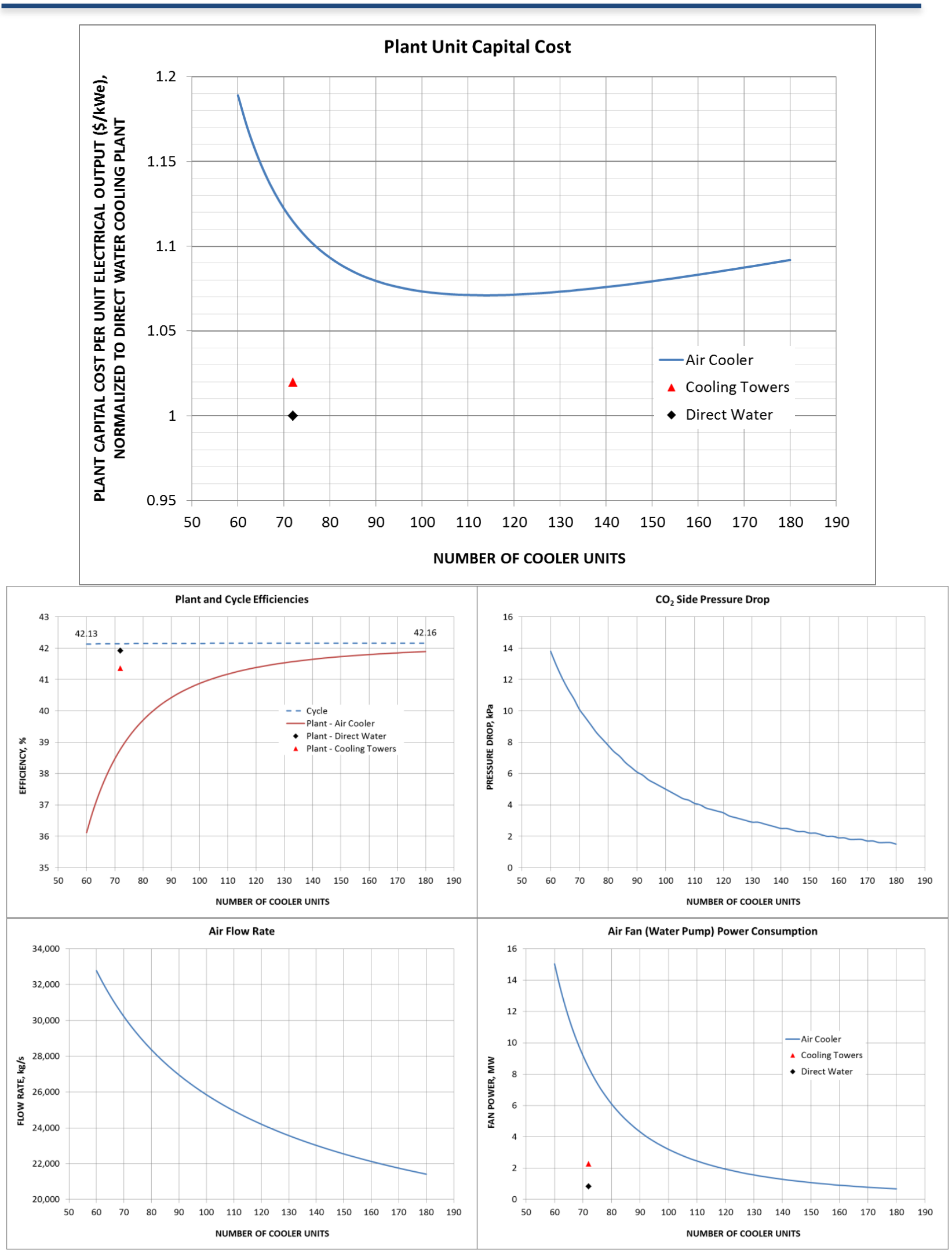

Figure 18. Cost-Based Cooler Optimization at Reference AFR-100 Conditions. 


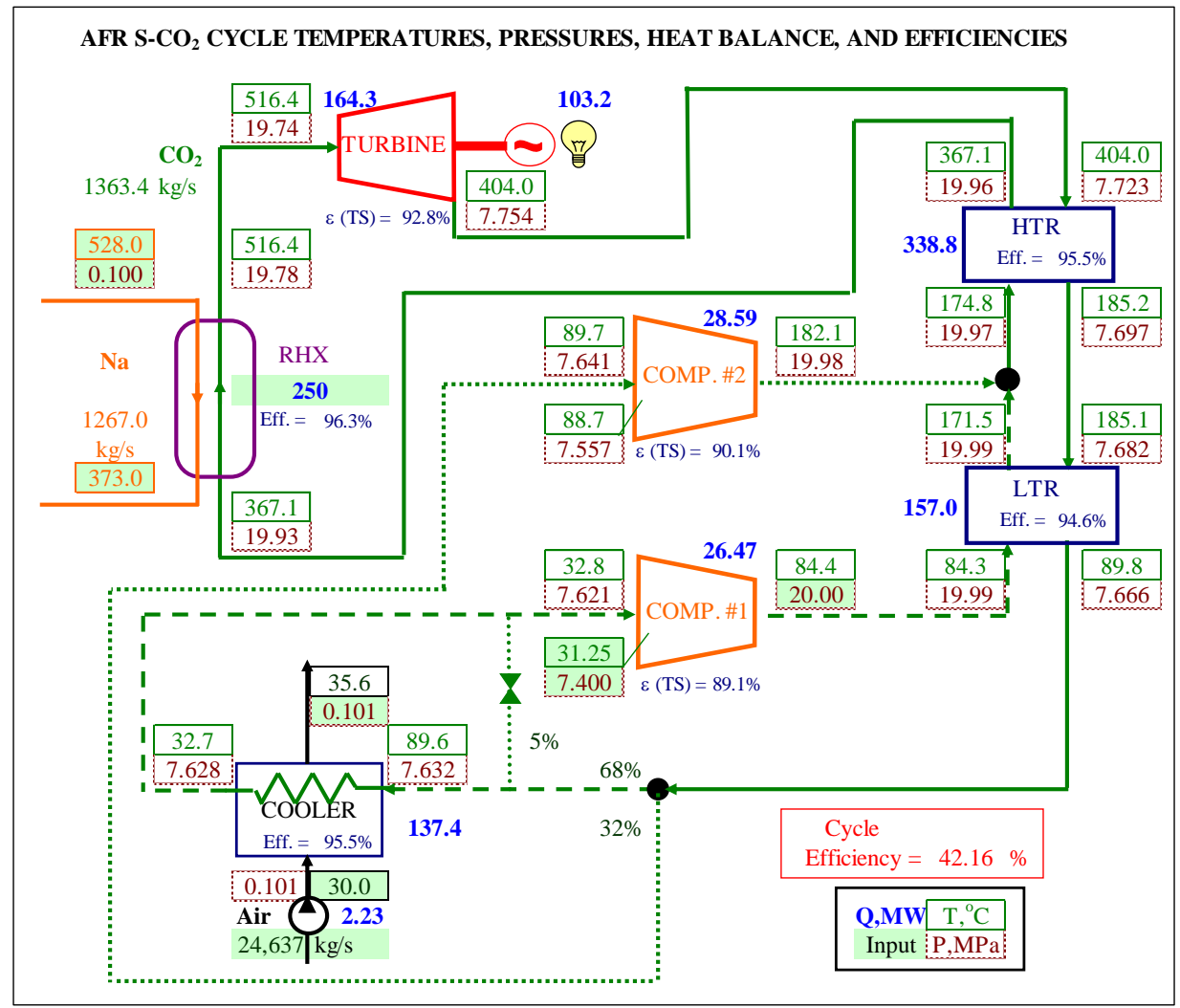

Figure 19. Cycle Conditions with Optimal Cooler Design for Reference AFR-100 Conditions.

\subsubsection{Air Cooler Design Optimization at Optimal AFR-100 Conditions for Dry Air Cooling}

For the calculations immediately above, the Reference AFR-100 conditions were assumed. However, the most recent work on the $\mathrm{sCO}_{2}$ cycle air cooling analysis [1] suggests that the $\mathrm{sCO}_{2}$ cycle conditions for the dry air cooling application may be different from those in Figure 17. In that work, it was found beneficial to increase the minimum cycle (compressor-inlet) temperature from $31.25{ }^{\circ} \mathrm{C}$ to $35^{\circ} \mathrm{C}$ while also increasing compressor inlet pressure along the pseudo-critical line to $8.2 \mathrm{MPa}$ and increasing compressor-outlet pressure to $25 \mathrm{MPa}$.

The increased pressure requires changes in the design of the heat exchangers to increase wall thicknesses (except for the cooler, where the effect of the $\mathrm{CO}_{2}$ pressure on tube thickness is ignored) and to the $\mathrm{CO}_{2}$ pipes. Also, the number of $\mathrm{HX}$ units for the reactor heat exchanger as well as high- and low-temperature recuperators was re-optimized based on the cost for these new conditions. Table 7 lists modifications to the cycle conditions and component designs introduced in Reference [1]. The last line in Table 7, the change in the turbine number of stages, was not adopted from Reference [1], where a simplified analysis with fixed turbine efficiency was carried out, but is rather introduced in the present work to maintain this turbine efficiency level. In addition to the values in Table 7, the cost increase in $\mathrm{CO}_{2}$ cycle piping was estimated in Reference [1] for the higher-pressure design. 
Table 7. Cycle and Component Design Changes between Optimal Water and Air Cooling Designs

\begin{tabular}{|l|l|c|c|}
\hline \multirow{4}{*}{ Component } & Design Parameter & $\begin{array}{c}\text { Water } \\
\text { Cooling } \\
\text { Value }\end{array}$ & $\begin{array}{c}\text { Air } \\
\text { Cooling } \\
\text { Value }\end{array}$ \\
\hline \multirow{4}{*}{ Cycle } & Minimum temperature & $31.25^{\circ} \mathrm{C}$ & $35^{\circ} \mathrm{C}$ \\
\cline { 2 - 4 } & Minimum pressure & $7.45 \mathrm{MPa}$ & $8.2 \mathrm{MPa}$ \\
\cline { 2 - 4 } & Maximum pressure & $20 \mathrm{MPa}$ & $25 \mathrm{MPa}$ \\
\cline { 2 - 4 } $\begin{array}{l}\text { Reactor Heat } \\
\text { Exchanger }\end{array}$ & Compressor flow split fraction & $67 \%$ & $68 \%$ \\
\cline { 2 - 4 } & $\mathrm{CO}_{2}$ side p/d & 96 & 84 \\
\cline { 2 - 4 } $\begin{array}{l}\text { High } \\
\text { Temperature } \\
\text { Recuperator }\end{array}$ & $\mathrm{CO}_{2}$ side plate thickness & 1.6 & 1.4 \\
\cline { 2 - 4 } & Number of units & 48 & $1.65 \mathrm{~mm}$ \\
\cline { 2 - 4 } $\begin{array}{l}\text { Low } \\
\text { Temperath sides } \\
\text { Recuperator }\end{array}$ & Plate thickness, both sides & 1.3 & 38 \\
\cline { 2 - 4 } & Number of units & 48 & 1.4 \\
\cline { 2 - 4 } & Plate thickness, both sides & 1.3 & 1.065 \\
\hline Turbine & Number of stages & 6 & 8 \\
\hline
\end{tabular}

With the PDC input modifications listed in Table 7, the cooler size optimization was repeated. The results are presented in Figure 20. The first immediately noticeable result in Figure 20 is that the plant capital cost per unit electrical output is smaller and is close to the cooling tower option. Compared to the cheapest option of direct water cooling, the $\$ / \mathrm{kWe}$ increase is only $2 \%$ with the optimal cycle and cooler design at 67 units. Also, notice that compared to Figure 18, the scale on the horizontal axis and most of the vertical axes has changed. The smaller number of units reflects a smaller heat exchanger with increased temperature approach at the cold end. For the same reasons, a lower air flow rate is now needed, leading to a reduction in air fan power. In fact, with the heat exchanger size close to that for the optimal $\$ / \mathrm{kWe}$ cost (around 70 units), the air fan power is less than the combined power requirement for the water cooling tower option (water pump plus air fans for cooling towers) at the reference AFR-100 conditions.

The results in Figure 20 basically confirm the most recent finding [1] that the commercially available air cooler option for the $\mathrm{sCO}_{2}$ cycle is not much more expensive, compared to either direct cooling water or water cooling with cooling towers. The benefits, of course, of dry air cooling are that no water will be required for ultimate heat removal. However, the results in Figure 20 should be viewed with two important considerations in mind. First, although the results in Figure 20 include the incremental cost increase from a thicker heat exchanger and $\mathrm{CO}_{2}$ piping at higher pressures, they do not include some other cost increases, such as from the higher pressure rating of the $\mathrm{CO}_{2}$ control valve. Perhaps the most important cost change not included in this analysis is the cost increase of the turbomachinery. For both turbine and compressors, higher pressure will require thicker casings. Also, as described above, the turbine number of stages has been increased from six to eight, which certainly will increase the cost of the turbine. Both these considerations are not included in this analysis simply because no reliable cost estimate for $100 \mathrm{MW}$-class $\mathrm{CO}_{2}$ turbomachinery is accessible to the authors at this moment. The second important consideration for Figure 20 is that it compares the dry cooling option at $25 \mathrm{MPa} \mathrm{sCO}_{2}$ 
cycle conditions with water cooling at $20 \mathrm{MPa}$ conditions. For example, the water tower cost may be less for $25 \mathrm{MPa}$ cycle conditions, such that the results for this option in Figure 20 may not be optimal. However, the difference from the water cooling tower optimization may not be significant, as it will be shown below, the required heat removal in the cooler and in the water cooling towers is not that different between the $20 \mathrm{MPa}$ and $25 \mathrm{MPa}$ designs. 

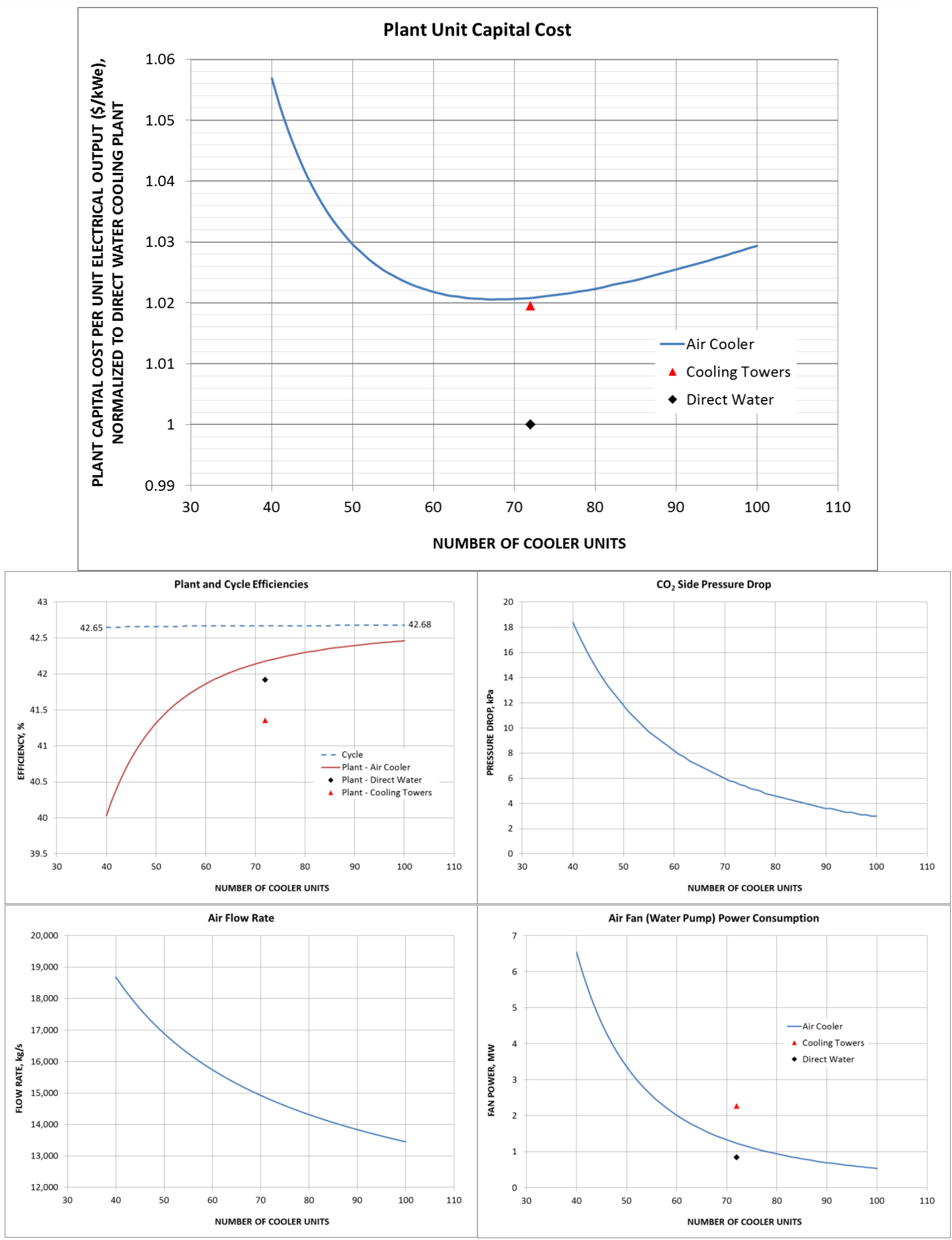

Figure 20. Cost-Based Cooler Optimization at Optimal Air Cooling Design at 25 MPa. 
The $\mathrm{sCO}_{2}$ cycle conditions with the optimal cooler size of 67 units are shown in Figure 21 . These results are very close to those obtained in the previous work (Figure 2). This time, though, the results are entirely obtained from the integrated cooler and cycle calculations in the Plant Dynamics Code. The net plant output in Figure 21 is 105.2 MWe, which is even slightly higher than 104.8 MWe for the reference AFR-100 conditions with water cooling in Figure 3. That output is achieved at higher pressure and higher cost, such that the $\$ / \mathrm{kWe}$ with air cooling is about $2 \%$ higher than with direct water cooling at lower pressure.

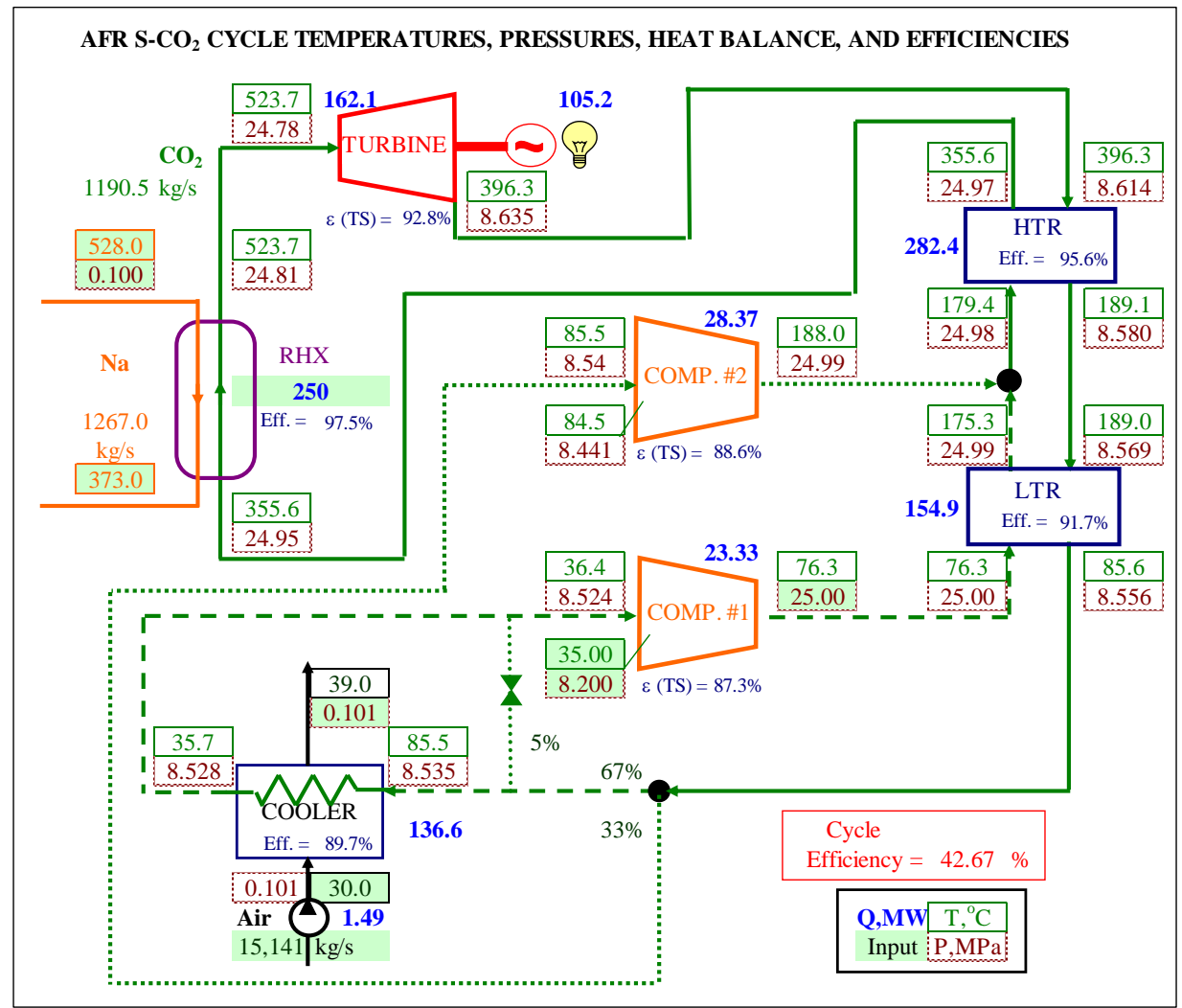

Figure 21. $\mathrm{sCO}_{2}$ Cycle Conditions at $25 \mathrm{MPa}$ and Optimal Cooler Design.

Figure 22 shows the results of the cycle analysis calculations with the tube geometry and heat transfer and pressure drop correlations from Kays and London [16] described in Section 3.4. The main differences from the Harsco design used for the figures above are the dimensions of the fins on the air side. In order to approximately maintain the cooler cost, for the results in Figure 22, the total number of tubes for all units is preserved from the Harsco design. Compared to the results in Figure 21, this heat exchanger design results in a higher required air flow rate, leading to higher air fan power and lower net plant output, thus confirming the benefits of the design Harsco selected for this application. At the same time, the differences are not that large, so the open literature design and correlations can be used, if needed, for future scoping studies of air cooling options for $\mathrm{sCO}_{2}$ cycles. 


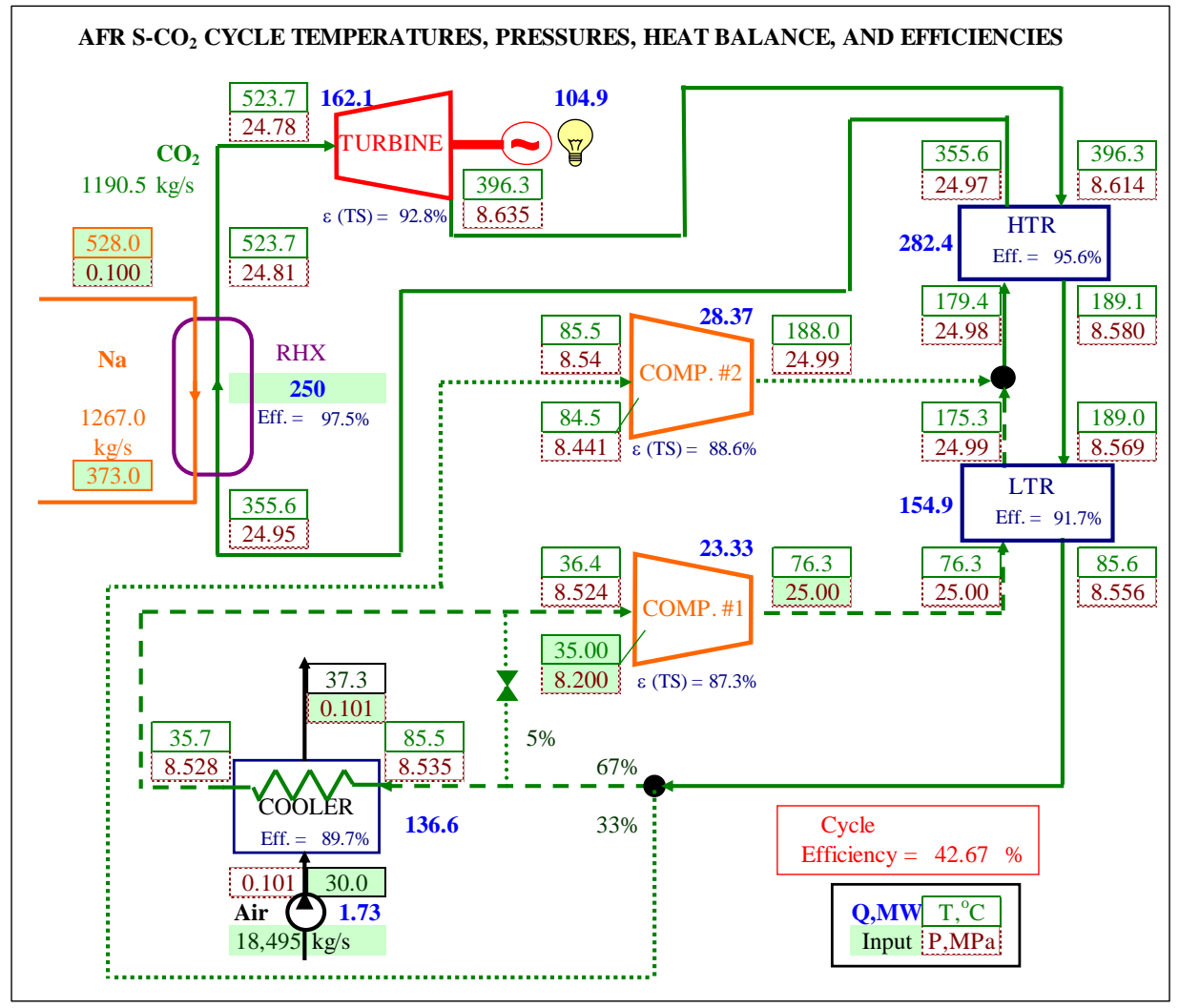

Figure 22. $\mathrm{sCO}_{2}$ Cycle Conditions with Air Cooler Design from Open Literature. 


\section{Comparison with an Air-Cooled Steam Condenser}

To compare the $\mathrm{sCO}_{2}$ dry air cooler with an air-cooled steam condenser, a simplified analysis of a steam condenser was carried out. To obtain the steam conditions at the condenser, a preliminary steam plant model for AFR-100 SFR was developed using the GateCycle software [20]. The model is based on a similar model developed previously for the ABR-1000 SFR [21] assuming heat rejection to a water heat sink, but the turbine inlet temperature and pressure were increased form $454{ }^{\circ} \mathrm{C}$ and $15.5 \mathrm{MPa}$ to $500{ }^{\circ} \mathrm{C}$ and $16 \mathrm{MPa}$ to be consistent with higher AFR-100 reactor temperatures and $\mathrm{sCO}_{2}$ cycle temperatures and pressures. The GateCycle model of the AFR-100 steam plant is shown in Figure 23. At this point, no optimization of the AFR-100 steam cycle was carried out. The reference condenser back pressure of $5 \mathrm{kPa}$, with a corresponding saturation temperature of $32.9^{\circ} \mathrm{C}$, is selected for water cooling assuming that a water heat sink with temperature around $20^{\circ} \mathrm{C}$ is available. The condenser heat duty in Figure 23 is $138.3 \mathrm{MW}$, which is very close to $137.2 \mathrm{MW}$ for the reference $\mathrm{sCO}_{2}$ cycle in Figure 3.

It was realized, though, that condensing steam at $32.9^{\circ} \mathrm{C}$ may be challenging with air cooling, for which $30{ }^{\circ} \mathrm{C}$ is assumed for the air temperature in the rest of this report. The steam temperature in the condenser may be increased by raising the condenser pressure, but at the expense of reducing the steam cycle efficiency, as shown in Figure 25, where the cycle efficiency was obtained using the AFR-100 GateCycle model. For example, at $10 \mathrm{kPa}$, the saturation temperature is $45.8{ }^{\circ} \mathrm{C}$, which makes it much more practical for air cooling with a $30{ }^{\circ} \mathrm{C}$ inlet temperature. However, as Figure 25 demonstrates, increasing the condenser back pressure from $5 \mathrm{kPa}$ to $10 \mathrm{kPa}$ results in about a 1.5 percentage points loss in cycle efficiency. The steam cycle conditions at $10 \mathrm{kPa}$ condenser pressure are shown in Figure 24. It needs to be noted that for this preliminary analysis of a steam cycle condenser, no re-optimization of steam cycle was carried out with increased condenser back pressure (except increasing the pressure between the turbines to maintain the steam fraction at turbine blades above the GateCycle recommended value of 0.85). In particular, unlike in the $\mathrm{sCO}_{2}$ cycle analysis above, the main steam pressure is still retained at $16 \mathrm{MPa}$, since no cost data is currently available for steam cycle components to investigate the effect of higher pressures on component costs. 


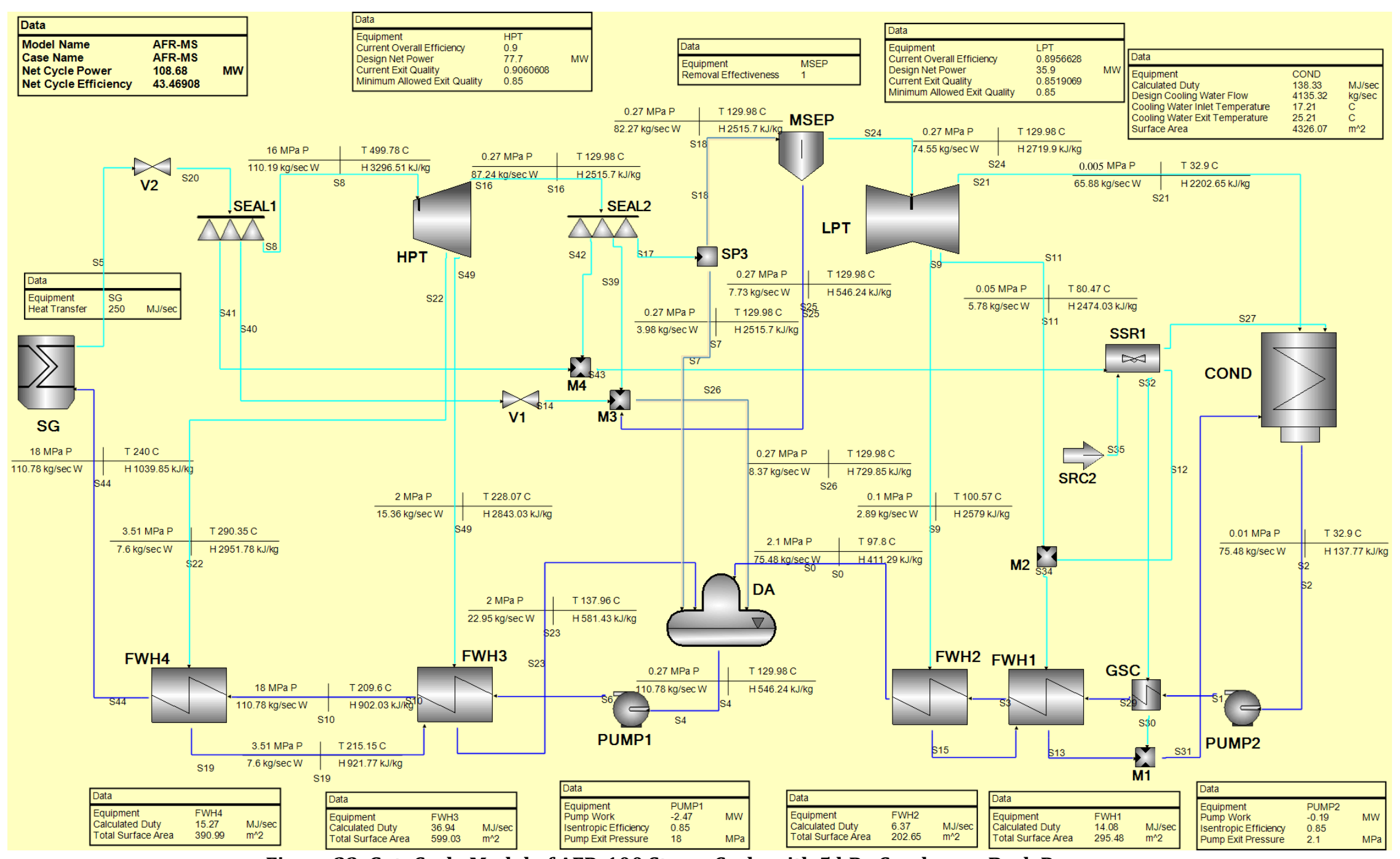

Figure 23. GateCycle Model of AFR-100 Steam Cycle with 5 kPa Condenser Back Pressure. 


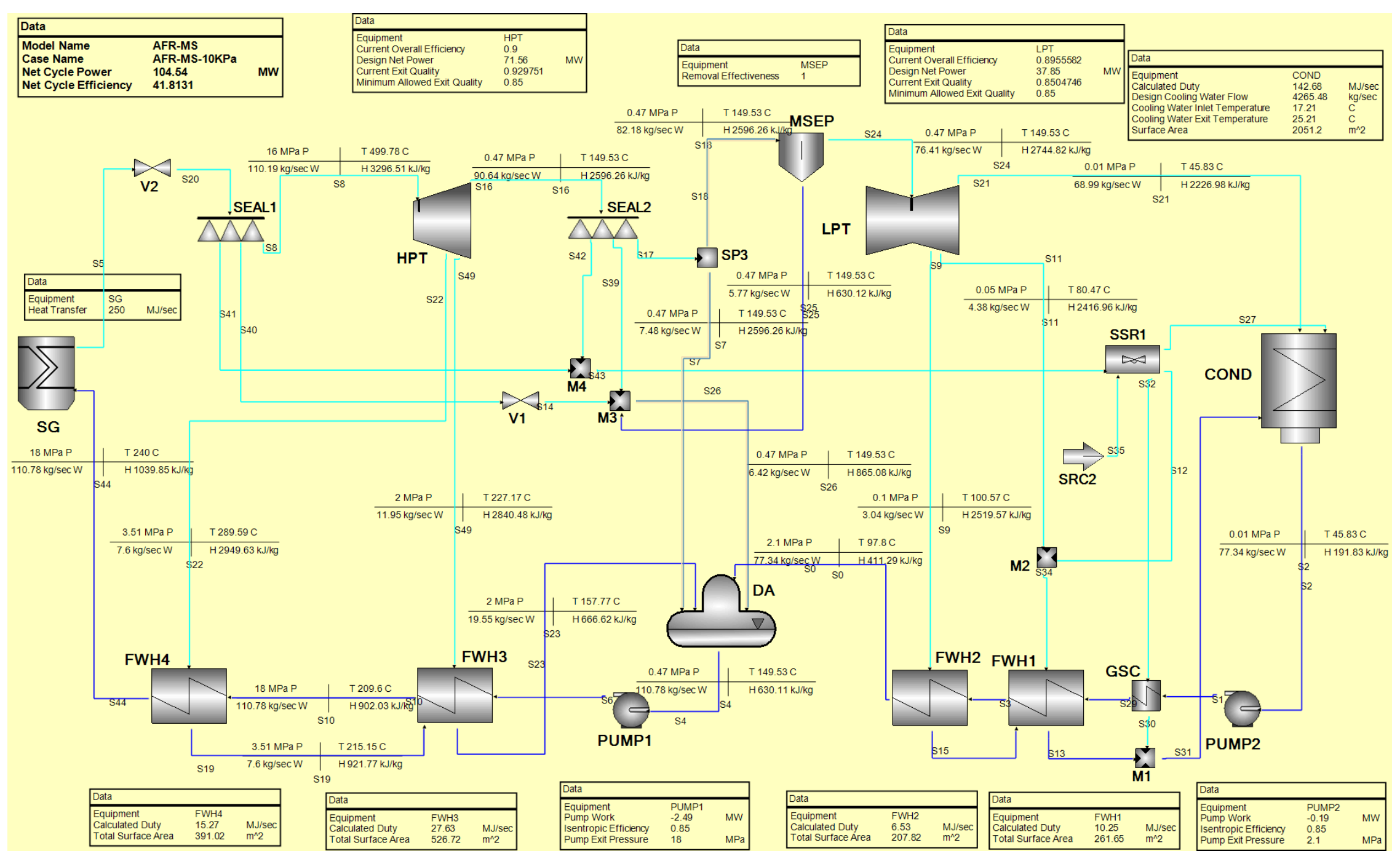

Figure 24. AFR-100 Steam Cycle with 10 kPa Condenser Back Pressure. 


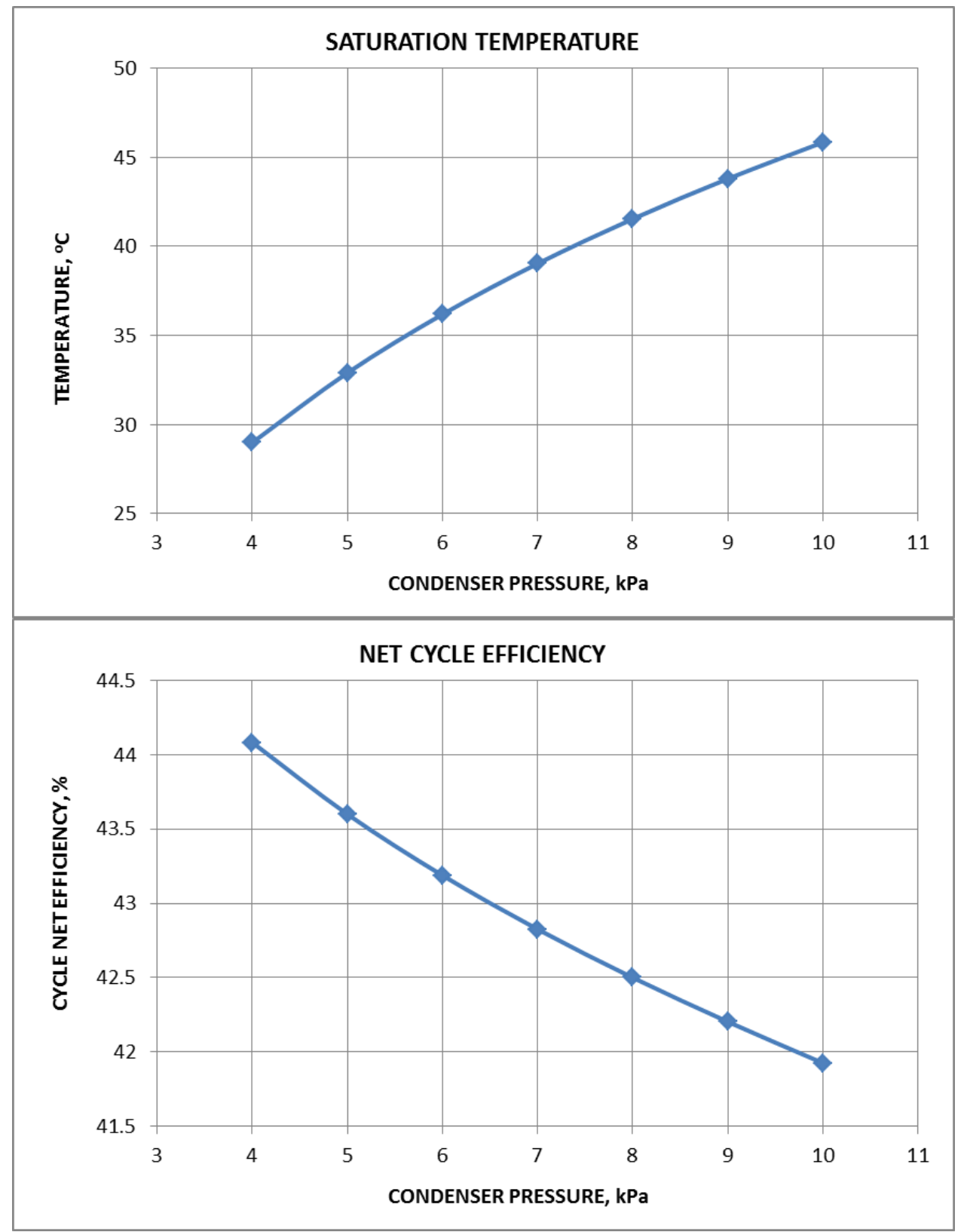

Figure 25. Condenser Temperature and Cycle Efficiency as Functions of Condenser Back Pressure.

\subsection{Air-Cooled Steam Condenser Sizing Analysis}

Because the PDC heat exchanger subroutines were not designed to handle two-phase flow, they could not be currently used for the sizing analysis of a steam condenser. Instead, simplified spreadsheet-type calculations were carried out to size the air-cooled steam condenser based on a LMTD approach and constant properties assumption. The LMTD approach requires an iteration process on the total heat transfer area to match the desired heat removal capability and the actual heat transfer rate, the latter of which is evaluated as: 
$\dot{Q}_{a c t}=U_{a} A_{a}(L M T D) F$

where,

$\dot{Q}_{a c t}=$ actual heat transfer rate, $\mathrm{W}$,

$U_{a}=$ overall heat transfer coefficient based on air side, $\mathrm{W} / \mathrm{m}^{2}-\mathrm{K}$,

$A_{a}=$ total heat transfer area based on air side, $\mathrm{m}^{2}$,

$L M T D=$ logarithmic mean temperature difference, ${ }^{\circ} \mathrm{C}$,

$F=$ correction factor on the $L M T D$.

The total heat transfer area based on the air side, $A_{a}$, is the same as that previously defined in Section 3.3. For condensing applications, the factor, $F$, is one, and the LMTD is defined as:

$$
L M T D=\frac{T_{a, o}-T_{a, i}}{\ln \left(\frac{T_{s a t}-T_{a, i}}{T_{s a t}-T_{a, o}}\right)}
$$

where,

$T_{a, i}=$ air inlet temperature, ${ }^{\circ} \mathrm{C}$,

$T_{a, o}=$ air outlet temperature, ${ }^{\circ} \mathrm{C}$,

$T_{\text {sat }}=$ saturation temperature of the steam/condensate, ${ }^{\circ} \mathrm{C}$.

It should be noted that, in the above definition, the steam-side pressure drop has been neglected, and a constant steam saturation temperature is assumed. The overall heat transfer coefficient based on air side is defined as the reciprocal of the total thermal resistance based on air side that consists of three parts:

$$
U_{a}=\frac{1}{\left(\frac{1}{h_{a}}+R_{f, a}\right) \frac{1}{\eta_{a}}+\frac{\ln \left(d_{t, o} / d_{t, i}\right) A_{a}}{2 \pi L_{t} k_{w}}+\frac{A_{a}}{A_{t} h_{t}}}
$$

where,

$h_{a}=$ air-side heat transfer coefficient, $\mathrm{W} / \mathrm{m}^{2}-\mathrm{K}$,

$R_{f, a}=$ air-side fouling resistance, $\mathrm{m}^{2}-\mathrm{K} / \mathrm{W}$, if present,

$\eta_{a}=$ air-side surface area efficiency defined in Section 3.3,

$d_{t, o}=$ tube outer diameter, $\mathrm{m}$,

$d_{t, i}=$ tube inner diameter, $\mathrm{m}$,

$L_{t}=$ tube length, $\mathrm{m}$,

$k_{w}=$ tube wall thermal conductivity, $\mathrm{W} / \mathrm{m}-\mathrm{K}$,

$A_{t}=$ tube-side total heat transfer area defined in Section $3.3, \mathrm{~m}^{2}$,

$h_{t}=$ tube-side condensation heat transfer coefficient, $\mathrm{W} / \mathrm{m}^{2}-\mathrm{K}$.

The three terms in the denominator of the above equation denote the air-side thermal resistance, wall thermal resistance, and tube-side thermal resistance, respectively. The air-side heat transfer coefficient has been previously discussed in Section 3.4.1. In the present sizing analysis for the air cooled steam condenser, the Harsco unit design is adopted and the iteration process is on the number of units required to achieve the desired heat removal duty. Based on the previous 
discussions, the Briggs and Young correlation predicts heat transfer better for the Harsco design and thus is adopted for the air side. For the tube side, the laminar and turbulent film condensation correlations from [22] are adopted, written as:

$$
\begin{aligned}
& h_{c, \text { laminar }}=0.761\left[\frac{k_{l}^{3} \rho_{l}\left(\rho_{l}-\rho_{v}\right) g L_{t}}{W_{t} \mu_{l}}\right]^{1 / 3} \\
& h_{c, \text { turbulent }}=0.065 \frac{k_{l} \rho_{l}^{1 / 2}}{\mu_{l}} \operatorname{Pr}_{l}^{1 / 2} F_{v c}^{1 / 2}
\end{aligned}
$$

where,

$k_{l}=$ liquid thermal conductivity at saturation temperature, $\mathrm{W} / \mathrm{m}-\mathrm{K}$,

$\rho_{l}=$ liquid density at saturation temperature, $\mathrm{kg} / \mathrm{m}^{3}$,

$\rho_{v}=$ vapor density at saturation temperature, $\mathrm{kg} / \mathrm{m}^{3}$,

$\mu_{l}=$ liquid dynamic viscosity at saturation temperature, Pa-s,

$g=$ gravity acceleration constant, $\mathrm{m} / \mathrm{s}^{2}$,

$W_{t}=$ condensate mass flow rate in each tube, $\mathrm{kg} / \mathrm{s}$,

$\operatorname{Pr}_{l}=$ liquid Prandtl number at saturation temperature.

The condensate mass flow rate in each tube, $W_{t}$, can be determined from the desired heat removal rate and the latent heat of condensation at the specific pressure. $F_{v c}$ is calculated as:

$$
\begin{aligned}
& F_{v c}=\frac{f G_{v, m}^{2}}{2 \rho_{v}} \\
& G_{v, m}=\left(\frac{G_{v, i}^{2}+G_{v, i} G_{v, o}+G_{v, o}^{2}}{3}\right)^{1 / 2} \\
& f=\frac{0.078}{\left(\frac{d_{t, i} G_{v, m}}{\mu_{v}}\right)^{1 / 4}}
\end{aligned}
$$

where,

$\mu_{v}=$ vapor dynamic viscosity at saturation temperature, Pa-s,

$G_{v, i}=$ vapor mass flux at the inlet, $\mathrm{kg} / \mathrm{m}^{2}$-s,

$G_{v, o}=$ vapor mass flux at the outlet, $\mathrm{kg} / \mathrm{m}^{2}-\mathrm{s}$.

In the present analysis, it is assumed that the vapor enters dry and saturated at the inlet and is completely condensed at the exit. With this assumption, $G_{v, m}$ reduces to $0.58 G_{v, i}$. It is stated in [22] that the tube-side condensation heat transfer coefficient should take the maximum of the values determined by the above two correlations.

The LMTD approach was applied to the sizing analysis of the condenser at two back pressures, namely, $5 \mathrm{kPa}$ and $10 \mathrm{kPa}$. For the sake of a direct comparison with the previous sizing results for the $\mathrm{sCO}_{2}$ air cooler shown in Table 2, the total heat transfer duty for the condenser was assumed to be $137.47 \mathrm{MW}$, and air inlet temperature was assumed to be $30^{\circ} \mathrm{C}$. In addition to the iteration on the number of units mentioned earlier, there is a second fold of iteration on the air flow rate in 
order to restrict the total fan power to be below $5 \mathrm{MW}$, with an assumption of $90 \%$ fan efficiency. The sizing results of the condenser are summarized in Table 8. As can be seen, as the pressure increases, the increased steam saturation temperature leads to a higher LMTD, and correspondingly less units required to meet the same heat transfer duty. Compared to the $\mathrm{sCO}_{2}$ air cooler design, the $5 \mathrm{kPa}$ condenser design calls for more Harsco units, while the $10 \mathrm{kPa}$ condenser design calls for much less, demonstrating the feasibility of dry air cooling for the steam Rankine cycle. However, this feasibility in terms of an order of magnitude smaller number of units is realized at the sacrifice of the cycle efficiency as discussed earlier.

Table 8. Sizing Results of the Air Cooled Steam Condenser

\begin{tabular}{|c|c|c|c|c|c|c|c|}
\hline & $\begin{array}{c}\dot{Q} \\
(\mathrm{MW})\end{array}$ & $\begin{array}{c}T_{\text {sat }} \\
\left({ }^{\circ} \mathrm{C}\right)\end{array}$ & $\begin{array}{c}T_{\text {air }, o} \\
\left({ }^{\circ} \mathrm{C}\right)\end{array}$ & $\begin{array}{c}\dot{m}_{\text {air }} \\
(\mathrm{kg} / \mathrm{s})\end{array}$ & $\begin{array}{c}\Delta p_{\text {air }} \\
(\mathrm{Pa})\end{array}$ & $\begin{array}{c}\dot{Q}_{\text {fan }} \\
(\mathrm{MW})\end{array}$ & $\begin{array}{c}\text { Number } \\
\text { of Units }\end{array}$ \\
\hline $\mathrm{sCO}_{2}$ & 137.47 & -- & 34.9 & 27734 & 190 & 5.0 & 86 \\
\hline $5 \mathrm{kPa}$ & 137.47 & 32.9 & 32.3 & 58823 & 88 & 5.0 & 282 \\
\hline $10 \mathrm{kPa}$ & 137.47 & 42.8 & 40.1 & 13468 & 386 & 5.0 & 28 \\
\hline
\end{tabular}

\subsection{Air-Cooled Steam Condenser Optimization}

The condenser sizing calculations described above are carried out based on an assumption of a 5\% (5 MW for AFR-100 design) air fan power requirement. To find the optimal condenser design and optimal fan power, a cost-based optimization of the air cooled condenser size, similar to that for $\mathrm{SCO}_{2}$ air cooler in Section 5.2, was carried out for the steam condenser. The analysis was done for the two considered condenser conditions:

- Reference at $5 \mathrm{kPa}$ and $32.9^{\circ} \mathrm{C}$ (Figure 23), and

- Higher back pressure at $10 \mathrm{kPa}$ and $45.8^{\circ} \mathrm{C}$ (Figure 24).

In both cases, the condenser size was varied and the air flow rate was selected to match the required condenser heat duties $-138.3 \mathrm{MW}$ th at $5 \mathrm{kPa}$ in Figure 23 and $142.6 \mathrm{MW}$ th at $10 \mathrm{kPa}$ in Figure 24. For each condenser size, the air side pressure drop and fan power was calculated using the Excel model described in Section 6.1; the fan power was subtracted from the gross generator output to obtain the net plant electrical output and corresponding net plant efficiency. Also, the condenser cost was added to the plant capital cost, which was assumed to be equivalent to 4780 $\$ / \mathrm{kWe}$ for the reference design. Although this reference number is the same one used for the $\mathrm{sCO}_{2}$ cycle analysis in Section 5.2, the cost results presented below for the steam cycle should not be directly compared to those of the $\mathrm{sCO}_{2}$ cycle for two reasons. First, the cost of the reactor and other steam cycle components, such as turbines and feedwater heaters, is not currently available. Those costs are simply assumed to be the same as for the $\mathrm{sCO}_{2}$ cycle in this work to compare different air cooler condenser designs. Second, the cost of the water-cooled condenser for the reference steam plant in Figure 23, as well as the water pumping power, are not currently available for the AFR-100. So, the cost results below will be compared to the reference steam plant without the cost of the water condenser and water pumps; i.e., the air-cooled condenser cost and air fan power will be added to the reference plant. This preliminary technique is sufficient to compare different air-cooled condenser options, but should not be used to compare to other plants, such as $\mathrm{sCO}_{2}$ cycle. 
The results of the cost-based optimization for the air-cooled condenser are shown in Figure 26. Each plot has two curves for the two condenser conditions. Results in Figure 26 confirm that condensing at $32.9{ }^{\circ} \mathrm{C}$ requires both a much larger condenser and a higher air flow rate. So, even if the cycle efficiency is higher in this case, the net plant efficiency is comparable between the 5 $\mathrm{kPa}$ and $10 \mathrm{kPa}$ designs, and the much smaller condenser capital cost makes the $10 \mathrm{kPa}$ design much more economical in terms of $\$ / \mathrm{kWe}$ value. According to Figure 26, the optimal design has 50 Harsco condenser units operating at $10 \mathrm{kPa}$ and $45.8^{\circ} \mathrm{C}$. Again, the cost results in Figure 26 are normalized to a steam plant without condenser and water pump power requirements, so they should not be compared with the $\mathrm{sCO}_{2}$ results in Figures 18 and 20. Also, it is important to note that these results are preliminary and may not provide the absolute optimal value for the steam condenser. As discussed above, the actual cost of other steam cycle components would be needed for more accurate cost optimization. Also, the steam cycle design at $10 \mathrm{kPa}$ was not optimized, for example, for the main steam pressure value. Besides, the optimal design in Figure 26 is selected based only on two data points which is not always sufficient to find the absolute minimum value and design.

Nevertheless, despite the preliminary and simple nature of this study, an important observation can be made from the results in Figure 26. Table 9 compares the main cycle and cooler/condenser results for the $\mathrm{sCO}_{2}$ cycle (from Figure 21) with those for the steam condenser (from Figure 26). Even though there are some differences, overall, the results for the $\mathrm{sCO}_{2}$ cycle cooler and steam cycle condenser are quite close in terms of cycle efficiency, plant output, the cooler/condenser size, and air fan power. These results suggest that both power conversion cycles can be utilized for dry air cooling applications, provided that the conditions for each cycle are selected appropriately. 

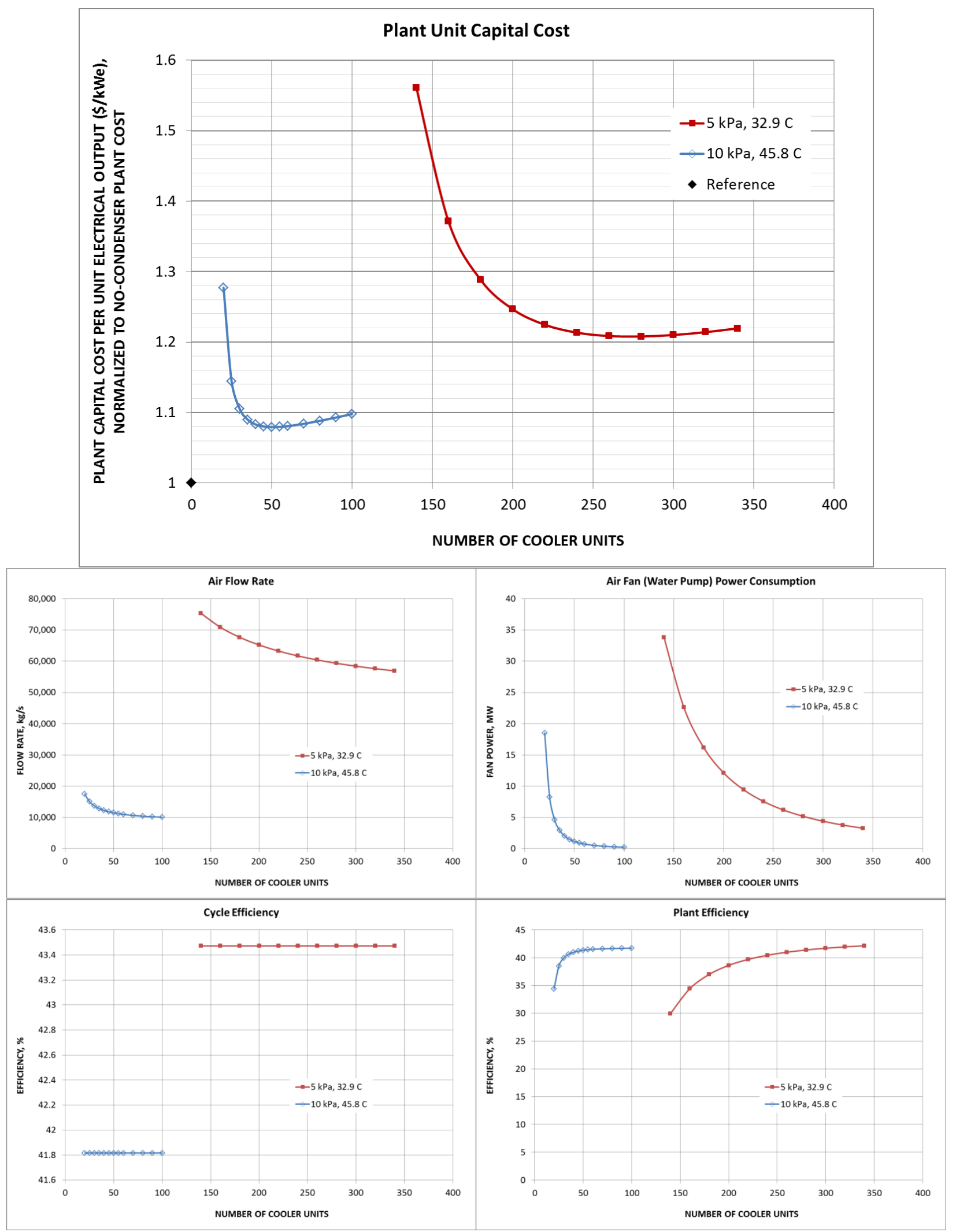

Figure 26. Cost-Based Air-Cooled Condenser Optimization. 
Table 9. Comparison of Optimal $\mathrm{sCO}_{2}$ Air Cooler with Optimal Steam Condenser

\begin{tabular}{|l|c|c|}
\hline \multicolumn{1}{|c|}{ Parameter } & $\mathbf{S C O}_{\mathbf{2}}$ Cycle & Steam Cycle \\
\hline Cycle efficiency, $\%$ & 42.7 & 41.8 \\
\hline Net plant efficiency, \% & 42.1 & 41.4 \\
\hline Net plant output, MWe & 105.2 & 103.4 \\
\hline Maximum cycle pressure, $\mathrm{MPa}$ & 25 & 18 \\
\hline Turbine inlet temperature, ${ }^{\circ} \mathrm{C}$ & 524 & 500 \\
\hline Cooler/condenser heat duty, MWth & 136.6 & 142.7 \\
\hline Number of cooler/condenser units & 67 & 50 \\
\hline Air flow rate, $\mathrm{kg} / \mathrm{s}$ & 15,141 & 11,482 \\
\hline Air fan power, $\mathrm{MW}$ & 1.49 & 1.15 \\
\hline Air outlet temperature, ${ }^{\circ} \mathrm{C}$ & 39.0 & 42.3 \\
\hline
\end{tabular}




\section{Summary}

The ANL Plant Dynamics Code has been extended to incorporate modeling for air coolers with fans blowing air upward in crossflow over horizontal finned tubes containing flowing $\mathrm{CO}_{2}$ that are currently commercially available from Harsco, for example. Such air coolers are practical and cost effective. Their availability means that it is not necessary to conduct development on heat exchangers for dry air cooling. It is only necessary to work with a vendor to identify a suitable air cooler with a tube material compatible with $\mathrm{sCO}_{2}$ at the appropriate conditions.

The supercritical carbon dioxide $\left(\mathrm{sCO}_{2}\right)$ Brayton cycle's capability to reject heat with dry air cooling is emerging as one of the most significant benefits of the cycle. The benefits of dry air cooling for any power plant are obvious, since not relying on water for heat rejection significantly extends the siting options for a power plant. The most recent work at ANL and elsewhere shows that due to the specifics of heat rejection from the $\mathrm{sCO}_{2}$ cycle, there are some benefits in adopting dry air cooling for this cycle compared to the Rankine steam cycle.

The work on dry air cooling analysis for $\mathrm{sCO}_{2}$ cycles at ANL has been going on for a few years. In early work, it was concluded that although dry air cooling is possible, it would most likely be cost-prohibitive since it would require either a very large heat exchanger, a large air circulation power requirement, or both. However, that analysis assumed compact counterflow heat exchangers for air cooler applications. Crossflow heat exchangers were not considered in previous work on $\mathrm{sCO}_{2}$ cycles because of a notion that they wouldn't be able to cool $\mathrm{CO}_{2}$ very close to the critical point - a requirement for $\mathrm{sCO}_{2}$ cycles to achieve high efficiency.

In order to investigate if the crossflow heat exchangers can in fact be utilized for $\mathrm{sCO}_{2}$ coolers, the ANL Plant Dynamic Code (PDC) was extended to include design and performance calculations for these heat exchangers. The main difference from the previously implemented counterflow arrangement is the two-dimensional temperature field inside the heat exchanger. In addition, a multi-pass arrangement is often implemented in these heat exchangers. The PDC heat exchanger subroutines were extended to include calculations of crossflow heat exchangers with two-dimensional temperature fields and possible multi-pass flow arrangements.

Several heat exchanger design options were investigated. The first is a commercially-available modular air cooler design in which air is blown upward by fans across horizontal finned tubes through which the $\mathrm{CO}_{2}$ flows. This is a standard commercially-available air cooler technology (e.g., Harsco), although the application to $\mathrm{SCO}_{2}$ is new. The tubes usually have a significant amount of large aluminum fins on the outside surface to increase the heat transfer area on the air side. The code calculations for this type of the heat exchangers were first confirmed against the manufacturer's quote for a $\mathrm{sCO}_{2}$ cooler application and satisfactory agreement was obtained. After that, the parametric studies on the heat transfer and pressure drop correlations, design choices, such as tube/fin geometry, number of tube rows, and number of passes, as well as a grid convergence study were carried out. The results of these studies basically confirmed that the design proposed by the vendor is at least close to the optimal design. Also confirmed in this analysis was the capability of finned tube crossflow heat exchangers to achieve sufficiently small temperature approaches such that the $\mathrm{CO}_{2}$ flow can be cooled to temperatures very close to the critical point of $30.98^{\circ} \mathrm{C}$ even with an assumed air ambient temperature of $30{ }^{\circ} \mathrm{C}$. Although the 
heat exchangers would still be large for this application (about 70 times larger, by volume, than the previously investigated compact water-cooled heat exchangers); due to simplicity of the design and well-established technology, these heat exchangers turned out to be a relatively inexpensive option. Size is not that important since the air coolers are located outside instead of inside of a building structure.

The other heat exchanger design option considered in this work was compact diffusion-bounded heat exchangers, similar to those investigated in the previous air cooling analysis, but with a crossflow arrangement. The crossflow configuration was indeed found to be beneficial for this application. The main reason is that for the air cooling applications, the pressure drop on the air side needs to be held to a low value (not much more than $100 \mathrm{~Pa}$ ) in order to maintain a reasonable power requirement for the air fans/blowers (5\% or less of the plant output). The crossflow designs help reduce the air side pressure drop by allowing shorter channel lengths and larger flow areas on the air side, while still maintaining long flow paths and high Reynolds numbers on the $\mathrm{CO}_{2}$ side. As a result, the calculations have shown that for the same air fan power requirements and the same $\mathrm{CO}_{2}$ side conditions, the total volume of the heat exchanger cores is reduced by about a factor of four for a crossflow design, compared to a similar counterflow design. This design option was also found to be more compact than the finned tube design reducing the heat exchanger core volume by about $50 \%$. However, when the cost of the crossflow compact diffusion-bonded heat exchanger was estimated, it turned out to be a significantly more expensive option than the finned tube design. Even though the compact diffusion-bonded heat exchanger cost was scaled from earlier manufacturer quotes and is probably outdated, in order to be cost-competitive with finned tube design for this application, the compact diffusion-bonded heat exchanger cost needs to be reduced by about a factor of six from those previous quotes. Similar to the finned tube design, a sensitivity study on design options, such as core dimensions, channel arrangement on plates, number of passes, and channel zigzag angles, was carried out. However, none of the considered design options resulted in a significant reduction of the heat exchanger cost such that the compact diffusion-bonded heat exchanger remains a more expensive option for the $\mathrm{CO}_{2}$ air cooler application. This is due to the fact that the main feature of these compact heat exchangers - small channels size - is not very well suited for the air cooler applications.

As a result of the heat exchanger design analyses, the commercially available modular finned tube design is selected as a better option and as a reference option for the $\mathrm{sCO}_{2}$ air cooler application. The performance analysis and further optimization of the design was continued when the crossflow heat exchanger subroutine was integrated into the PDC and the combined performance of the entire cycle with a commercially available air cooler was investigated. First, the analysis was carried out for the reference AFR-100 Sodium-Cooled Fast Reactor (SFR) $\mathrm{sCO}_{2}$ cycle conditions, where the $\mathrm{CO}_{2}$ is cooled to conditions just above the critical point $-31.25^{\circ} \mathrm{C}$ and 7.4 $\mathrm{MPa}$ at the compressor inlet. A cost-based optimization on the cooler size (number of units) was carried out to find the optimal design which minimizes the plant capital cost per unit electrical output $(\$ / \mathrm{kWe})$. The plant $\$ / \mathrm{kWe}$ cost is selected for the optimization because it combines both the capital cost, including the cooler cost, and the plant net output, which includes the power requirement for the air fans. It was found that with the optimal cooler design with 112 units (each unit having dimensions of $18.6 \mathrm{~m}$ long, $4.6 \mathrm{~m}$ wide, and $0.2 \mathrm{~m}$ tube stack height), the plant $\$ / \mathrm{kWe}$ cost is about $7 \%$ higher than with direct water cooling and $5 \%$ higher than water cooling with 
cooling towers to reject heat to the ultimate air heat sink. These results already show significant improvement over the earlier analysis with counter flow air coolers, where a 40-60\% increase in the $\$ / \mathrm{kWe}$ cost was estimated for dry air cooling compared to direct water cooling.

Because this analysis shows that a large heat exchanger would still be required, the cost-based optimization was repeated for different $\mathrm{sCO}_{2}$ cycle conditions. In order to reduce the cooler size, the temperature approach on the cold end of the cooler was increased by means of increasing the $\mathrm{CO}_{2}$ temperature at the compressor inlet form $31.25^{\circ} \mathrm{C}$ to $35^{\circ} \mathrm{C}$. In the earlier analysis, it was found that for this compressor inlet temperature, it is beneficial to also increase the compressor inlet pressure along the $\mathrm{CO}_{2}$ pseudocritical line from 7.4 MPa to 8.2 $\mathrm{MPa}$ and also increase the compressor outlet pressure from $20 \mathrm{MPa}$ to $25 \mathrm{MPa}$. Because of the higher cycle pressures, the designs of the heat exchangers subject to high pressure - the recuperators and Na-to- $\mathrm{CO}_{2} \mathrm{HX}-$ were revised to increase structural thicknesses. Similarly, the thickness of the $\mathrm{CO}_{2}$ pipes was increased according to the pressure increase. In addition, it was found beneficial to increase the number of stages in the turbine from six to eight for a larger pressure ratio in this cycle design. The integrated cycle and cooler calculations confirmed that the optimal cooler size for this application is indeed reduced by almost a factor of two - from 112 units to 67 units. But more importantly, due to optimizing the $\mathrm{sCO}_{2}$ cycle conditions for dry air cooling, this smaller air cooler size is achieved with virtually the same cycle efficiency. As a result, the plant $\$ / \mathrm{kWe}$ cost is further reduced compared to dry air cooling with the reference AFR-100 conditions to a value which is only $2 \%$ higher than with direct water cooling and basically the same as heat rejection to air with water cooling and cooling towers.

To compare the size of the $\mathrm{CO}_{2}$ air cooler and the cycle performance with dry air cooling with those for a Rankine superheated steam cycle plant with dry air cooling, a preliminary analysis of a steam cycle and air-cooled condenser has been carried out. Since implementation of a condenser calculation into the PDC would require significant code revisions to treat phase change, a simplified spreadsheet-type analysis of an air-cooled condenser was carried out. In this analysis, constant properties and heat transfer coefficients were assumed and the heat transfer rate is calculated based on a LMTD approach. The same Harsco air cooler design is assumed for the steam condenser calculations with steam flow replacing the $\mathrm{CO}_{2}$ flow inside the tubes. Calculations of heat transfer on the steam side are done in a simplified form based on condensation correlations from the open literature; calculations of heat transfer on the air side are performed similarly to those implemented in the PDC for finned tubes. To obtain conditions for an air-cooled steam condenser, a preliminary model of a steam plant power converter for the AFR-100 SFR was developed using the GateCycle software. The condenser sizing calculations were done for two conditions on steam side: a reference state at $5 \mathrm{kPa}$ condenser back pressure and $32.9^{\circ} \mathrm{C}$ and a higher temperature corresponding to $10 \mathrm{kPa}$ back pressure and $45.8{ }^{\circ} \mathrm{C}$. Both calculations show that a steam condenser with the Harsco design would be feasible, but, obviously, low-temperature conditions would require a very large heat exchanger and air flow rate for the assumed air inlet temperature of $30{ }^{\circ} \mathrm{C}$. Based on the condenser sizing results, a preliminary cost-based optimization was carried out for the same two sets of steam conditions. For these calculations, the steam cycle efficiencies were calculated by the GateCycle software. The results show that the efficiency decreases from $43.5 \%$ at $5 \mathrm{kPa}$ to $41.8 \%$ at $10 \mathrm{kPa}$. Still, due to much smaller condenser and smaller air circulation power requirement, the $10 \mathrm{kPa}, 45.8^{\circ} \mathrm{C}$ case is calculated to be more economical resulting in a lower $\$ / \mathrm{kWe}$ plant cost. When compared 
to the optimal conditions for the $\mathrm{sCO}_{2}$ cycle, the main cycle and heat exchanger results, including cycle and plant efficiencies, plant power output, cooler/condenser size, air flow rate, and air fan power for the steam cycle are remarkably close.

Overall, based on the analysis presented in this report, the following conclusions can be made:

1. The crossflow heat exchanger designs are better suited for $\mathrm{sCO}_{2}$ dry air coolers than counter flow designs.

2. The commercially available modular finned tube air coolers are found to be the most practical and economical option which works well for this application. Since this heat exchanger design is a well-established, commercially available, and cost effective technology, no further search for other heat exchanger options is needed.

3. When the $\mathrm{sCO}_{2}$ cycle and the cooler design and size are jointly optimized for dry air cooling, the economic impact of dry air cooling is found to be minimal compared to direct water cooling and basically non-existent compared to heat rejection to air with water cooling towers. However, dry air cooling requires no water usage which greatly extends siting options for a power plant.

4. Both the $\mathrm{sCO}_{2}$ cycle and the Rankine steam cycle can be utilized for dry air cooler applications. For the AFR-100 application, both cycles can provide similar favorable cycle efficiency, heat exchanger size, and air fan power, provided that the conditions for both cycles are properly optimized for air cooling.

5. The steady-state part of the PDC has been extended to include crossflow heat exchanger options and is ready for any further integrated cycle-cooler analysis in the future. (The dynamic part of the code still needs to be modified to handle two-dimensional temperature fields in transient equations). 


\section{Acknowledgements}

Argonne National Laboratory's work was supported by the U. S. Department of Energy Advanced Reactor Technologies (ATR) Program under Prime Contract No. DE-AC0206CH11357 between the U.S. Department of Energy and UChicago Argonne, LLC. The work presented here was carried out under the Energy Conversion Technology area of the ATR Program. The authors are grateful to Gary Rochau (SNL), the Technical Area Lead, Bob Hill (ANL/NE), the National Technical Director, as well as Brian Robinson and Carl Sink (U.S. DOE), Headquarters Program Managers for the project. 


\section{References}

[1] S.R. Pidaparti, P.J. Hruska, A. Moisseytsev, and J.J. Sienicki, "Technical and Econoimic Feasibility of Dry Air Cooling for the Supercritical CO2 Brayton Cycle Using Existing Technology," The 5th International Symposium - Supercritical CO2 Power Cycles, 2016.

[2] T. J. Held, J. Miller, and D. J. Buckmaster, "A Comparative Study of Heat Rejection Systems for sCO2 Power Cycles," The 5th International Symposium - Supercritical CO2 Power Cycles, 2016.

[3] T.M. Conboy, Carlson M.D., and G.E. Rochau, "Dry-Cooled Supercritical CO2 Power for Advanced Nuclear Reactors," Journal of Engineering for Gas Turbines and Power, vol. 137, 2015.

[4] A. Moisseytsev and J. J. Sienicki, "Investigation of a Dry Air Cooling Option for an S-CO2 Cycle," in 4th International Symposium - Supercritical CO2 Power Cycles, Pittsburgh, PA, 2014, September 9-10.

[5] T. J. Held, Peronal Communication, 2014.

[6] Heatric Division of Meggitt (UK) Ltd. (2016) [Online]. http://www.heatric.com/

[7] Harsco Industrial Air-X-Changers. (2015) [Online]. http://www.harscoaxc.com/

[8] A. Moisseytsev, "Passive Load Follow Analysis of the STAR-LM and STAR-H2 Systems," Texas A\&M University, Ph.D. Dissertation 2003.

[9] V. Dostal, "A Supercritical Carbon Dioxide Cycle for Next Generation Nuclear Reactors," Massachusetts Institute of Technology, D.Sc. Dissertation 2004.

[10] A. Moisseytsev, J. J. Sienicki, and D. C. Wade, "Cycle Analysis of Supercritical Carbon Dioxide Gas Turbine Brayton Cycle Power Conversion System for Liquid Metal-Cooled Fast Reactors," in Proceedings of ASME International Conference on Nuclear Energy (ICONE-11), Tokyo, Japan, 2003, pp. ICONE11-36023, April 20-23.

[11] A. Moisseytsev and J. J. Sienicki, "Cost-Based Optimization of Supercritical Carbon Dioxide Brayton Cycle Equipment," in American Nuclear Society 2011 Winter Meeting, Washington, DC, 2011, October 30-November 3.

[12] A. Moisseytsev and J. J. Sienicki, "Development of a Plant Dynamics Computer Code for Analysis of a Supercritical Carbon Dioxide, ANL-06/27 Brayton Cycle Energy Converter Coupled to a Natural Circulation Lead-Cooled Fast Reactor," Nuclear Enginnering, Argonne, IL, ANL-06/27, 2006.

[13] A. Moisseytsev and J. J. Sienicki, "ANL Plant Dynamics Code and Control Strategy Development for the Supercritical Carbon Dioxide Brayton Cycle," in 2009 Supercritical CO2 Power Cycle Symposium, Troy, NY, 2009, April 29-30.

[14] D.E. Briggs and E.H. Young, "Convection Heat Transfer and Pressure Drop of Air Flowing Across Triangular Pitch Banks of Finned Tubes," Chemical Engineering Progress Symposium Series, vol. 59, pp. 1-10, 1963.

[15] K.K. Robinson and D.E. Briggs, "Pressure Drop of Air Flowing Across Triangular Pitch Banks of Finned Tubes," Chemical Engineering Progress Symposium Series, vol. 62, pp. 177-184, 1965.

[16] W.M. Kays and A. L. London, Compact Heat Exchangers. New York: McGraw-Hill, 1984. 
[17] S.L. Jameson, "Tube Spacing in Finned Tube Banks," ASME Transactions, vol. 67, pp. 633642, 1945.

[18] D.Q. Kern and A.D. Kraus, Extended Surface Heat Transfer. New York: McGraw-Hill, 1972.

[19] A. Moisseytsev, J. J. Sienicki, D. H. Cho, and M. R. Thomas, "Comparison of Heat Exchanger Modeling with Data from CO2-to-CO2 Printed Circuit Heat Exchanger Performance Tests," in 2010 International Congress on Advances in Nuclear Power Plants (ICAPP 10), San Diego, CA, 2010, p. 10123, June 13-17.

[20] GE Power \& Water. (Version 6.1.2) GateCycle Software. [Online]. https://getotalplant.com/GateCycle/docs/GateCycle/index.html

[21] A. Moisseytsev, E. Hoffman, and C. Grandy, "Selection of Core Outlet Temperature and Impacts on Fast Reactor Economics," Nuclear Technology, vol. 173, pp. 251-269, 2011.

[22] Wolverine Tube Heat Transfer Data Book. (2016) [Online]. http://www.wlv.com/wpcontent/uploads/2014/06/databook/ch3_2.pdf 


\section{Argonne}

Nuclear Engineering Division

Argonne National Laboratory

9700 South Cass Avenue, Bldg. 208

Argonne, IL 60439

www.anl.gov 